Portland State University

PDXScholar

$1-1-2010$

\title{
Somatization and Engagement in Mental Health Treatment
}

Teresa Chianello

Portland State University

Follow this and additional works at: https://pdxscholar.library.pdx.edu/open_access_etds Let us know how access to this document benefits you.

\section{Recommended Citation}

Chianello, Teresa, "Somatization and Engagement in Mental Health Treatment" (2010). Dissertations and Theses. Paper 706.

https://doi.org/10.15760/etd.706

This Dissertation is brought to you for free and open access. It has been accepted for inclusion in Dissertations and Theses by an authorized administrator of PDXScholar. Please contact us if we can make this document more accessible: pdxscholar@pdx.edu. 
Somatization and Engagement in Mental Health Treatment

by

Teresa Chianello

A dissertation submitted in partial fulfillment of the requirements for the degree of

\author{
Doctor of Philosophy \\ in \\ Social Work and Social Research
}
Dissertation Committee:
Laurie Powers, Chair
Daniel Coleman
Matthew Modrcin
Vikki Vandiver
Leslie McBride

Portland State University

(C) 2010 


\begin{abstract}
Somatization, the presentation of physical symptoms without an identifiable cause, is among the most common problems in primary medical care. Treatment approaches are typically offered within the medical consultation interview once the medical provider distinguishes between physical and emotional etiology. This dualistic strategy is especially troublesome for patients whose physical complaints cannot be validated and who are recommended for only mental health therapy. The aim of this study was to examine how medical practitioners can instead motivate patients to consider both physical and emotional treatment. An analogue intervention consisting of an enhanced consultation interview was compared to a care as usual consultation interview on the key outcome of motivation to engage in mental health treatment. A total of 129 participants with medically unexplained symptoms were randomly assigned to these two conditions. Motivation to engage in mental health treatment was evaluated with the FMP Questionnaire, Credibility and Expectancy Questionnaire, and the newly developed Motivation to Engage in Therapy questionnaire (MET). Results of ANCOVA revealed significant differences between the two analogue consultation interviews on 3 out of 5 outcome measures. The largest effect was found for the MET followed by the credibility and expectancy subscales (1.6, .9, and .8). This finding suggests that a particular type of discourse between medical provider and patient can lead to increased motivation for holistic care treatment for those with somatization.
\end{abstract}




\section{Acknowledgments}

I would like to express my deepest appreciation to my committee chair, Professor Laurie Powers who provided her expertise, generous support, and undying patience during the dissertation process. I very much appreciate her wisdom and guidance; both gifts that she gave freely and often. I would also like to extend a special thank you to Professor Dan Coleman, whose enthusiastic and exceptional knowledge in statistical methods helped to push my understanding of analyses to another level. Moreover, I would like to express my heartfelt appreciation to each committee member. I feel so fortunate to have such insightful, energetic and compassionate professors serving on my committee.

Finally, I would like to express my thanks to three researchers who granted me permission to use their measures in this dissertation: Grant J. Devilly: Credibility/Expectancy Questionnaire; W. Rief, W. Hiller, \& M. Fichter: SOS-7; and, W. Schneider, H. Basler, and B. Beisenherz: FMP. 


\section{Table of Contents}

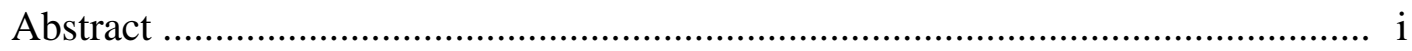

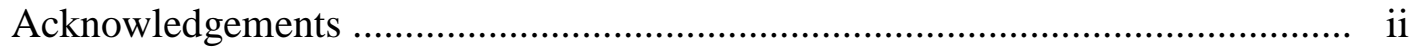

List of Tables ........................................................................................ vii

List of Figures .................................................................................. viii

Chapter 1. Introduction................................................ 1

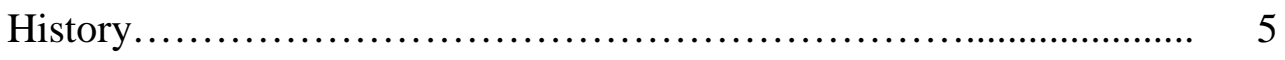

Definitions..................................................... 12

Prevalence....................................................... 14

Public Health Relevance ........................................ 16

Importance for Social Work.................................... 17

Benefits for Practice \& Policy..................................... 19

Chapter 2. Literature Review

Characteristics affecting somatization............................ 24

Figure 1. Diagram of characteristics associated with somatization..... 36

Treatment Models............................................... 37

Medical Approaches...................................... $\quad 37$

Mental Health Approaches................................ 44

Cognitive Behavioral Treatment............................... 45

The Medical Consultation Process................................. 49

Provider Factors........................................ 50

Patient Factors........................................ 53

Difficulties Referring to Mental Health............................. 56

Chapter 3. Theoretical Models....................................... 63 
Figure 2. Theories for motivation to engage in therapy.............. 67

Application of Theoretical Models to Dissertation Study.............. 70

Research Questions............................................. 74

Chapter 4. Methodology

Figure 3. Overview of Design................................... 76

Figure 4. Participant Flow Chart................................ 77

Sample.................................................... 78

Motivation for Therapy Measures............................... 81

Interventions................................................ 86

Procedures...................................................... 87

Analyses................................................. 89

Chapter 5: Results................................................. 92

Statistical Tables

Table 1. Descriptives for sociodemographic characteristics ........... 100

Table 2. Correlation matrix for MET- posttest...................... 102

Table 3. Factor analysis loadings.............................. 103

Table 4. Correlation among MET-posttest, FMP, Credibility/ Expectancy......................................... 104

Table 5. Analysis of covariance for outcome measures: Comparison of analogue care as usual consultation and enhanced consultation interviews...................................

Table 6. Regression analysis for interaction terms controlling for the overall positive affect of the enhanced consultation condition on the MET and Credibility measures.............. 


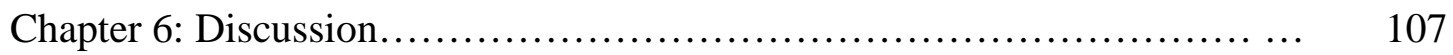

Theory Integration............................................ 112

Strengths and Limitations....................................... 116

Practice Implications............................................ 120

Medical providers, mental health providers and

patients................................................. 122

Future Directions........................................... 125

References................................................ 127

Appendices

Appendix A. Somatization Model of Care............................. 145

Recruitment

Appendix B Recruitment Flyer .................................. 146

Appendix C. Provider Letter..................................... 147

Appendix D. Post in Craigslist and all newspapers.................. 148

Appendix E. Advertisements for Newsletters and Magazines........ 149 Instruments

Appendix F. SOMS-7 .................................... $\quad 150$

Appendix G. Demographic Questionnaire........................ 154

Appendix H. FMP........................................... 156

Appendix I. Credibility Expectancy Questionnaire......................157

Appendix J. Motivation to Engage in Therapy (MET)

Pretest............................................ 159

Appendix K. Motivation to Engage in Therapy (MET)

Posttest............................................... 160

Appendix L. Expert Panel Rating Questionnaire for

Vignettes............................................. 161

Appendix M. Discussion A (Vignette of 
consultation as usual interview)................... 162

Appendix N. Discussion B (Vignette of

enhanced consultation interview)................... 164

Miscellaneous

Appendix O. Telephone Script.............................. 166

Appendix P. Patient Consent Form........................... 168

Appendix Q. Instruction Sheet................................ 171

Appendix R. Resource Information Sheet....................... 172

Appendix S. Thank you note............................... 173 
List of Tables

Table 1. Demographics...............................................

Table 2. Correlation matrix for MET- posttest......................... 102

Table 3. Factor analysis loadings................................. 103

Table 4. Correlation among MET-posttest, FMP, Credibility/Expectancy.....................................

Table 5. Analysis of covariance for outcome measures:

Comparison of analogue care as usual consultation and enhanced consultation

interviews..................................................

Table 6. Regression analysis for interaction terms controlling for the overall positive affect of the enhanced consultation condition on the MET and Credibility measures............................. 


\section{List of Figures}

Figure 1. Diagram of characteristics associated with somatization..........................................

Figure 2. Theories for motivation to engage in therapy..................

Figure 3. Overview of design.......................................

Figure 4. Participant Flow.... 


\section{CHAPTER 1: INTRODUCTION}

Somatization is the presentation of physical symptoms without an objective and identifiable cause, and the condition is among the most common and challenging problems in primary medical care (Bakal, Steiert, Coll \& Schaefer, 2006). There has been considerable examination of both etiology and treatment for somatization. In spite of many advances, the condition continues to be plagued with uncertainty and complexity. Somatization is beset by inherent problems of the dualistic practice philosophy that operates in medicine and mental health. This perspective forces symptoms to be reduced to fit into rigid pathological categories that are physical or

psychological (Salmon, Peters, \& Stanley, 1999). The “either, or” approach invites controversy especially when physical etiology is ruled out, leaving only a psychological reason for the symptoms. Patients with a naïve understanding of psychological influences might assume that symptoms are under their control and could be overcome with will power (Kirmayer \& Looper, 2006; Salmon, 2007). Consequently, they may feel responsibility and blame. These feelings can be further fueled when they are accused of having invalid or imagined symptoms (McFarlane, Ellis, Fafoem, Barton, Browne, \& Hoof, 2008).

When there is a dualistic explanation for the etiology of physical symptoms, a contest between provider and patient is likely to ensue with patients attempting to preserve their integrity and self-concept (Ring, Dowrick, Humphris, Davies, \& Salmon, 2005). Patients may try to accomplish this by fighting to prove that the 
physician hasn't looked hard enough and a diagnosis has yet to be established (Salmon, 2007). Others "up the ante” by increasing the number or severity of symptoms and still others may doctor shop until their physical problem is substantiated (Dowrick, Ring, Humphris \& Salmon, 2004). Even if skilled providers acknowledge that the patient's condition may be composed of both physical and psychological problems, this information may often be communicated in a too late, too little fashion, and after ruling out physical etiology. Patients may perceive the explanation and subsequent recommendation as a last resort and feel abandoned or dismissed (Peters, Stanley, Rose \& Salmon, 1998). Regardless, the patient is left with the burden of responsibility for symptoms that that cannot be labeled within the current taxonomy. The weight of uncertainty, alone, is enough to evoke significant stress (Nettleton, 2006).

Both patient and medical provider are influenced in their beliefs and understanding of the evaluation and treatment for somatization through a societal lens. Perspectives in the United States, for example, tend to endorse a dualistic framework for treatment of many medical conditions. These perspectives tend to set up a "no win" scenario for those with medically unexplained symptoms that fail to fit neatly into a specific category. The dualistic paradigm calls for classifying symptoms into mental or medical, eclipsing the notion of integrative care. Moreover, medical provider and patient alike have been socialized to believe that physical care is considered more credible and virtuous compared to mental health care, which 
suggests weakness and deficiency. (Komiti, Judd, \& Jackson, 2006; Lawrie, 2000). The associated stigma attached to mental health care is still prominent and has been shown to impede willingness to engage in psychological treatment (Kirmayer, Groleau, Looper, \& Dao, 2004). Together, bias toward physical care and stigma that often accompanies mental health care converge to make assessment and treatment of somatization a difficult undertaking. They are evident in practice, nosology, and reimbursement policy (Komiti, Judd, \& Jackson, 2006).

Creating a social standard for weaving together medical and psychological care can help reduce stigma, be more effective and improve satisfaction for patient and provider (Moran, 1999). Some encouraging hints of change suggest a shift in societal views towards mental health care. For example, The Paul Wellstone Mental Health and Addiction Equity Act, HR 1424, 2008) requires insurance plans to create more parity between mental health and physical health care coverage. This law ensures that an insurance company's requirement for mental health reimbursement is more equitable with health care reimbursement, in demand for co-payments and deductibles as well as in limitations on visits and cap on lifetime dollar amount. This legislation may be a cornerstone for transforming the societal view of dualistic care with which our country has been so strongly tied.

Optimal outcomes for those who have been identified with somatization will more likely be realized if attention to the psyche and body are approached and treated simultaneously (Aiarzaguena, Grandes, Salazar, Gaminde, \& Sanchez, 2008). 
There has been recent support for this multifaceted approach (Looper \& Kirmayer, 2002; Morriss, et al., 2006; Smith, et al., 2006). Yet, most patients are reluctant to engage in psychological treatment (Arnold, Speckens, \& van Hemert, 2004; Barsky, \& Ahern, 2004; Sumathipala, Hewege, Hanwella, \& Mann, 2000). Thus far, these approaches have not been able to fully determine methods that affect patients' motivation to engage in therapy in concert with medical care. Those with somatization are thought to be characteristically different in ways that make discussion and compliance with mental health more challenging than other patients who seek help from their primary care provider. And a central difference is their firmly held belief that there is a somatic cause of their symptoms; thus, suggestions of psychological sequelae or treatment can position the patient at odds with their self-concept (Barsky \& Borus, 1999). Any successful model of treatment will need to address these and other crucial issues that affect patient motivation to engage in mental health treatment. The physician is typically the gateway to formulating a treatment plan for somatization, and he or she can use the patient-doctor consultation process as the venue to enhance motivation of the patient with somatization to engage in mental health treatment (Kravitz, 2001).

The focus of this dissertation is the identification of issues that could be discussed by the physician during the consultation process that would motivate the patient to engage in mental health therapy while maintaining a medical relationship. A discussion of somatization's history, definitions, prevalence, consequences and 
importance to social work and policy is first presented. Chapter Two provides a review of the literature on patient characteristics thought to contribute to somatization, and treatment approaches, highlighting difficulties inherent in referring patients to mental health treatment and how the consultation process between patient and provider can impact motivation for therapy. Next, Chapter Three offers a cognitive theory of motivation which informs and supports the study's approach. Chapter Four details the study's methodology and Chapter Five presents the results. Chapter Six concludes with the findings, strengths and limitations of the study.

\section{The Problem of Somatization}

\section{History}

Somatization, a term first used by psychoanalyst, Wilhelm Stekel, in the early 1900's, reflects physical symptoms with an underlying psychological conflict (Marin, \& Carron, 2002). Somatization has been recognized for centuries although the terms used to define its nature and etiology have undergone many transitions. These shifting meanings continue to exert influence on diagnosis and treatment. The Egyptians were thought to be the first ones to examine medically unexplained physical symptoms, but it was the Greeks, over 4,000 years ago, who first used the word hysteria (Gilman, King, Porter, Rousseau, \& Showalter, 1993) to describe a host of unexplained physical ailments. Hysteria, which literally translates to "womb", was thought to arise from a physical etiology, affecting only females with the womb as the source of pain. However, sometime during the 18th century, the 
term hysteria was re-conceptualized as having a psychological etiology. Unexplained physical symptoms were no longer understood to be associated with bodily mechanisms but rather contrived and embellished with an emotional foundation. This altered framing may have set in motion the "either/or" body or mind conundrum evident in our diagnostic and classification system today. Hysteria has been used as the dominant term to describe unexplained pain up until the early 1900's, however remnants of this earliest meaning can still be observed in the DSM-IV-TR (American Psychiatric Association, 2000). An example is conversion hysteria, which had its roots in the $19^{\text {th }}$ century and was first advanced by Freud and Breuer. This concept describes how underlying anxiety created by unconscious conflict is transformed into a somatic symptom in order to protect an individual from overwhelming negative emotions (Van der Hart, \& Friedman, 1989). This characterization remains in the DSM-IV-TR diagnostic classification as simply conversion disorder. Interest in mind and body evolved out of two frameworks: psychosomatic medicine and psychoanalysis (Taylor, 2002). These different yet overlapping camps exerted influence on the understanding and interpretation of hysteria. The word hysteria was not replaced at this time but was joined by another term "psychosomatic", which was coined in 1818 by Heinroth (Panconesi \& Argentieri, 2000). The term "psychosomatic" contains the roots of psyche and soma, suggesting that mind and body are distinct entities, however they act together to influence physical symptoms. The idea that these concepts are separate yet related is addressed 
through a psychoanalytic perspective offered by psychoanalyst, D. W. Winnicott. He proposed that psychosomatic problems were a function of a weakened connection between the body and mind which destabilizes the ego or causes a split in the individual's personality in defense of threat to the personality (Meissner, 2006). The conceptual dance between monism and dualism continues to remain a polemic in diagnosis and treatment.

In theory, the term psychosomatic seems to embrace the monistic position regarding the mind and body by conveying the interdependence of both. However, in application, especially with respect to treatment, psychosomatic is a dualistic paradigm. Those with psychosomatic illness are examined by distinguishing what symptoms arise from the body and what symptoms arise from the mind, thus treating them as separate conditions. The popularity and interpretation of the term “psychosomatic” peeked during the 1950’s, (Woolfolk \& Allen, 2007) and faded thereafter, but its pejorative meaning could be still be appreciated in the literature and continued into the $21^{\text {st }}$ century. A study by Stone, Colyer, Feltbower, Carson, and Sharpe (2004) found that in 34\% of the 477 newspapers articles they examined, the use of psychosomatic was used to describe an imaginary or malingering illness.

The reductionistic framework created by separation of mind and body can be a useful mechanism to understand medical pathology and apply treatment. For example, if a patient presents with a fractured leg, it would be both understandable and appropriate to provide direct assessment and treatment with physical care. Yet, 
many conditions may be a complex web integrating many systems. Over the past decade, an emerging field of study referred to as psychoneuroimmunology-the complex interplay between behavior, brain and the immune system-- has been gaining momentum. Once considered a fairly restricted and closed system, the immune system is currently thought to interact in a bi-directional way with the brain and behavior via chemical and electrical signals (Maier, Watkins and Fleshner, 1994). Therefore, problems with immunity cannot be simply explained nor treated in purely physical way. Stressors can affect immune function through hormones and autonomic activation, resulting in physical and psychological symptoms.

A good example of this process is depression. Depression can activate autonomic outflow and release hormones which, in turn, impacts immunity. Depressed individuals often have elevated levels of glucocorticoids in their blood (Mitchell, \& O'Keane, 1998; Ströhle, 2003). Glucocorticoids are naturally-produced steroid hormones, or synthetic compounds that inhibit the process of inflammation. The elevated levels are thought to be caused by impaired glucocorticoid receptor feedback at the level of the hypothalamic-pituitary-adrenal (HPA) axis. Glucocorticoids can act with depression and can negatively affect immunity response through modulation of neural and hormonal factors. Conversely, lowered immune function is associated with depression. Psychological processes such as behavior and emotion can thereby influence the bi-directional network of immunity and brain and be affected by it. 
Another example of this complex interplay is fibromyaliga, a syndrome at the forefront of the spirited debate between physical and psychological etiology. Fibromyalgia is a condition that might very well have a physical etiology but, because there are no objective diagnostic tests available, the weight of explanation leans towards psychological orientation. There is developing evidence, however, that disturbances or abnormalities in the neuroendocrine systems may be largely responsible for fibromyalgia symptoms (Peterson, 2007). In particular, fibromyalgia seems to be associated with abnormalities in glucocorticoid sensitivity. Glucocorticoid receptor affinity is thought to lower hypothalamic-pituitary-adrenal (HPA) axis resiliency (Macedoa, Hessec,Turnera, Meyerd, Hellhammerc, \& Mullera, 2008).

Some also might argue that the dualistic approach to health care serves a pragmatic function for managing structural differences in access to care (Kirmayer \& Young, 1998). In those societies where there is an implicit understanding that treatment is afforded to those who present with physical symptoms versus psychological symptoms, the presentation of somatization can be understood as a practical approach to access care. However, this argument doesn’t fully explain the expression, interpretation and treatment of somatization.

Culture also may play a large part in how symptoms are expressed. Although research has documented that somatization is ubiquitous and found in countries around the world, not all require the distinction between physical and psychological 
symptoms in order for individuals to receive care (Keyes, \& Ryff, 2003). Viewing physical or psychological symptoms as a cultural construction provides a slightly different conceptualization of somatization (Kirmayer \& Young, 1998). This framework suggests that somatization can't be separated from the socio-cultural experience in which the individual is situated. Ethnographic expressions of distress come to bear on the understanding, presentation and interpretation of somatization. Often physical symptoms coexist with emotional stress, if not underlying it. These observations are apparent in ethnocultural groups regardless of access to health care. For example, the Korean "syndrome” hwa-byung is characterized by physical symptoms such as heaviness, burning muscular aches, dry mouth, insomnia, and indigestion—all of which are understood and attributed to suppressed rage (Pang, 1990). There is more than a tacit understanding that symptoms of this syndrome are interwoven with suppressed feelings of anger and resentment that contribute to pain in the chest. Individuals with hwa-byung readily associate emotional stress with manifestations of physical symptoms. The extent to which these symptoms are embedded in social and cultural processes reveal and support discourse consistent with the expression of physical symptoms, suffering and treatment. Interestingly, these syndromes lie outside our current nosology. In the DSM-IV-TR they are listed in a separate section, which seems to imply acceptance of both physical and psychological presentation and treatment without establishing pathology for one or the other. 
It is difficult to imagine a presenting medical condition in which assessment and treatment might be improved if both brain and behavior (mind and body) were considered. As medicine is evolving with the onset of newer disciplines such as psychoneuroimmunology and psychoneuroendocrinology, the chasm between mind and body is further being challenged and possibly narrowing (Woolfolk \& Allen, 2007). Nevertheless, there still seems to be more acceptance of mixed etiology for medically presented symptoms in contemporary medicine. Acceptance of mixed treatment is less well established (Dimsdale, \& Dantzer, 2007).

It is important to acknowledge that just as the dualistic view can be observed as reductionistic, so too can the monistic approach which suggests that both physical and psychological symptoms co-exist with the equal magnitude. It has been suggested that the influence of either physical or psychological attribution lie on a continuum with one or the other exerting different degrees of influence at any one time (Aiarzaguena, et al., 2008). This fluid relationship offers a more flexible and wider view from which to diagnose and treat somatization. Embracing this perspective that both physical and psychological factors can weigh in at different degrees and different times, eclipses the need to diagnose and label symptoms as purely one or the other. Treatment of symptoms with an integrated holistic approach will be most effective, irrespective of etiology.

How medical providers perceive and subsequently offer treatment options for somatization largely depends on their respective ideological stance towards 
symptoms and disease, which also is embedded in socio-cultural values (Kirmayer, Groleau, Looper, \& Dao, 2004). In the Western world, medical providers might not fully appreciate cultural underpinnings that influence presentation and treatment of symptoms. Social workers on the other hand-by virtue of their education-- have a fundamental understanding of the impact of social and cultural influences on behavior. With additional training, social workers can play a key role in raising awareness in medical providers.

\section{Current Definitions}

Somatization (formerly known as Briquet’s Syndrome (Guze \& Perley, 1963) made its way into one of the diagnostic classifications in the DSM III and is currently one of the most common terms used to describe the development and persistence of physical problems for which there is no organic basis that can be objectively tested or demonstrated (Keyes \& Ryff, 2003; Oyama, Paltoo \& Greengold, 2007). Medically unexplained symptoms (MUS) is another term observed in the literature, often used interchangeably with somatization. MUS terminology has been criticized for presupposing that no explanation for symptoms exist (Brown, 2007). However, this term remains neutral towards any dualistic expression. Unfortunately the use of different terminology has perpetuated the debate of mind vs. body with no term to date accepted as adequately portraying the condition. Essentially these terms force providers to make a differential diagnosis primarily through exclusion of symptoms that can be physical or psychological. 
While the controversy over classification criteria continues, a term that provides common ground provides a solution. The term selected for this study was "somatization” for two reasons: it fits with the nomenclature more commonly understood by mental health professionals and the focus of the study was identification of strategies to engage patients in mental health therapy.

There is some disagreement about the diagnostic criteria for somatization. The DSM-IV-TR classification for Somatization Disorder requires onset before age 30, symptoms which last for several years, including at least four unexplained pain symptoms, two unexplained non pain gastrointestinal symptoms, one sexual or menstrual symptom and one pseudoneurological symptom (American Psychiatric Association, 2000). The International Statistical Classification of Diseases and Related Health Problems (ICD-10) requires a history of six unexplained symptoms from which two must be from gastrointestinal, cardiovascular, genitourinary, and skin pain (World Health Organization, 1993). These criteria have been relaxed with most studies (e.g., Feder, et al., 2001; Hiller, Rief, \& Brahler, 2006) using the abridged somatization disorder (sometimes referred to as "subthreshold somatization”). This construct of somatization was developed by Escobar, RubioStipec, Canino, \& Karno (1989) and requires six unexplained physical symptoms for females and four for males; one of which has been present within the last year. Often the diagnosis is determined by ruling out organic etiology (De Gucht \& Maes, 2006). The DSM-IV-TR and ICD-10 also include diagnostic categories for somatization. In 
the DSM-IV-TR, undifferentiated somatoform disorder is defined as one or more physically unexplained symptoms lasting for 6 months and the ICD-10 requires multiple unexplained physical symptoms lasting for six months (Woolfolk \& Allen, 2007). Moreover, the term somatization has extended beyond symptoms to syndromes such as chronic fatigue, fibromyalgia and irritable bowel. Although these classifications can present difficulty in understanding and synthesizing the research, the interpretations share a common thread; a chronic physical complaint that cannot be adequately explained by physical findings and for which the application of both mental and physical treatment is essential (De Gucht \& Fischler, 2002; Woolfolk \& Allen, 2007).

\section{Prevalence}

The prevalence rates of somatization also present some challenges as they are subject to differences in type of setting, measure and time (e.g., year vs. lifetime) (Gureje \& Simon 1999; Hiller, Rief, \& Brahler, 2006). Rates also vary depending on whether they were estimated for somatization, somatoform or the abridged definition of somatization used by Escobar, et al. (1989), the ICD-10 or DSM-IV-TR. For somatization disorder, the strictest diagnostic criteria of the ICD-10 or DSM-IV-TR, which includes multiple complaints from different and specified organs, the prevalence of somatization is actually quite low-around $1 \%$ to $5 \%$ both in the general population and in primary care (Escobar, Gara, Silver, et al., 1998; Fink, Sorrenson, Engberg, Holm, Munk-Jorgensen, 1999; Katon \& Walker, 1998). 
Prevalence estimates for somatoform in primary care, a broader classification within the ICD-10 or DSM-IV ranges between 15\% to 30\% (Kroenke, 2003; Kirmayer, Groleau, Looper, \& Dao, 2004). For the abridged definition of somatization in primary care, the range of prevalence rates are from 19\% to 22\% (Escobar, RubioStipec, Canino, \& Karno, 1989; Escobar, Waitzkin, \& Cohen, 1998; Escobar, Waitzkin, Silver, Gara, \& Holman, 1998; Gureje, Simon, Ustun, \& Goldberg, 1997; Kirmayer \& Robbins,1991).

Prevalence rates that distinguish age categories also have been studied. Using the DSM-IV classification, Fink et al. (1999) found estimates for prevalence as high as $30 \%$ for those between 18 and 65 . Others also using the same classification distinguished between age groups. De Waal, Eckhof, \& van Hemert (2004) found differences in prevalence of somatization for the following age categories: $22 \%$ for those ages between 25 and 45; 15\% for those ages between 45 and 65 and 5\% for those ages between 65 and 79 .

Regardless of the criteria used for somatization, women appear to be at higher risk than men (Leiknes, Finset, Moum, \& Sandanger, 2007; Woolworth \& Allen, 2007). There also is evidence that somatization is prevalent in many countries around the world, although there are differences in prevalence (Kisely \& Simon, 2006), with Latin America having the highest level (Gureje, Simon, Ustun \& Goldberg, 1997). 


\section{Public Health Relevance}

\section{Consequences}

Several studies have documented negative consequences for unexplained somatic complaints, such as emotional and physical suffering as well as increased use of health resources (Katon et al., 1991; Shaw \& Creed, 1991). In particular, those with somatization suffer marginalization and stigmatization (Ring, et al, 2005), and disability (Escobar et al., 1987; Simon \& VonKorff, 1991). These individuals also are at risk of iatrogenic harm (physician induced harm by words or therapy), especially during the course of ruling out physical etiology (Ring, et al., 2005; Rosendal, Olesen \& Fink, 2005; Salmon, Ring, Dowrick, \& Humphris, 2005). Unexplained physical symptoms can lead to extensive, intrusive and less appropriate tests (Katon et al., 1991; Oyama, Paltoo \& Greengold,. 2007; Salmon, et al., 2005; Smith, Monson \& Ray, 1986) and even surgery (Salmon, 2007).

The devastating consequences of somatization are palpable for increased health care costs. In a study by Smith, Monson and Ray (1986), patients with somatization were shown to incur health care related expenses 9 times higher than the average costs of health care per capita in the US. A controlled study conducted by Hiller, Fichter, and Rief (2003) demonstrated that those patients with somatoform disorders were found to have a 2.2 fold higher than average inpatient and outpatient health care costs in a two year period prior to receiving cognitive-behavioral treatment. After treatment, noteworthy savings in health care costs were realized; 
$24.5 \%$ for outpatient care and $36.7 \%$ for inpatient care. These costs were found to be independent of comorbid mood and anxiety disorders as well as medical illness. A more recent study of approximately 2000 patients measured medical care utilization and costs in two hospital-affiliated primary care practices (Barsky, Orav \& Bates, 2005). Even after adjusting for anxiety and depressive disorders, those with somatization had more hospital admissions, inpatient costs, emergency room visits, primary care visits, and specialist visits, compared to those without the diagnosis.

\section{Importance for Social Work}

Social work has a long tradition of providing mental health treatment. According to the NASW Behavioral Health Practice Update (October, 2003), approximately $50 \%$ of social workers are employed in mental health. The social worker's biopsychosocial orientation provides a strategic advantage for addressing individuals with somatization from a holistic perspective, regardless of setting. With this background and training, a social worker can be an ideal member of a health care team that can provide the mental health treatment component for those with somatization, whether in the hospital or primary clinic. Looper and Kirmayer (2002) support having both medical and psychological services under one roof. This approach conveys a supportive message for integrative treatment and further reduces barriers for patient's motivation to engage in mental health treatment. Models of care which comprise a physician and social work team have been introduced and piloted in sites around the country (The Permanente Journal, 1998), with promising 
opportunities for social workers to bring their biopsychosocial perspective to patients with somatization.

There are a few potential obstacles for social workers to overcome in supporting individuals with somatization. Social workers may not always be the first resource considered for addressing the mental health issues facing those with somatization. Social work's presence in the medical arena has been traditionally limited to the impatient care setting (McGuire, Bikson, \& Blue-Howells, 2005). Social workers used in primary care clinics are rare. Perhaps their absence in this setting reinforces the perception by providers and patients alike that social workers are ill equipped to address complex and holistic problems such as somatization (Lesser, 2000). Social workers are often relegated to the tasks of discharge planning rather than looked upon as a formidable discipline with mental health expertise and equal credibility with the medical provider (Cowles, \& Lefcowitz, 1995). Social workers often compete with nurses and other disciplines such as psychology for counseling referrals (Smith, et al., 2003).

Social work, equipped with its biopsychosocial framework, can serve as the lens through which somatization is viewed. This function can help broaden understanding of the various interpretive stances of somatic symptoms that reside in both provider and patients. Regardless of whether symptoms might be the expression of as actual perturbations in physiology, metaphor for psychological conflict, psychogenic pathology; social-economic, cultural, or some other idiom of distress 
(Kirmayer \& Young, 1998), social workers can help medical providers and patients move towards holistic care. Social workers can promote appreciation of, and empathy for, medical providers whose efforts may be thwarted by the duality of medicine-- its categorical and inflexible prescription for treatment options. So too can social workers honor the ideological stance of patients for whom help with suffering is not predicated on the distinction between physical and psychological but rather the acknowledgement of their experience. Findings from the current study support how social workers can help guide medical practitioners and patients toward integrative treatment and optimal care.

\section{Potential Benefits of Integrative Care Approach for Policy and Training}

Integrative treatment planning needs to be considered in the formulas for

medical and mental health reimbursement. The medical provider's initial discussions with patients as well as ongoing collaboration with mental health providers are valuable services that promote comprehensive health care and deserve remuneration. The introduction of managed care can be viewed as an important mechanism to evaluate and monitor as well as to curtail health care's skyrocketing costs (Moran, 1999). Although managed care's vigilance for cost control can be appreciated, its success in curbing financial expenditures was accomplished, in part, by taking a disproportionately harder line toward mental health care, compared to physical care. This approach results in forfeiting integration of physical and mental health care 
which, in turn, promotes dualistic care and reinforces stigma around psychological treatment. It seems timely for a costs saving strategy alteration. Studies have shown that integrative care can improve provider and patient care satisfaction (Kirmayer, Froleau, Looper, \& Dao, 2004). It can also improve patient outcomes of reduced symptoms and severity, as well as decrease costs. A meta-analysis conducted by Chiles, Lambert and Hatch (1999) demonstrated that psychological interventions can impact medical costs across various medical and psychological settings. Psychological interventions were characterized as either psychotherapy (consisting of crisis intervention, short-term psychotherapy, relaxation training and group therapy) or psychoeducation (behavioral medicine pre-post procedural instruction geared toward anxiety reduction and management of expectations, and biofeedback. While there was a significant effect for both types of interventions, psychoeducation outperformed psychotherapy in outpatient settings with a larger effect (.52 vs. .21). However, this finding is not surprising since psychotherapy is time limited in most settings such as hospitals, and physical health is often an indirect focus in mental health settings. When evaluating costs saving for medical care in outpatient counseling settings, it is difficult to identify costs offsets for medical conditions as these are not usually specified as the reason or focus of the treatment. Nonetheless, regardless of how counseling is characterized, there are significant advantages to the patient and health care costs with psychotherapeutic and psychoeducation interventions. 
While there are a few medical specialties — aging, chemical dependency and rehabilitative medicine-- that have already adopted the physical and mental health team approach, there remain other specialties besides primary care that remain embedded in dualistic practice. Among these, for example, are cardiology, neurology, and gynecology. Many outpatient clinics could also benefit from a joint perspective and integrative model for patient care.

If social work is to become an integral player on the medical team to address somatization, it will likely require acquisition of new skills or refinement of old ones. These skills may include comprehensive knowledge of somatization—how it is diagnosed, its diverse presentations, elements of optimal care; the prevailing cultural stigma of psychotherapy; and the theoretical and logistic barriers related to patient's motivation for integrative treatment. This could be accomplished in schools of social work or other venues. Similarly, using integrative intervention models may pose new challenges for medical care providers who also will need additional training. This training could be integrated into teaching hospitals for medical practitioners. It is conceivable that combined teaching efforts for medical and mental health professionals might afford the best strategy to obtain the requisite knowledge to manage the intricacies involved in helping and caring for this population.

\section{Summary}

Somatization is a multifaceted and persistent problem. It has been defined through a series of shifting perspectives beginning in the $18^{\text {th }}$ century, which have 
yielded both informed and ambiguous understandings of this condition. Yet, there seems little doubt that the problem is prevalent and its consequences severe. Mental health therapy in addition to medical care is integral to the successful treatment for those with somatization (Deary, Chalder \& Sharpe, 2007). Society plays a central role in shaping the particular orientation to health care that guides how both patients and medical providers alike expect to evaluate and treat patients with medically unexplained physical symptoms (Kirmayer \& Looper, 2006). Patient and provider biases towards dualism coupled with the stigma around psychological care can result in patient's tightened grip on beliefs about the physical nature of their symptoms and corresponding physical treatment. Although society is slowly embracing some of the aspects of integrated care (e.g., new legislation), it has a ways to go before integrated care is truly accepted. Until then, patients and providers will most likely forfeit psychological care and defer to medical treatment to ameliorate suffering for those with somatization even though this practice may result in outcomes that are unacceptable to both patient and provider.

Recommendation for integrative treatment must make explicit that the role of mental health therapy will be to help with the management of symptoms (regardless of the etiology), which negates implications that the patient's symptoms are all in their head. Mental health therapy can specifically attend to the distress known to be associated with an unexplained diagnosis (Rhodes, McPhillips-Tangum, Markham, \& Klenk 1999). Social work is in a unique position to provide mental health 
treatment to these patients. Findings from the present study inform medical providers in methods for engaging patients in therapy as well as enhancing social worker's development of additional collaborative skills. 


\section{CHAPTER 2: LITERATURE REVIEW}

The literature highlights those characteristics thought to put individuals at risk for development of somatization as well as those characteristics that affect treatment of this condition. It should be noted, however, that much of the literature and associated research have been conceptualized from dualistic rather than integrative perspectives. As such, patient factors, in contrast to medical practitioner factors, are given greater emphasis, which may unfairly underscore patient accountability. Additionally, most of the studies conducted derive their findings from correlational data which precludes understanding of cause and effect. Therefore, based on existing research, it is difficult to determine precisely which causal factors actually impact somatization. Nevertheless characteristics shown to be associated with somatization bear mention and include childhood experience of illness in parents and parent's experience with illness behavior, PTSD, personality traits, attributions, expectations, depression, health anxiety and worry, and sensitization. (See Figure 1).

\section{Characteristics Affecting Somatization}

\section{Parental Illness.}

Hotopf, Mayou, Wadsworth, and Wessely (1999) found that children with unexplained medical symptoms or children with a family member who had unexplained medical symptoms were more likely to develop somatization later in life, compared to those children without a personal or family history of somatization. 
Similarly, Craig, Cox and Klein (2002) found that adults with somatization were more likely to report that as children they had a parent or other family member with a physical illness, compared to adults who were not diagnosed with somatization. Additionally, a study by Hotopf, Wilson-Jones, Mayou, Wadsworth, and Wessely (2000) revealed that there was a strong risk factor for somatization in those children with fathers who identified their health as poor.

\section{Posttraumatic Stress Disorder (PTSD).}

There has also been a compelling line of evidence that demonstrates an association between PTSD and unexplained physical symptoms ( Andreski, Chilcoat, \& Breslau, 1998; Escalona, Achilles, Waitzkin, \& Yager, 2004; Gillock, Zayfer, Hegel, \& Ferguson, 2005; Leserman, 2005). For example, Andreski, et al.(1998) demonstrated with a HMO sample of 1000 patients that those with PTSD were more likely to express somatic symptoms than any other disorder. Escalona et al., 2004 found that, after controlling for mood and anxiety disorders, posttraumatic stress was one of the strongest predictors of somatization. In particular, numbing was found to be the most robust feature of PTSD associated with somatization. The association between PTSD and medically unexplained physical symptoms is particularly strong for women (Gill, Szanton, \& Page, 2005). Moreover, PTSD for women has frequently been linked to early adverse life experiences such as child abuse (Spertus, Yehuda, Wong, Halligan, \& Seremetis, 2003). These adverse childhood experiences have, in turn, been demonstrated to affect the development and course of 
somatization in adulthood (Stuart \& Noyes, 1999). PTSD is currently being considered central to understanding how fear and avoidance may underlie chronic pain pathology. PTSD is considered to affect memory and attention, which result in alternate and perhaps inaccurate processing and interpreting of information (McFarlane, et al., 2008).

\section{Personality Traits.}

Personality traits also have been considered to be a factor in somatization. There appears to be evidence to suggest that somatization is correlated with higher incidence of personality disorders, in general (Noyes, et al., 2001) and neuroticism, in particular. However, others have shown associations between somatization and schizotypal, obsessive-compulsive and paranoid personality disorders. The behavioral patterns related to personality disorders can have an impact on the medical consultation. Patients with personality disorders can feel misunderstood, disrespected, and pessimistic in this context. Consequently, these negative interactions between patient and medical provider interfere with treatment planning and ultimately symptom improvement (Vandenbergen, Vanheule, Rosseel, Desment \& Verhaeghe, 2009).

Negative affectivity is a stable personality trait that has been measured by various scales and referred to as neuroticism, maladjustment and trait anxiety (Watson \& Pennebaker 1989). This negative affectivity dimension is characterized by negative mood, general dissatisfaction, distress and negative self-concept. Watson 
and Pennebaker found that while there is a strong association between negative affectivity and health complaints, negative affectivity failed to predict long-term health outcomes. Rather, those who had negative affectivity may have a predisposition to be vulnerable to somatization. Noyes, et al., (2001) also found that negative reactivity was related to those with somatization. Additionally, Noyes and his colleagues found that scores for neuroticism and lower agreeableness were higher for those with somatization than for controls. In a review by Deary, et al., (2007), neuroticism was found to be associated with elevated response to stress, and increased vulnerability to physical illnesses, as well as being correlated with heightened attention to potential indications or cues of physical pain.

\section{Causal Attributions.}

Causal attribution is a construct defined as the interpretation and assignment of a cause to a problem (Weiner, 1986). It is important because the act of interpretation and explanation of a cause will most likely lead to a particular cognitive and behavioral response. The attributed cause can be positive or negative, controllable or uncontrollable, internal or external, stable or unstable (this reflects the extent to which a cause can change), physical or psychological.

The concept of causal attribution has made considerable contributions to the literature on a number of social phenomena such as depression, responsibility judgments, well-being and motivation (Jones, Kanouse, Kelley, Nisbett, Valins, \& Weiner, 1974; Weiner, 1995; Abramson, Seligman, \& Teasdale, 1978). In general, 
somatic attributions have been shown to be correlated with poor physical functioning, increased number of chronic complaints, and increased health care use Taillefer, Kirmayer, Robbins, and Lasry (2002). Additionally, the need for medical assessments and corresponding treatments were more strongly correlated with somatic attributions as compared to psychological attributions (Rief, et. al, 2004). More recently, this concept provided some insight into the possible development and maintenance of somatization as well as its effect on motivation for treatment. In fact, attribution theory will be further discussed in the next section as one of three dimensions of a cognitive model to explain motivation of patients to engage in mental health therapy along with medical care.

An example of a positive attribution for bodily sensations is the normalization of symptoms. Normalizing of symptoms was found to be one of the main distinguishing factors in high and low utilization of health care in a study by Sensky, Macleod \& Rigby (1996). Patients with frequent visits (an average of 12 visits in a year) to their medical provider and a matched comparison group (on sex and age) that hadn’t see their provider in a 2-year period were assessed. Those patients with frequent visits were less able to generate normalizing attributions for their physical symptoms and less likely to initiate a normalizing attribution as their initial response, compared to the comparison group. Their health costs related to visits were much higher than those of the comparison patients. An example of a negative attribution can be observed in a study by Rief, Hiller, and Margraf (1998). 
Patients who had a restricted view of health and who believed they were weak also had a lower threshold for stressful events and lower tolerance of body complaints than a clinical comparison group which did not had not been diagnosed with somatoform disorders. Those with somatization and hypocondriasis were found to interpret somatic sensations in a catastrophizing way and construed even the slightest discomfort or even fatigue as a disease. Additionally, those who had these negative attributions were more likely to have poorer outcomes than those without these diagnoses.

The relationship between other causal attributions and psychological adjustment for patients with somatic complaints were examined in a meta-analysis conducted by Roesch and Weiner, 2001. The results of the review found that those patients with internal, unstable, and controllable attributions about their physical symptoms were more positive about their ability to do something about their illness (coping) and they used more emotion-focused and cognitive approach strategies that those with external, unstable and controllable attributions. This latter group was also shown to experience more negative beliefs and lower expectancy for coping with their illness. They employed a more avoidance coping approach and had poorer psychological adjustment.

In a review by Rief and Broadbent (2007), it was suggested that attributional styles are perhaps multi-dimensional rather than one-dimensional. Patients who were diagnosed with somatization may have two to three different illness attributions and 
these led to different problems. However, the extent to which individuals have fixed and rigid attributions may contribute to the negative interactions during the consultation between patient and medical provider. These negative interactions, in turn, could lead to dissatisfaction as well as increased utilization of health care.

\section{Expectations/Perceptions.}

Studies have demonstrated that expectations can affect the perception of suffering associated with illness. For example, in a study by Lorenz et al. (2005), participants who anticipated lower intensity of pain, which was experimentally induced, did in fact experience less intense pain compared to those who anticipated higher intensity of pain. Lorenz et al. suggests that developing expectations of bodily complaints can serve as a primer for scanning and interpreting future physical sensations. Similarly, perceptions can influence somatic symptoms. Those with medically unexplained symptoms appear to perceive themselves as having a strong sense of bodily weakness (Reif, et al., 1998). A 2-year follow-up study by Frostholm, et al., (2007) examined whether perception were associated with selfrated health. The factors were referred to as illness perceptions and included illness identity label, control, consequences, emotional representations (helpless and hopeless), and timeline. Approximately 1785 patients (ages 18-65) from 28 general practice clinics completed the study. Patients were enrolled during a 3-week period and diagnosed by their physician as having medically unexplained symptoms or a specific presenting physical disease. Both groups were asked to complete an illness 
perception questionnaire at the beginning and at 3, 12 and 24 months. Linear regression analyses revealed that negative illness perceptions were demonstrated to be more evident in patients with somatization and predicted changes in their health status over a two-year period. Studies of somatization have also used the expectancy to measure motivation for therapy (Timmer, Bleichardt \& Rief, 2006; and Schneider, Klauer, Janssen \& Tetzlaff, 1999). For example Timmer, et al., investigated the relationship between patient's initial motivation for cognitive therapy and 12-month follow-up changes in their physical symptoms. Their study showed that improvement in somatic symptoms occurred for those who took a more active role in, and demonstrated more favorable attitudes towards psychotherapy. However, these findings need to be understood in the context of correlational analyses that cannot distinguish whether expectations affect somatization or the other way around.

\section{Depression.}

Depression and somatization seem to be risk factors for one another (Rief, Schefer, Heiller, \& Fichter, 1992), and both are correlated with reduced threshold for pain. However, somatization can present with or without depression. Somatization and depression seem to be associated with different measures of pain (Henningsen, Zipfel,\& Wolfgang, 2007). Sherman et al., (2004) examined the associations with the perception of pain in women with somatization and depression. Although this study examined these women's responses that were diagnosed with a limited disorder (temporomandibular disorder), findings revealed that attentional and perceptual (pain 
sensitivity) measures of pain were closely associated with somatization and behavioral (pain tolerance or avoidance) measures of pain were strongly correlated with depression.

\section{Health Anxiety.}

Health anxiety and illness worries appear to be positively correlated with the onset and prediction of somatic complaints (VerKuil, Brosschot, \& Thayer, 2007). It has been suggested that illness anxiety is negatively associated with improvement or diminution of symptoms. A cycle results in which rumination over symptoms leads to increased attention to symptoms which leads to amplification of pain and illness (Ursin, 2005). In a study by Hadjistavropoulos, Craig, and Hadjistavropoulos (1998), 782 undergraduate psychology students completed an illness questionnaire. A random selection of those with health anxiety and those without health anxiety were randomly assigned to receive different diagnostic information about their condition. Participants with health anxiety (defined as negative interpretations and behavioral responses that could lead to increased reassurance seeking) or non-health anxiety (as measured by Illness attitude Scale) were given positive or negative feedback regarding their symptoms. Those with health anxiety were less likely to draw on optimistic health information, less likely to use flexible observation skills for monitoring physical symptoms and less likely to engage in protective strategies, compared to those with non-health anxiety. Health anxiety can also lead to excessive scanning. For example, Barsky and Ahern (2004) demonstrated that there is a 
tendency for those with somatization to be hypervigilent towards stimuli and this tendency is related to their health outcomes.

\section{Sensitization.}

Types of sensitization appear to contribute to somatization (Verkuil, et al., 2007). Sensitization is considered to increase the possibility of medically unexplained symptoms through amplified processing of physical problems. Sensitization can be thought of as a multifaceted process involving the dynamic interplay of cognitive, somatic, and neurobiological factors. This formulation of sensitization can be used to help more concretely describe how somatization might be developed or maintained.

Cognitive sensitization is biased for selective processing of information. A study supporting this type of sensitization found that individuals had a tendency to disproportionally remember information centered on health issues (Martin, Buech, Schwenk, Rief, 2007). Another example of cognitive bias is found in a study with individuals who were given information about a specific physical health condition. Those individuals with health anxiety were biased towards a negative interpretation of their condition compared to those individuals without health anxiety (Hadjistavropoulos, Craig, \& Hadjistthatavropoulos, 1998). Rygh et al. (2005) suggest that not only anxiety, but depression, stress, and attention can alter the processing pathways beginning with the sensation of a stimulus to the physiological and psychological experience of pain, resulting in a lower threshold for discomfort. 
In other words, a benign sensation can be interpreted as a painful experience depending on the level of anxiety, stress or attention associated with it.

Somatic sensitization is the awareness of bodily symptoms and sometimes referred to as somato-sensory awareness (Burton, 2003). Those with somatization seem to be not only more aware of physical symptoms, but intensify them as well. An example of somatic sensitization can be appreciated in a study by Barsky, Ahern, Bailey, \& Delamater (1996) who showed that those with normal tests but who had elevated levels of body awareness had increased sensitivity to the heart beating faster. Heightened body (somato-sensory) awareness also seems to affect the number of physical symptoms and corresponding pain tolerance. Those individuals with a high awareness of somatic processes also have a higher number of physical complaints and a lower pain threshold (Verkuil et al., 2007).

Neurobiological sensitization could be considered as another type of sensitization that involves deregulations in the hypothalamus pituitary adrenal (HPA) axis that is thought to be associated with medically unexplained symptoms (Roelofs \& Spinhoven, 2007). This complex communication system is comprised of the hypothalamus, pituitary, and adrenal glands. It interfaces with the nervous and immune systems and modulates stress by adjusting cortisol production, neurotransmitter activity, and certain hormones. Any deregulation or abnormalities in the HPA axis can cause a cascade of problems and symptoms. Among these are anxiety, depression, and intolerance to stress and physical complaints. Chronic 
environmental stress such as adverse life events, worry, and rumination are thought to contribute to protracted activation or "heightened neural or neuroendocrine response” (Brosschot, Pieper, \& Thayer (2005). This protracted response is referred to as allostatic load, which has been linked to somatic complaints (Eriksen \& Ursin, 2002).

\section{Summary}

Based on the aforementioned discussion, Figure 1 presents patient characteristics thought to pose a risk for the development of somatization. It is important to note, however, that these characteristics are derived from a viewpoint that is partial to psychological sequelae and based on correlational findings. 


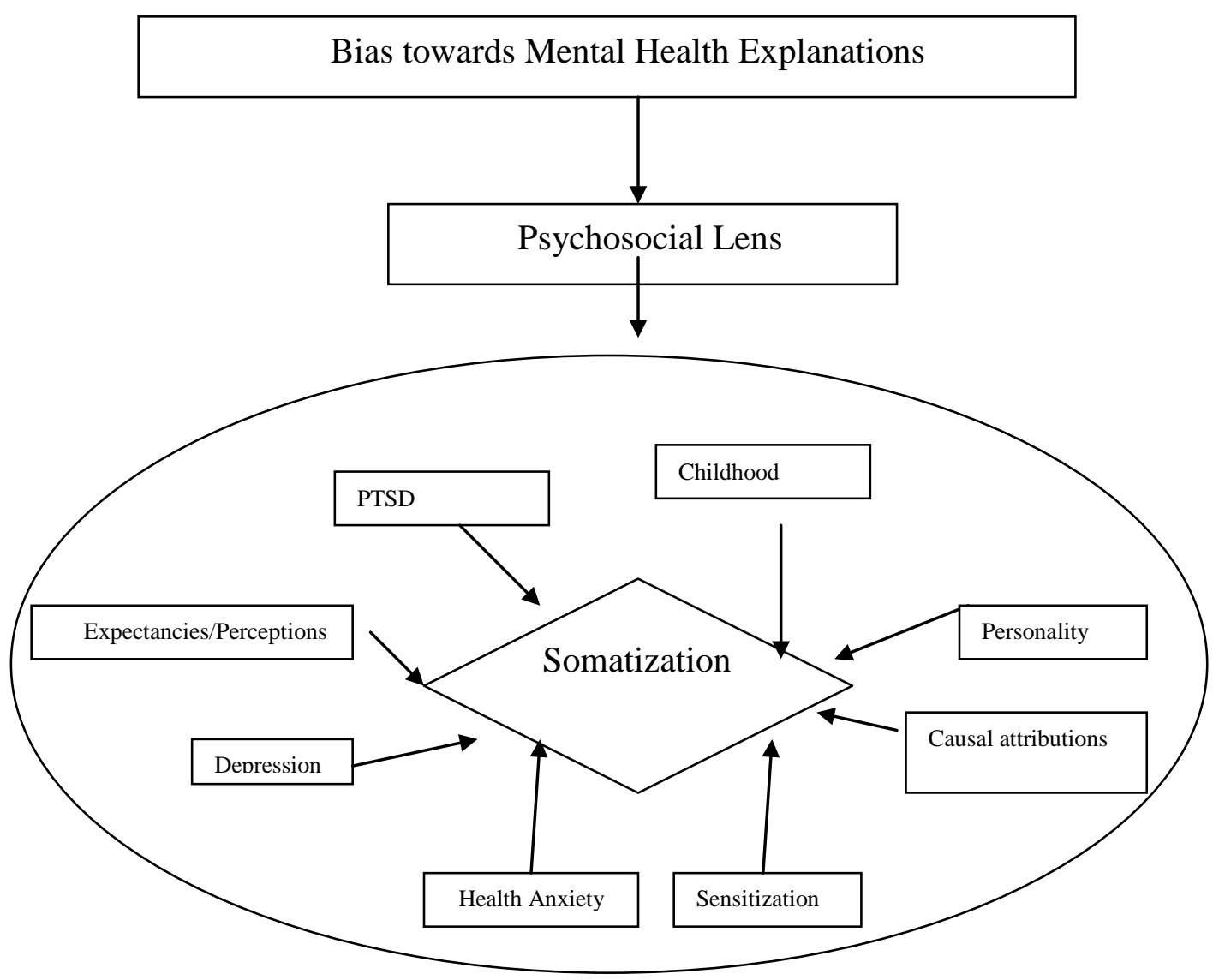

Figure 1. Diagram of characteristics associated with somatization.

The dualistic orientation (the dominant position being physical) through which our society views certain problems like somatization tends to explain the unexplainable by locating the mechanism of cause within the individual. If the cause is not physical, it must be psychological. Since psychological symptoms, compared to physical symptoms, continue to generate stigma, patients may unfairly internalize blame and responsibility for their health problems. Stigma can further lead patients to believe that their symptoms must be all in their heads and/ or they might be crazy. 
Although psychological characteristics have been shown to be associated with medically unexplained symptoms, they are not yet fully understood and their effects are difficult to isolate from each other. Regardless, these characteristics, along with physical factors, merit concern and warrant consideration within the integrative treatment plan approach. A fully comprehensive treatment paradigm must consider physiology, personality, life experiences, cognitions and physician-patient interactions.

The next section highlights both dualistic and integrative treatment approaches that have been used to assist patients with somatization.

\section{Treatment Models}

\section{Medically Oriented Approaches to Intervention}

Findings from several studies quantifying discrete and helpful communication for the medical provider and patient form the basis of medically oriented approaches (Salmon, Ring, Dowrick, \& Humphris, 2005). These approaches have shown modest improvements in patient satisfaction; yet, only marginal and inconsistent improvement in physical and psychological symptoms. These results occur even with the newly minted versions integrating a mental health component offered by physicians. Furthermore, none of these models seem ideal for those with somatization (Ring, et al., 2005) because they are largely based on the reattribution framework with extensions referred to as collaborative care. 
The reattribution model is a patient-centered, structured consultation delivered by a physician and has three main components: helping patients feel understood, broadening the agenda, and making a link between physical and psychological mechanisms (Goldberg, Gask \& O’Dowd, 1989). Only a few studies have found this model to be helpful in attenuating somatic symptoms but not the emotional symptoms that accompanied them (Dickinson, Dickinson, deGruy, et al., 2003; Larish, Shweickhardt, Wirsching, \& Fritsche, 2004; Morriss et al., 2007). Morris et al. conducted a cluster randomized controlled trial of 16 practices for which general practitioners received reattribution training. They compared those patients who had medically unexplained symptoms and received the reattribution model and those patients who received care as usual. The controlled trial failed to show that the reattribution model led to improved outcomes for these patients. For those studies (Morriss et al, 1999; Torgerson, 2001) that found positive findings for patient health outcomes, there were serious methodological problems. Morris, et al. describes some of these limitations as lack of randomization and contamination in the treatment and control groups.

Emphasis on patient centered communication strategies can also be seen in other versions of the medically-oriented model. Collaborative Care models have adopted a biopsychosocial framework incorporating reattribution concepts with medical providers delivering most if not all care. This model consists of a sequential process (5-step patient centered communication to promote relationship) and a 3-step 
process to educate and promote treatment (Smith, et al., 2003, 2006). Physicians or nurse practitioners are taught a protocol which includes a modified version of cognitive-behavioral treatment. The Collaborative Care model is essentially the same model but emphasizes integration of appropriate disciplines that may include professionals such as physical therapists, pain therapists, social services, and psychological services. Smith et al. (2006) showed that a multidimensional intervention (patient-centered, CBT principles, antidepressants, exercise relaxation train, physical therapy, and by primary care provider), delivered by primary care personnel to 200 patients with medically unexplained physical symptoms, led to overall mental health improvements in those with somatization ( $\mathrm{OR}=1.92)$. However, it remains unclear how much the improvements in mental health function was accounted for by CBT over the other treatments. This study, however, is perhaps the best prototype for integrated care for somatization as it incorporates both physical and mental health care. It is worth mentioning that in this model, mental health services are offered "only as needed on an individual basis" (Smith et al., 2003, p. 479). Counseling is promoted when patients are diagnosed with severe depression and after antidepressants fail. Mental health treatment is considered an adjunct to care rather than a treatment that stands alone. It is not usually offered at the beginning of care, but later when physicians observe that the emotional problems are interfering with medical protocol. Similar models have been developed in other countries such as China and Italy where the goals are improved integration of 
physical and psychological services, increased referrals to mental health by physicians, and increased patient acceptance of mental health (Yeung et al., 2004; Berardi et al., 2002). However, physical and psychological outcomes associated with this medically-oriented consultation model continue to be under review.

There is some support for another type of medically-oriented model in which the physician treating the patient receives a written consultation letter from a psychiatrist who provides education and treatment management (Rost, Kashner, \& Smith, 1994; Smith, Monson, \& Ray, 1986). Smith et al. (1986) randomized 41 patients with somatization disorder to a condition in which the physician received a consultation letter or to a control condition (waitlist). At a 3-month interval, patients were evaluated by research assistants who were blind to group assignment. Compared to the control group, the group for which physicians were provided with a consultation letter had a 53\% decrease in health care expenses, which was largely a result of decreased hospitalization costs. There were no changes in physical or psychological status in either group. This study was replicated using a larger sample by Rost, et al., 1994 with similar results.

One variation of this model was studied by van der Feltz-Cornelis, van Oppen, Ader, \& van Dyck (2006) in which a psychiatrist accompanied the physician during the consultation process with the patient. General practice physicians were given training in basic cognitive behavioral techniques (CBT). The findings revealed a decrease in the severity of patients' chief unexplained somatic symptoms. It should 
be noted that these countries have institutionalized socialized medicine. The costs of a simultaneous visit by both the psychiatrist and the physician, along with the time that is required for the physician to provide even a diluted version of CBT, is often prohibitive in the United States.

There are proponents from countries with socialized medicine, namely Spain and the UK, that have found significant but modest effect sizes for general practitioners (GP's) providing mental health intervention. Aiarzaguena, et al., (2007) showed that teaching GPs psychosocial and communication intervention skills can help improve patient's overall quality of life, but with only modest effect sizes. The argument for having the GP's carry out an attenuated psychosocial intervention was that patients would find it more acceptable. It would in essence be more in line with the patient's self-concept if psychological treatment were provided in a medical setting. However, these authors concluded that interventions provided by specialists in mental health produced larger effects and many of these patients would fair better with therapy delivered by them.

While these medically-oriented models have demonstrated positive outcomes with those who have medically unexplained physical symptoms, they pose inherent problems that might be overcome with the more holistic approach offered in the current study. Derived from the literature, the following list summarizes key problems with medically-oriented treatment models. 
1. Medically-oriented models typically do not provide comprehensive care from the start of treatment. The attribution model has shown to be somewhat helpful, but it may not be as effective if offered alone-without mental health therapy (Kirmayer \& Looper, 2006; Morris et al., 2007).

2. Costs savings for these models has not yet been substantiated. The collaborative care model has performed fairly well and has shown improvement in mental function, depression, physical disability and depression. However, it was not shown to have a cost advantage over care as usual (Luo et al., 2007).

3. Many private practice clinics do not have sufficient resources to implement these models. Many private practice clinics lack the funding, time, and staff required by these models. Findings from studies conducted in HMO settings or in countries with socialized medicine cannot necessarily be translated to private practice clinics. 4. The onus for the entire range of care is on the physician. The common thread across these models is reliance on physicians or other medical providers to learn how to deliver and be responsible for the outcome of care. Research has demonstrated that medical providers find it difficult to integrate the reattribution model in primary care (Dowrick et al., 2008). Some of these barriers include patients’ deep rooted beliefs about the causes of their symptoms, time limitations and complexity of patients’ presentations. Salmon and others have examined physicians' reluctance to not only deal with these patients but also to obtain the training required (Morriss et al., 2007; Salmon et al., 2007). 


\section{Medically-oriented models typically provide inadequate treatment of}

concomitant psychological issues. Many patients present with comorbid psychological issues which these models do not address and which could interfere with or derail treatment for those with medically unexplained symptoms. In the collaborative care model studied by van der Feltz et al., 2006), 70\% of patients had co-morbid psychiatric disorders. It has been demonstrated that a history of childhood abuse and associated family dysfunction are more likely in patients with MUS than in those with physically explained symptoms (Katon, Sullivan, \& Walker, 2001; Barsky, \& Ahern, 1996). Even though medical providers routinely treat depression and anxiety, psychological issues such as PTSD and abuse might not be easily identified or appropriately treated. Primary care providers are not necessarily adept at assisting patients with psychological challenges (Dowrick et al. 2008). CBT application requires a fundamental knowledge of the therapeutic process as well as specific training in, and practice with, the technique. In a study conducted by Aiarzaguena, et al., (2006) in which patients were randomized to a collaborative care model or a care as usual condition; the authors conceded that those patients with complex psychological problems could have benefited from more mental health treatment.

\section{Summary}

The provision of mental health therapy is more effective when delivered by mental health specialists. While Smith, et al. (2006) demonstrated that physicians 
can treat patients with medically unexplained physical symptoms using the collaborative care model, treatment was conducted within an HMO. This venue offers advantages that many private practice clinics do not have. The current reimbursement structure for medical providers in this country would likely be a limitation for providing the quality psychosocial intervention that is available through mental health specialists. Finally, research has shown that medical providers are not willing to be trained in these models and do not necessarily want to address psychosocial problems (Salmon et al., 2007).

\section{Mental Health Oriented Approaches to Intervention}

Part of the difficulty in assessing mental health treatment for somatization has been synthesizing the amalgamation of studies which use different diagnostic criteria such as single vs. multiple symptoms; overlapping psychosocial interventions (some use cognitive treatment, others cognitive with behavioral treatment); individual and group treatment; various types of professionals other than trained therapists; and take place in different levels of care (primary vs. secondary). Additionally, the interventions studied have addressed several different outcomes including physical symptoms; reduced physician visits, intensity of symptoms, etc. There are several systematic reviews and randomized controlled studies examining studies that focus on somatic complaints and CBT, however, some of the conclusions are based on a loose definition of CBT. For example, in some of the studies reviewed, CBT is referred to as cognitive, behavioral, or relaxation therapy or a combination. 
In spite of some of the methodological challenges, there is consensus that psychological therapy and CBT in particular can be effective (Brown, 2007; Deary, et al., 2007; Roelofs \& Spinhoven, 2007). CBT is thought to help the individual address maladaptive beliefs about and coping with symptoms.

\section{Cognitive Behavioral Treatment: Systematic Reviews and RCTs.}

The effectiveness of CBT for somatization has been examined by a number of investigators (e.g., Kroenke \& Swindle, 2000; Looper \& Kirmayer, 2002; Raine et al., 2002; Sumathipala, 2007). Their studies have consistently demonstrated positive results for this particular type of mental health therapy.

A critical review offered by Kroenke and Swindle, (2000) found that cognitive-behavioral therapy (CBT) was promising for those with somatization. They identified 29 randomly controlled trials in which $71 \%$ of the patients with CBT demonstrated more improvement in their physical functioning as compared to those in the control conditions. They recommended that CBT could be used as first line response or as an adjunct to the stepped care model used by physicians for treating these patients. That physical symptoms were improved independent of psychological distress suggests that reduction in physical symptoms may be mediated through distressing cognitions rather than through depressive or anxiety symptoms. Thus, targeting coping, illness worry and catastrophizing may attenuate physical problems. It was recommended that since many studies find patients are unwilling to engage in mental health therapy, future studies should examine those with somatization who 
are offered CBT and actually accept. It also seems reasonable to investigate how and who offered them, and what barriers were encountered.

In another systematic review by Raine et al. (2002) of 61 studies, it was concluded that cognitive behavioral therapy (which also included graded exercise), had a substantial effect on somatic symptoms of those with back pain and chronic fatigue. However, both graded exercise and cognitive therapy demonstrated a large effect size in secondary care (mental health specialist) only and not primary care (individual who were recruited from the community or by their primary care physician). A review (aggregating studies of IBS, CFS, fibromyalgia, and somatization) by Allen et al. (2002) of 34 randomized, controlled studies, using many of the same studies as Raine, concluded that only a modest effect size was found for psychotherapy interventions and that the studies were of short-term duration.

Looper and Kirmayer (2002) provides a descriptive review of approximately 30 randomized controlled studies that found support for the effect of cognitive behavioral therapy in primary care for several types of somatoform disorders (hypochondriasis, undifferentiated somatoform, chronic fatigue syndrome and noncardiac chest pain). The largest effect was found for a reduction in somatic symptoms. For example, in Speckens, et al., (1995) study of medically unexplained symptoms, effect size for patients with CBT at 6 months was .54 while in McCleod, Budd, and McClelland (1997), at 6 months was .43. 
In addition to these reviews, there have been several other studies investigating the effects of CBT on individuals with somatization. Bleichardt, Timmer, and Rief (2004) conducted a randomized controlled trial of CBT in tertiary care (psychiatric hospital) and, after a one-year follow-up; they found a large effect size (Cohen's d = 1.22) for reduction in number of symptoms. Hiller, Fichter, and Rief (2003) also found modest effects for CBT on somatic symptoms in tertiary care (Cohen's d=. 58).

In a randomized clinical trial study of cognitive-behavioral therapy with somatization patients, Allen et al., (2006) found that the intervention group, consisting of $\mathrm{CBT}$ and psychiatric letter with recommendations to the physician, showed greater improvement over the control group (psychiatric letter only). Those in the intervention group were 8.3 times more likely to be rated as improved at 3 months; 11.6 more likely at 9 months and 12.7 at 12 months. There was a reduction in physical complaints as well as decrease in health care costs.

A study conducted by Escobar et al., (2007) demonstrated the potency of time limited CBT for patients with somatization. Among 172 individuals with medically unexplained symptoms receiving CBT, were 4.1 times more likely to be rated as improved in physical symptoms by the clinician. Similarly, in another randomized controlled trial, Martin and colleagues (2007) found that one-session CBT compared to care as usual, made a significant difference in both number of doctor visits and severity of symptoms for those with somatization. 
In a more recent investigation, Sumathipala (2007) examined five systematic reviews and 29 randomized controlled trials on treatment of somatization in the US, UK, Netherlands, Australia, Sweden and Germany in primary, secondary and tertiary care. The strength of evidence for the effectiveness of interventions was based on type of study design and the assigned score using a hierarchy (e.g., Level I or Level II). Level I evidence was based on systematic reviews and level II evidence was based on randomized controlled trials (RCTs). The only level-1 evidenced-based treatment for medically unexplained physical symptoms appears to be CBT delivered by mental health professionals. In this review, those receiving CBT improved in physical symptoms more than control subjects did in $71 \%$ of the studies.

In sum, neither medical nor psychological models can singularly address somatization effectively. It is noteworthy that some of the studies assessing the effectiveness of medically oriented models for treatment of somatization consider both medical and psychological care. Yet, in studies examining the impact of psychological care for somatization, a discussion of medical care is essentially absent in the treatment protocol. Still, medically oriented models that offer a combined physical and psychological treatment plan fail to demonstrate the effectiveness of the mental health component. When mental health therapy is delivered by physicians and medical practitioners rather than trained mental health professionals, the effect is not as strong or absent (Luo, Goddeeris, Gardiner, Smith, 2007). This may be due to the different interpretation and delivery of CBT. For 
example, CBT was defined as cognitive restructuring using diaries, scheduled visits and medications.

However, the role of the medical provider during the medical consultation is central for encouraging patients to seek mental health treatment. The next section will discuss a promising approach to facilitate a combined treatment plan for patients with somatization.

\section{The Medical Consultation Process}

Given that patients will likely initiate visits from the primary care provider, the patient-physician consultation becomes the focal point for a successful referral to mental health therapy. The consultation process is the juncture at which medical professionals interact with patients to help address these issues, assuage fears, influence views about symptoms, and propose what treatment might work best (Di Blasi, et al., 2001). But the consultation process is also fertile ground for potential alienation of the patient. Both provider and patient factors can affect the quality of the consultation process and can have important consequences for the treatment trajectory. A discussion of provider and patient factors that intersect and often collide during consultation helps to identify and inform strategies that could foster the coordinated delivery of mental health therapy with physical treatment. 


\section{Provider Factors}

Medical providers affect how patients perceive their symptoms, patient's expectations for the direction and type of treatment, as well as patient's responses during the consultation process (between medical provider and patient). A systematic review by Di Blasi, et al., (2001) examined 19 randomized controlled trials in which the physician's responses affected patient's expectations about treatment. Ten of these trials found significant effects for practitioners who influenced patient's views about the effect of a therapy and who had strong impact on patient's health outcomes. Many of these responses can be categorized as rejection, collusion, confrontation and empowerment (Salmon, Peters \& Stanley, 1999; Salmon, 2007).

\section{Rejection.}

Medical providers have been shown to marginalize patients with somatization by stereotyping them as “frequent attenders” “difficult” or “heartsink”(Bensing \& Verhaak, 2006; Bergh, Baigi, Fridlund \& Markland, 2006; Butler \& Evans, 1999). The term "heartsink" speaks to the frustration and sometimes exasperation that physicians feel towards patients with unexplained medical symptoms. This frustration often leads to disregard for patient's complaints and the assumption that symptoms are invalid (Wileman, May, Chew- Graham, 2002). When providers deny a patients' reality, they may tacitly suggest that patients are imagining their symptoms and are therefore culpable. (Salmon, Peters, \& Stanley, 1999). Providers can even feel hostile towards these patients. Many providers are left confused about 
the uncertainty of motives for presentation and legitimacy of patients with somatization, this can lead to premature “disposal” of the patient (Chew-Graham, 2005).

\section{Collusion.}

Collusion is described as “sanctioning the patient's beliefs by acquiescence” (Salmon, Peters, \& Stanley, 1999, p. 373). Medical providers often do not feel equipped to deal effectively with somatization and may instead yield to the patient's suggestions (Hartz, et al., 2000). Medical provider's treatment decisions, however, may be based more on their perception of patient's wishes than the patient's true preferences (Salmon, et al. 2005). It also has been demonstrated that some medical providers adapt their biomedical interventions at least in part to presumed patient preferences (Cockburn \& Pit, 1997). They overestimate patients’ wish for biomedical interventions. These interventions include prescriptions and referrals, and are thought to contribute to and perpetuate somatization (Little, Dorward, Warner, \& Stephens, Moore, 2004). Collusion can backfire; especially when a physician too readily accepts the patient's explanation. This response ironically leads to the patient's lowered confidence in the provider’s expertise (Salmon, Peters \& Stanley, 1998).

\section{Confrontation or Criticism.}

Medical providers typically do not value or want to provide psychological support to patients (Salmon, et al. (2007). Even with overt cues from patients for 
emotional reassurance, physicians are reluctant to respond to this request, especially for those with somatization. Yet, many providers believe and suggest that patient's physical symptoms stem from psychological issues. These psychological explanations for patient's symptoms are often interpreted by patients as confrontation or criticism. Using a qualitative design, Salmon recorded and coded medical consultations between patient and their physicians to examine physician's motivation for communication with the patient that was labeled criticism or confrontation by the patient. It had previously been suggested that this style of communication was a way for the physician to avoid emotional engagement. However, Salmon found that a rationale underlying physicians withholding of emotional support was the belief that it is better for the patient since it would reduce dependency and facilitate patient responsibility. Thus, while engaging in a confrontation style is done with the patient's best interest in mind, unfortunately it seems to have a deleterious impact on the consultation.

\section{Empowerment.}

Empowerment is a particular feature of consultation that cultivates collaboration. It promotes patient's skills and strengths that are needed to manage their symptoms. The underlying message conveyed is one that removes blame and stigma (Salmon, et al., 1999). Salmon (2005) recommends that providers include tangible, exculpatory explanations grounded in patient's concerns and views as a more effective in the communication process between medical provider and patient. 
While this patient-centered focus appears to promote the most favorable response by the patient, it is infrequently communicated.

\section{Patient Factors}

Those with somatization have been shown to have unrealistic expectations, to exhibit non-compliance with treatment, and to have unsuccessful treatment outcomes (Oyama, Paltoo, \& Greengold, 2007). Additionally, these patients have frequent interpersonal conflict with medical staff attempting to help them. These behaviors and associated difficulties appear to arise from, and are influenced by, the patient's self-concept.

\section{Self-concept}

The self-concept or self-identity can be understood as an organized mental structure or representation of how we see, view, think, perceive, and understand ourselves (Kilhlstrom \& Kilhlstrom, 1999). It is composed of more permanent characteristics such as attitudes, beliefs, skills, abilities and personal attributes that make up the real self, the perceived and the ideal self. Incongruence is a lack of fit between these components and becomes a threat (Farber, Brink, \& Raskin, 1998). The individual defends against this threat through denial and distortion in order to cope with the ensuing anxiety. These defenses thus serve as protection when the selfconcept is incongruent or does not match behavior. Physical symptoms promote cognitive and emotional reactions that, in turn, create a need to make sense of what is happening (Leventhal \& Cameron, 1987). In keeping with their self-concept, 
individuals attempt to understand what might cause their symptoms, how long they will last, and ideas about what might help them get better. The very notion that medically unexplained symptoms are thought to impersonate psychological distress can indirectly challenge the patient's self-concept through questioning their legitimacy (Werner, Isaksen, \& Malterud, 2004; Peters, Stanley, Rose, \& Salmon, 1998). This is often what happens during a medical consultation. The patient's self concept embodies an illness representation that is organized around the belief that symptoms are physical and the medical provider, having ruled out medical etiology believes the symptoms are psychological. This conflict increases the risk of patients feeling humiliated and a negative outcome of consultation.

Several qualitative studies have shown that patients with somatization tend to be reluctant to consider psychological explanations because doing so directly challenges their self concept (Werner, Iisaksen, \& Malterud, 2004; Nettleton, 2006, May et al., 2000; Rhodes et al., 1999). Mays et al. (2000) examined patients with chronic pain and demonstrated how patients engaged in strong efforts to avoid the possibility of being labeled as having a psychological problem, especially since it was incompatible with their beliefs about themselves. Nettleton (2006) found that patients with medically unexplained symptoms had a high need for legitimacy, which was difficult to maintain when providers begin to discuss possible psychological explanations. Rhodes et al. (1999) conducted a study of patients with back pain and found that those patients whose medical tests substantiated their 
somatic condition felt vindicated and legitimate. Conversely, those patients who were unable to secure evidence for their pain felt "de-legitmated” (p.1201). When medical providers in the consultation process attribute an emotional cause to physical symptoms, many patients feel inadequately cared for, offended, and that their suffering has been “psychologized” (Bensing \& Verhaak, 2006). Additionally, patients will likely maintain their position that their problem is physical and they will be reluctant to consider mental health treatment. That patients are reticent to entertain the notion of psychological treatment might be related to stigma, which can accompany any discussion of mental health care. These studies underscore how important it is for the provider to suggest a treatment plan that neither labels the problem within one or the other category of etiology nor prescribes to one type of treatment over the over. Instead, the central message that needs to be communicated to the patient is that etiology may be unknown, but that integrative care can be most effective in easing the physical symptoms and stressful issues that arise from somatization.

A cognitive process affecting the self-concept is cognitive dissonance. Specifically dissonance is stress caused by attempting to manage two opposing thoughts or ideas simultaneously (Leary, MacDonald, \& Price Tangney, 2005). This process may help to explain why patients are so adamant about seeking care through medical avenues and eschewing mental health treatment (Kihlstrom, \& Kihlstrom, 1999). If they believe their symptoms to be somatic, then pursuing treatment by a 
medical provider is consistent with their self-concept. The act of going to a medical provider rather than a mental health provider further justifies and corroborates what patients might believe — that their symptoms are physical and should be treated using physical intervention. And this response might work as long as the provider substantiates the patient's beliefs by agreeing to physical treatment.

\section{Difficulties with Referring Patients to Mental Health Therapy}

There has been much speculation but little known about how medical providers can facilitate the discussion of mental health therapy with patients and which approach can result in a successful referral. Studies have shown that while psychological intervention is effective for somatization, it is typically not acceptable to majority of patients (Barsky \& Ahern, 2004; Kashner, et al., 1995; Kroenke, 2007; Shaw \& Creed, 1991; Schneider, Beisenherz \& Freyberger, 1990; Sumathipala, et al., 2000; Woolfolk \& Allen, 2007). For example, Schneider and his colleagues used a number of scales to examine therapy expectations for 865 patients suffering from different levels of somatopsychic disorders. These scales consist of statements that reflect the subjective experience of the disease, lay concept, general attitudes and the expectations concerning treatment, along with previous experiences with psychotherapeutic concepts of treatment. The results of the study showed that neurotic patients with primarily psychic symptoms demonstrate the highest motivation for psychotherapy and patients with somatopsychic disorder had a significantly lower motivation for psychotherapy than typical psychiatric patients. 
There also has been some speculation regarding how patients with somatization may be inherently different in ways that set them apart from patients with other medical or psychological issues. These differences may pose unique barriers to mental health intervention (Dowrick, et al., 2008). Yet, only a handful of studies have examined this issue. For example, Schneider \& Klauer (2001) found those who made psychosocial attributions for somatic symptoms were more receptive to mental health treatment and also predicted better outcomes than those with somatization who where characterized by lower openness. In other words, patients who believed that their physical symptoms might be associated with psychological problems (depression, anxiety, etc.,) were more amenable to engaging in mental health treatment. Furthermore, these patients experienced better health outcomes such as reduced fatigue and pain. Studies by Speckens, van Hemert, Bolk, Hawton, and Rooijmans, 1995; Schneider, et al., 1990; and, Timmer, Bleichhardt and Rief (2006) demonstrated that patients suffering from somatization would be more likely to accept psychological treatment if they were younger and more educated. These patients were also more likely to have higher levels of physical complaints and distress, compared to older and less educated patients. Speckens et al., specifically investigated whether patients with somatization were willing to accept mental health therapy and how they might differ from those who find therapy less acceptable. Findings from this study revealed that those with somatization generally accepted referral for mental health therapy. Those that refused therapy had 
less severe physical symptoms. Possible explanations for these results were considered. 1) The physician asked patients to participate, 2) acknowledgement that psychological symptoms were equally likely a result of physical symptoms as the cause of them, and 3) therapy would take place on the premise. These explanations have some support in the literature. For example, when physicians endorse a particular treatment modality, it seems to have a stronger impact than neutral a neutral position (De Blasi, et al., 2001). Consequently, some believe that referrals for psychological therapy are thwarted because medical providers fail to have confidence in psychological treatment and are reluctant to suggest it (Brown, 2007). Their reluctance stems from uncertainty about the preparation and qualifications of therapists to manage the needs of those with medically unexplained symptoms. Moreover, some medical providers may believe that psychotherapy is not as important or essential to care and have conveyed this view when discussing why they themselves are reticent to offer emotional support. A qualitative study by Salmon et al. (2006) investigated why physicians were reluctant to be trained to improve management of patients without medically explained etiology. Their statements reflected a minimization and even a discounting view of psychosocial support to patients by using the word “just”. For example, “it’s just supporting the patient”, p. 567. It seems that physicians are ambivalent, reluctant or do not value this particular aspect of their role (Salmon, 2007). 
Patient centered models support and encourage providers to emphasize the link between physical and mental symptoms but this can backfire. The suggestion of psychological underpinnings can easily alienate the patient (Bensing \& Verhaak, 2006). Timing is often critical. It has been recommended that referring a patient to mental health therapy after exclusion of medical tests result in negative effects.

Additionally, Looper and Kirmayer (2002) advocate that treatment provided in the context of medical setting "shared care" is more consistent with patient's view of care and therefore an acceptable option. This type of care implies that both medical and emotional services are provided under one roof. Findings from a survey showed that $50 \%$ of patients who were referred to social workers would have refused to follow-up if it meant going outside the medical practice (Huntington, 1981).

Examining other populations that have identified barriers to mental health treatment also may expand our understanding of treatment for somatization. Findings from a study by Craske et al. (2005) showed that one of the greatest barriers to mental health treatment among those with panic disorder in primary care was finding out where to go for help. Other barriers included costs, timely appointments scheduled by mental health provider, stigma, and embarrassment in discussing a problem. It is possible that these barriers may also be present in those with somatization. 


\section{Summary}

Extensive research has been aimed at identifying characteristics thought to be associated with increased risk for somatization. However, these relationships are based on correlational studies for the most part, which cannot distinguish the bidirectional possibilities or potential roles of intervening factors. Many of these findings have informed medical and psychological models of treatment. However, the resulting models fall short of truly integrating both components into a cohesive approach to care for patients with somatization. For example, the patient-centered care model has been established as the basic prototype of medical treatment for individuals with somatization. This model's contribution has been largely effective in increasing patient satisfaction rather than in ameliorating patient symptoms (Sumathipala, 2007). Additionally, there are expectations of the medical care providers to be both medical and mental health practitioner, which doesn’t necessarily translate to quality psychological care. To date, a model in which physicians deliver the cognitive therapy component has shown to be ineffective (Morriss, et al., 2007). On the other hand, the psychotherapy model has been established as beneficial to both process and outcome, and it addresses both physical and emotional symptoms. Yet, without the integration of a medical component, patients are reluctant to take part in treatment. Along with mental health care, medical care helps establish authenticity for patient’s symptoms eliminates blame and provides ongoing observation and support for physiological concerns. Unifying 
medical and psychotherapeutic components of care can contribute to a more balanced assessment and treatment plan that works towards amelioration of symptoms and prevents the stigma that is inherent in the dualistic approach to treatment.

The consensus in the literature favors a "balanced approach" such that treatment focuses on both biomedical and emotional aspects (Henningensen, Zipfel, \& Herzog, 2007). This heuristic strategy provides the optimal arrangement for addressing the fluid mind/body continuum of which somatization is firmly embedded. The medical provider needs to stay on board to monitor and review the physical complaints and determine if further investigation is required - all of which promotes legitimacy and support for the patient. The focus and role of mental health treatment are to help the patient manage physical symptoms, and to uncover, address and cope with other stressors or issues that may be unknowingly linked to the physical symptoms. The overarching message is that therapy can help with the stress of symptoms rather than undercover latent psychological reasons why one has symptoms. In this way, the combination of physical and mental support provides a holistic way to address concerns of patients with medically unexplained symptoms. Moreover, mental health treatment can help patients reconcile concerns about their self-concept that might have been unleashed by the lack of objective tests to discover and validate their physical symptoms. 
The consultation process between medical provider and patient creates an ideal situation with which to formulate an integrative treatment plan in such as way that values the fluid nature of symptoms while promoting the benefits of both physical and mental health care. However, there is little known about how to transcend conditions and barriers for patients who can benefit from psychotherapy. This gap in the literature marks the need for the development of practical methods for the medical practitioner to successfully enhance patient's motivation for psychotherapy during the medical consultation process. 


\section{CHAPTER 3: THEORETICAL MODELS}

Although there is strong support for a combination of physical and psychological treatment approach to somatization, the dilemma of how to motivate patients to engage in therapy remains. Motivation has been shown to influence engagement, process and outcome of therapy (Bleyen, Vertommen, Steene, \& Audenhove, 2001; Deci \& Ryan, 1985; Joyce, Ogrodniczuk, Piper, \& McCallum, 2003. In particular, motivation plays a central role in the successful referral to mental health therapy for individuals with medically unexplained symptoms (Looper \& Kirmayer, 2002; Rumpold et al., 2005; Schneider \& Klauer, 2001; Timmer, et al., 2006).

Motivation has been studied from a variety of different perspectives and it is considered to be a continuous multidimensional construct for which there are several micro and macro theories (e.g., Deci \& Ryan, 1985; Freud, 1990; Maslow, 1943). Out of the several theories that have been used to explain motivation, there are three that appear to have the greatest explanatory value in describing a patient's motivation for mental health treatment: cognitive dissonance, attribution, and expectancy theories. These interrelated theories share an overarching cognitive framework which implies that information processing (which guides thoughts, emotions, and behaviors) is a primary factor in motivation (Huitt, 2006).

Furthermore, patient factors associated with somatization, as already discussed in the literature review, can additionally be informed by these theories. Figure 2 presents a 
diagram depicting the elements of each theory, and the following discussion describes the application of each theory to understanding patient motivation for therapy.

Cognitive Dissonance Theory

Cognitive dissonance is a theory that relates to an action taken in order to mitigate internal conflict or discrepancy with regard to one's beliefs and behaviors (Festinger, \& Carlsmith, (1959). The main tenet of this perspective (previously discussed on page 39 under self-concept) is that being presented with information or decisions which share two opposing views creates discomfort. Individuals will want to eliminate the distress and further avoid situations that will continue or intensify the imbalance. For example, some patients with somatization might lack motivation to engage in mental health therapy because they believe that the act of participation in mental health treatment validates that they are crazy or that they are imagining their physical symptoms. These beliefs are incompatible with their views about their mental health. In an effort to avoid this internal conflict, patients may simply avoid or refuse this type of treatment and continue their pursuit of medical treatment. Reconciling this discomfort will have a strong impact on patient motivation to participate in therapy and dissonance can be addressed during the consultation process between patient and provider. 
Attribution Theory

The main premise of attribution theory is that people think and behave depending on how they experience, interpret and assign causes for events (Weiner, 1986). Attributions provide a framework with which an individual makes assumptions and understands the world, and from which his or her future cognitions and actions will be made. Extending this framework to health, attributions are made about diagnosis of a health problem and treatment. Patient's attributions about their illness will guide their decisions about coping and motivation behaviors (Michela \& Wood, 1986). Heider (in Weiner, 1974) examined the polarity of internal versus external attributions as the primary type of attribution underlying and explaining motivation for behaviors. However, others have expanded this dimension to include the polarities of positive vs. negative, controllable vs. uncontrollable, stable vs. unstable, physical vs. psychological (Weiner, 1974; 1986; Roesch \& Weiner, 2001; Sensky, 1996). According to Weiner's theory, those individuals with stable, external and uncontrollable attributions have lower expectancies for future improvement and they can be resigned to believe that nothing can be done. In contrast, those with unstable, internal, and controllable attributions tend to expect that circumstances can be changed, controlled and lie within the individual to execute.

The type of attributions patients with somatization have about their symptoms have been shown to predict their behaviors directed toward engaging or avoiding treatment (Michela \& Wood, 1986). For example, if patients attribute a 
physical cause for their symptoms, they may not be able to appreciate how addressing psychological processes in conjunction with physical care might be helpful. Deale, Chalder and Wessely (1998) examined the differential effects of attributing physical versus psychological attributions to symptoms of chronic fatigue syndrome and health outcomes. Sixty-five patients who attended a clinic for treatment of fatigue were randomized into cognitive behavioral treatment or a control condition. Measures of casual attributions about fatigue and activity were taken before and after treatment. Those in the treatment group having physical attributions did not change: they found no association between attribution for fatigue and poor outcomes. However, at post treatment, fewer patients in the treatment group believed that avoidance of exercise and activity helped their fatigue levels. Their changes in beliefs about exercise and activity were associated with improved outcome for fatigue and disability. Along with the change in outcomes came a change in their causal attributions. Each of the different polarities mentioned above has different implications for individuals with somatization (see page 21-22 for additional studies that demonstrate how variable attributions are associated assessment and treatment of somatization). 


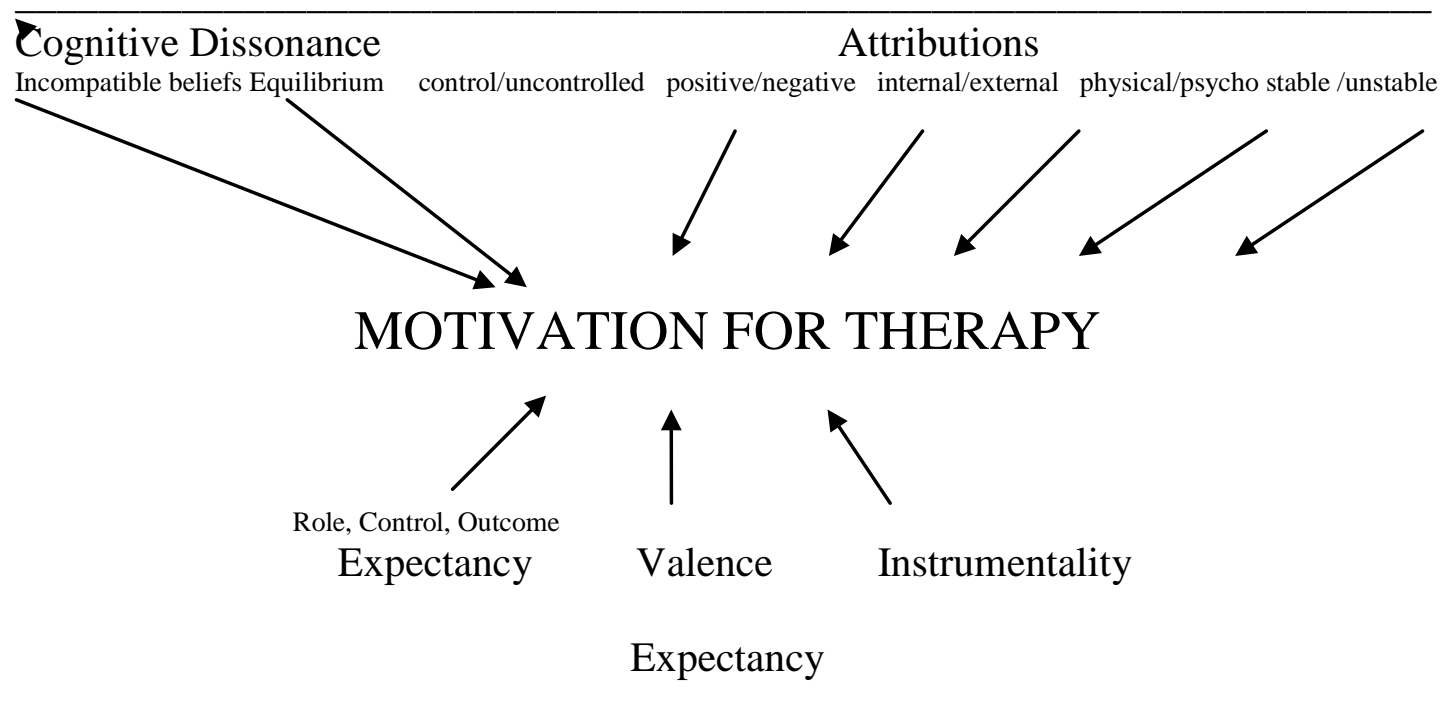

Figure 2. Theories underlying motivation to engage in therapy.

Expectancy Theory

Expectancy is another theory in the cognitive framework which also helps to explain motivation (Vroom, 1964). Although its formulation was first appreciated in the work place, the role of expectancy theory for explaining motivation has been subjected to wider application (Muchinsky, 2008). This theory has three central propositions: Expectancy is described as the association between effort and performance. In other words, how much you try and the result of your effort - the harder you try - the higher the probability of how much better you will do. Valence is the element which describes the individual's perception of how satisfying or attractive an outcome will be. Instrumentality is described as the individual's perception of the degree of association between performance and realization of the outcome. Delsignore and Schnyder (2007) elaborate on the three types of 
expectancies that influence whether an individual will be likely to participate in psychotherapy. Role expectancy is described as behavior congruent and expected of individuals who inhabit a certain position (e.g., clients have expectations about the appropriateness of themselves and therapist). Expecting to take an active and passive role has been shown to affect the extent to which therapy is beneficial. Control expectancy refers to the assigned effort attributed to the improvement: the client's efforts (similar to internal or control) or the therapist's efforts (external locus of control). Outcome expectancy refers to how useful or helpful clients believe the therapy will be to them.

Devilly and Borkovec (2000) define expectancy as a belief that improvements can be obtained. Additionally, these researchers include credibility as another dimension of the cognitive model of motivation to explain the variation in levels of motivation to engage in mental health therapy. Credibility is defined as "how believable, convincing, and logical the treatment is.” (Kazdin, 1979, p. 82). This concept attempts to capture those clients that may believe the therapy is helpful but not quite convinced it will work for them. Cognitive and affective elements underlie both expectancy and credibility dimensions.

Application of Theories to Assessment of Motivation for Therapy Having demonstrated their application to therapeutic motivation, these theories can further be shown to form the basis of many instruments designed to 
measure motivation for therapy for those with somzatization. Cognitive dissonance and attribution are among the dimensions measured to assess motivation for therapy in the FMP by Schneider and Klauer, 2001. The cognitive dimension of expectancy underlies the Credibility / Expectancy tool designed by Devilly and Borkovec (2000). More specifically, Schneider, Klauer, Janssen, and Tetzlaff (1999) posited that psychotherapy motivation is predicated on cognitive and general attitudes as well as influenced by socio-demographic variables. They pulled together several dimensions of cognitive theory and some of the tenets of psychodynamic theory to develop the construct of motivation for psychotherapy. A conceptual model, developed by Schneider, Basler and Beisenherz (as cited in Schneider \& Klauer, 2001) was tested by Schneider and Klauer (2001) with the formulation of an instrument called the FMP. This measurement included expectations of treatment and likelihood of success, degree of distress (suffering), and causal attribution for symptoms. Schneider and Klauer demonstrated that motivation for therapy among those with somatization was related to openness to psychotherapy and psychological attribution of the symptoms. Rompold et al. (2005) obtained similar findings for a motivation-enhancing study using the FMP and the therapeutic alliance scale (TA). A motivation-enhancing phase consisted of pretreatment up to 6 hours (3.9 sessions). Measurements on the FMP and TA were taken and compared at Time 1 and Time 2. Results from this study demonstrated that pre-therapy phased helped to increase openness to psychotherapy and enhanced treatment expectations. 
Application of Theoretical Models to the Dissertation Study

The dissertation study integrates these cognitive-based theories of motivation in an analogue intervention (enhanced consultation interview), and investigates whether they significantly impact the provider's ability to motivate patients to engage in mental health therapy during the consultation process. The enhanced consultation interview tested in the study incorporates these theories to address the following five issues that are thought to be salient for patients and amenable to facilitation of motivation.

1. Patients are biased towards the treatment strategy that assumes the dualistic nature of health care (McFarlane, et al., 2008). They anticipate labeling the symptom etiology in one or the other category (somatic or psychological). This can become especially pernicious when a medical explanation can't be found for their symptoms. These patients are left with a psychological one which causes internal conflict over two opposing beliefs (cognitive dissonance). Patients may feel misbelieved and begin to question their self-esteem (Nettleton, 2006). This challenge could lead to blame and responsibility (Salmon, 2007). To avert this predicament, the provider can, explain how physical and psychological causes are fluid with one or the other being more prominent at any given time. Additionally, it can be communicated that either physical or psychological factors or both may be influencing the presenting symptoms. Moreover, it can be helpful to mention that emotional stress is 
inextricably related to physical symptoms; it may be difficult to separate physical from emotional causes (attribution). These acknowledgements serve to deemphasize the importance of etiology, obviate blame and further reduce need for patients to defend the veracity of their beliefs (Speckens, et al., 1995). Finally, they can prevent escalation of symptoms or the persistent requests for additional tests.

2. Patients may assume that engagement in therapy will be conceding that the symptoms are all in their head or that they must be crazy (Bakal, Steirert, Coll, \& Schafer, 2006). Patients may not appreciate the purpose of therapy - how it can help manage or even attenuate some of the physical symptoms. This understanding can help make therapy a more logical and attractive option (Valence). The idea that thoughts, emotions, and behavior can contribute to symptoms as well as mitigate them might have not been understood (Schneider, et al., 1990). Consultation can further target apathetic, adverse and erroneous treatment expectations for mental health therapy in order to dispel myths about mental health therapy. Specifically the provider can discuss how therapy is a medium through which patients can develop essential tools to combat the stress associated with physical symptoms. Patients can then appreciate that their performance in therapy will lead to the improvement of their symptoms (Instrumentality).

3. Patients often fear losing the medical provider (Bakal, et al., 2006). Consultation can address concerns about the dichotomization of care and reassure the patient that mental health therapy does not come at the exclusion of ongoing medical 
care from the provider. Rather patients get a holistic approach in which both medical and emotional support are provided. The amelioration of fear over losing their medical provider reduces cognitive dissonance by eliminating the stress of sorting out whether their problem is physical or psychological. Providing reassurance to patients that they will continue their relationship with the medical provider also addresses causal attributions. It sends the message to patients that their symptoms are not their fault and warrant the type of support (external vs. internal) that medical care can offer. The medical provider's continued involvement also can serve as evidence that the physical aspect of the patient's condition is manageable (controllable vs. uncontrollable).

4. Patients can feel discarded or dismissed when mental health treatment is introduced after all other investigations have been exhausted (Peters, Stanley, Rose \& Salmon, 1998). The provider must "time” the introduction of mental health treatment so that it comes at the beginning of the consultation process rather than when there are no further medical tests to do. Early introduction of counseling can help normalize the integrative treatment plan, rather than giving the impression that psychological treatment is offered as a last resort or in an effort to appease the patient. This step can help prevent the patient from experiencing cognitive dissonance. Patients don’t have to juggle two opposing beliefs. Treatment presupposes that both physical and psychological symptoms are an inextricable problem and at the very minimum require expertise of both disciplines. 
5. Patients may lose momentum for interest in mental health therapy due to difficulty in navigating the referral process (Craske, et al., 2005). Having both mental health and medical care sharing the same facility (proximity) can eliminate obstacles often present in locating, contacting and requesting a mental health therapist. (Looper \& Kirmayer, 2002). Accessibility of the mental health worker in a medical clinic is symbolic of integrative care and may help the patients loosen their foothold on physical vs. psychological casual attribution. Patients can begin to appreciate that the medical provider's suggestion of obtaining psychological care is comparable to the suggestion of seeking a medical specialist for further evaluation and treatment. The physical vs. psychological dichotomy becomes blurred with both types of treatment understood as the norm and expected from a thorough health provider.

\section{Summary}

Cognitive dissonance, attribution and expectancies theories of motivation provide a framework with which to begin to understand and evaluate how information is processed and the degree to which it can exert influence on patients' resistance or engagement in psychotherapy. In particular, these theories can inform and guide an effective dialogue during the medical consultation, targeting the most critical issues thought to influence patient motivation to engage in mental health therapy. These issues include linking psychological and physical attribution of 
symptoms; dispelling myths about and explicating the purpose of psychotherapy; reassuring the patient of the medical provider's ongoing involvement and support; and attenuating difficulties emanating from the referral procedures for mental health (Looper \& Kirmayer, 2002; Martin, et al., 2007; Salmon, 2007: Schweickhardt, et al., 2007; Timmer, et al., 2006). The impact of these issues on patient's willingness to participate in therapy was systematically evaluated by examining patient response to medical consultation. The following research questions were examined.

\section{Research Questions:}

1. To what extent will patients be motivated to participate in mental health therapy? Hypothesis:

$\mathrm{H}_{\mathrm{O}}$ : Patients receiving the enhanced consultation interview will not show a significant increase in motivation to engage in mental health treatment as measured by the Motivation to Engage in Therapy Questionnaire posttest (MET posttest), FMP, and Credibility/expectancy questionnaires, compared to the enhanced consultation interview group.

$\mathrm{H}_{\mathrm{A}}$ : Patients receiving the enhanced consultation interview will show a significant increase in motivation to engage in mental health treatment as measured by the Motivation to Engage in Therapy Questionnaire posttest (MET posttest), FMP, and Credibility/expectancy questionnaires compared to the care as usual consultation interview group. 
2. To what extent will demographic variables (i.e., age, gender, employment status, etc.) and severity of symptoms be associated with increased motivation to engage in mental health treatment?

To further enhance this study, a newly developed Motivation to Engage in Therapy questionnaire (MET) was designed to examine specific issues which influence motivation but are not addressed in the other measurements. Additionally, the psychometric properties of this newly developed questionnaire were evaluated for internal consistency and validity. Although the FMP has been well documented as a valid measure in European countries, its psychometric properties with this sample of U.S. participants were also evaluated for the two subscales that were of most interest to this study (PTE and OP). 


\section{CHAPTER 4: METHODOLOGY}

The primary aim of this study was to evaluate the impact of an analogue enhanced consultation interview (between the physician and patient with somatization) on patient's motivation to engage in mental health therapy along with medical care.

\section{Design}

As shown in Figure 3, the study used an experimental group pre-post design. Patients with somatization were randomly assigned to one of two conditions: (1) consultation as usual or (2) enhanced consultation (Appendices J and K).

SOMS-7, FMP (PTE, OP Subscales), Credibility, Expectancy Subscales, and demographic questions

$\mathrm{R} \quad \mathrm{O} \quad \mathrm{X}$ (consultation interview as usual) $\mathrm{O}$

$\mathrm{R} \quad \mathrm{O}$ (enhanced consultation interview) $\mathrm{O}$

Note: Patients were assessed with The Motivation to Engage in Therapy

Questionnaire (MET) was given as a pre and posttest (MET-pretest and MET-

posttest). The pretest was conducted over the phone.

Figure 3. Overview of design. 


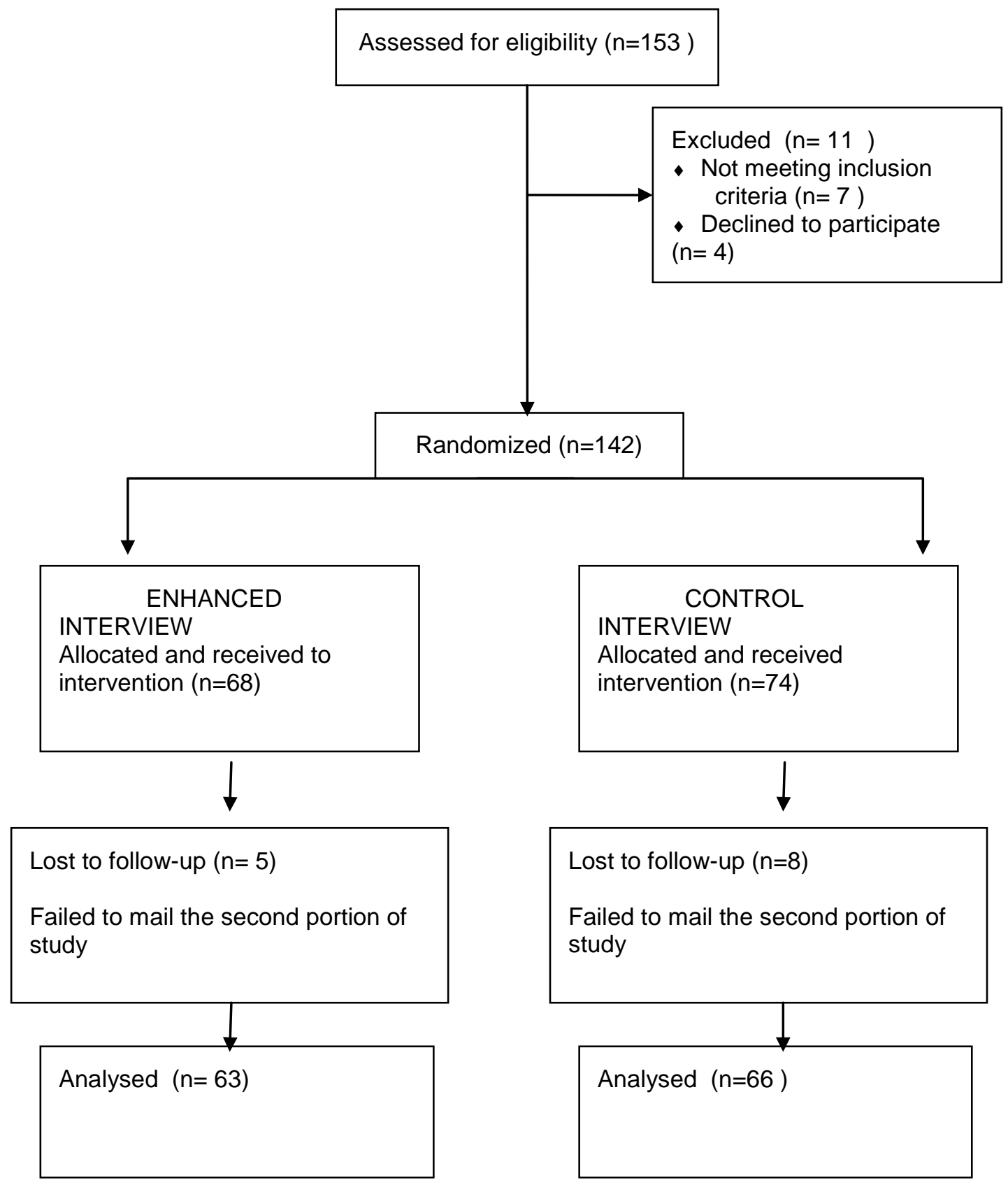

Figure 4. Participant Flow Diagram 


\section{Sample}

A power analysis was conducted to determine how many participants would be needed to provide the study with a reasonable chance of obtaining statistical significance among the two groups. A sample size analysis indicated that the hypothesized effect size between the analogue enhanced consultation interview and the analogue care as usual consultation interview groups, assuming .40-medium dispersion for the two means and an average correlation between the covariate: MET-pretest and the motivation questionnaires: MET-posttest, Credibility, Expectancy subscales and, PTE and OP subscales) of .40. Applying these assumptions indicated approximately 65 participants would be required per group (total $N=130$ ) to provide an $87 \%$ or greater chance of obtaining a statistically significance at the .05 level for the overall ANCOVA F-ratio (Bausell \& Li, 2002).

Participants were recruited between March and September 2009 from several venues throughout the Northwest (See Figure 4. Patient Flow Chart). Distributions of flyers were posted in general medical practices throughout Oregon (Appendix B). Along with the flyer, letters were sent to medical providers notifying them of the nature, purpose and timeline of the study, as well as a request for permission to post a patient recruitment flyer in their offices (Appendix C). Additionally, individuals were recruited by placing ads on Craigs List (Appendix D), and in news magazines and newsletters throughout the Northwest (Appendix E). 
Individuals included in the study were between the ages 18 and 65 who had at least two medically unexplained physical symptoms that persisted for the prior 6 months. Participant inclusion criteria were relaxed in comparison to the stricter criteria of somatization in order to capture a wider net of the more typical and problematic presentations represented in primary care. This broader definition of somatization is slightly more stringent than that of the DSM-IV - diagnosis of undifferentiated somatoform and the definition has been used in more recent studies such as Martin, Rauh, Fichter, and Rief (2007). Participants were excluded if they were actively being treated for a disease that produced physical symptoms (e.g., cancer).

One hundred and fifty-three individuals were screened for the study before acquiring the recommended total of 129 participants. Seven individuals failed to meet the eligibility criteria, four individuals thought the study would take too much time and decided not to participate, and 13 participants enrolled in the study did not complete the second assessment and were replaced by additional individuals recruited to the study. Moreover, it was later discovered that one of the 129 participants was 70 years of age. However, this case had a negligible effect on the results and was included in the final analyses. The total number of participants in the control group and experimental groups were 66 and 63 respectively. While participants were given the choice to complete the study questionnaires by email or regular mail, $87 \%$ of them chose to use regular mail. 
Demographic characteristics. The socio-demographic characteristics of the two groups are presented in Table 1. Participants were predominately non-Hispanic white, women, married or divorced, approximately 45 years of age, and with incomes below $\$ 25,000$. These characteristics are similar to other studies examining somatization (Hiller, Rief, \& Brahler, 2006).

\section{Measures}

\section{Symptom Measures}

The Screening for Somatoform Disorders (SOMS-7) was used to examine the number and severity of medically unexplained symptoms. It is a self-report measure which draws 53 items from the DSM-IV and ICD-10, requiring the respondent to rate the number and severity of each somatization symptom that is medically unexplained on a 5-point scale (Rief \& Hiller, 2003). The SOMS-7 has good internal consistency reliability (alpha $=.92)$ and adequate test-retest reliability coefficients (.71-.76). This scale is superior to others as it assesses medically unexplained symptoms as compared to medically explained symptoms. There are 52 items for women and 48 for men rated on a 5 -point scale from $0=$ not at all to $5=$ very severe (Appendix F). Summed items determine the score for number of symptoms and summed scores are totaled to determine the severity. Although the scale originated in Germany, it has been applied to studies in several different countries. 
Also included in this study was a demographic questionnaire composed of items used by many other researchers (e.g., Timmer, Bleichhardt, \& Rief, 2006; Schweickhardt, Larish, Wirsching, \& Fritzsche, 2007) (Appendix G).

\section{Motivation for Therapy Measures}

To assess the underlying dimensions of motivation for therapy for those with somatization who present to primary care for treatment, this study employed measures which reflected central factors thought to have a direct bearing on physician-patient interaction, both verbally and non verbally (Schneider \& Klauer, 2001). These included the FMP, the Credibility/Expectancy and the (MET) questionnaires.

The FMP assesses patient's attitudes towards their somatic problems and their motivation for psychotherapy (Schneider, et al., 1989; Schneider \& Klauer, 2001). This self-report instrument contains 47 items, rated on a 5-point scale (1=completely agree to $5=$ completely disagree (Appendix $\mathrm{H}$ ). There are 4 subscales with high scores reflecting more agreement with each of the following dimensions. The degree of psychotherapy motivation is the summed scores for each of the 4 subscales. The first two subscales measure illness attitudes. The Negative illness consequences (NIC) subscale consists of affective components measuring the amount of strain imposed by suffering, burden of suffering, consequences and secondary illness benefits. (e.g., "My outlook with regard to my condition is mostly optimistic.”). Higher scores reflect a stronger perception of suffering. The 
Psychological lay expectations (PLE) subscale measures the patient's view and assumptions about the underlying cause of their illness and the degree of psychosocial vs. somatic illness attributions (e.g., “As of late, my condition is actually of a physical origin.”). Higher scores indicate stronger psychological attribution for symptoms. The third scale: Psychotherapeutic treatment expectation scale (PTE) measures general expectation and attitudes about the functional value of physical vs. psychotherapeutic treatment - patient's ideas and anticipation of somatic over psychotherapeutic approaches to treatment (e.g., "True relaxation would help me more than any psychological treatment.”). The higher the score, the more positive attitude towards and favorable expectations of psychological treatment over physical treatment. The fourth scale, Openness to psychotherapy (OP) measures attitudes and experience about therapy - past and current, personal and vicarious. It also measures assumptions and general readiness to engage in therapy (e.g., "With help from psychological treatment, I can learn to better understand my physical afflictions, too.”). Higher scores indicate generally favorable attitudes for psychological treatment.

The FMP is a questionnaire with four subscales and developed in Europe in German language. Each of the subscales has strong internal consistency reliability (Cronbach’s alpha of .71-.86) and retest reliability from .67 to .96 (Schneider et al., 1989). This scale has been used in both inpatient and outpatient mental health settings for patients with somatization. This instrument was tested in German 
speaking countries with a different language and cultural and racial makeup from the U.S. The potential limitations and trade-offs for including this instrument in the study were carefully weighed. The strength of this instrument, which lies in its ability to assess individuals with somatization, was anticipated to provide more benefit than costs. This instrument was translated into English by a professional translator with the American Translators Association and its psychometric properties were evaluated for this country in the current study.

A reliability analysis was conducted on the FMP to examine the internal consistency of the scales for English speaking participants. Cronbach's alpha was computed for each of the 4 separate subscales: NIC Scale= Cronbach's $\alpha=.710$; PLE $=$ Cronbach's $\alpha=.700$; PTE $=$ Cronbach's $\alpha=.648$; and OP= Cronbach's $\alpha=.781$. A reliability estimate of Cronbach's alpha of .70 or higher is associated with high degree of consistency in scores among equivalent items. The reliability estimates were similar to those found in Schneider and Klauer (2001).

The Credibility Expectancy Questionnaire Version II consists of 6 statements regarding thoughts and feelings about the usefulness of therapy (Devilly \& Borkvec, 2000). Each statement is rated using a 9-point Likert scale from 1 - none at all to 9 - very logical, useful (Appendix I). The instrument is divided into two subscales: Credibility and Expectancy. Statements assessing credibility are contained in the first three questions and expectancy is derived from the last three statements. Scores were summed for each subscale and then standardized due to the use of two 
different scoring methods for the subscale of expectancy. This instrument had been previously shown to have strong internal consistency and test-retest reliability. The credibility subscale had Cronbach's $\alpha$ of between .81 and .86 and the expectancy subscale had a Cronbach's $\alpha$ of between .79 and .90. Inter-item correlation across studies ranged from between .53 and .85 for the expectancy subscale and .62 and .78 for the credibility subscale. Test-retest reliability for expectancy and credibility subscales were .82 and .75 , respectively. This scale measures how motivated individuals would be to participate in therapy, based on how credible they believe the therapy would be and what they expected from the therapy. This instrument was included in this study because it was thought to add additional information about the relationship between the effects of motivation and the experimental group, and to help validate the FMP instrument.

While both instruments, the FMP and Credibility/Expectancy questionnaires, examined the extent to which several factors are important in the consultation process in order to motivate individuals to engage in therapy, each presented a different set of limitations. First, while many of the issues thought to bear on motivation for those with somatization to engage in therapy are measured in the FMP, the instrument heretofore had not been tested in the U.S. population. Second, although the psychometric properties of the Credibility/Expectancy measure have been shown to be quite reliable, this instrument, as well as the FMP, lacked comprehensive coverage of other elements thought to influence motivation for 
engaging in mental health treatment, such as cognitive dissonance, medical provider abandonment, timing, and counselor proximity.

\section{Motivation to Engage in Therapy Questionnaire (MET)}

The Motivation to Engage in Therapy Questionnaire (MET) was developed to measure elements thought to influence motivation to engage in therapy from the literature review. Composed of 12 items with ratings on a 5-point Likert scale, this instrument was used both as a pretest (Appendix J) and posttest (Appendix K). Examples of some of the questions include the following: "I believe that whether my symptoms are caused by physical or emotional reasons, I need to get help for both”. "If my doctor recommended adding counseling to my treatment plan, I would feel that the doctor is looking for a way to get rid of me". "I worry that if I go to counseling my doctor will think that I don't need medical care". The reliability of the MET was evaluated for internal consistency reliability and yielded a strong Cronbach's alpha of .834. This coefficient represents the homogeneity of the measure or consistency across items. In other words, it examines the degree to which all the items measure the same underlying construct.

\section{Analogue Interventions}

Prior to the study, an expert panel consisting of 7 medical providers was asked to rate how much they agreed with 5 statements (using a 5- point Likert scale) about the care as usual consultation interview vignette to evaluate whether elements 
included represented a typical consultation (Appendix L). The expert panel also rated the enhanced consultation interview to asses whether differences between the two conditions were evident. Based on feedback from this panel, changes in both the care as usual and enhanced interviews were integrated into the following vignettes.

\section{Control Consultation Interview Condition.}

The literature provides support for a care-as-usual comparison group, based on the patient centered and attribution model by Goldberg, Gask, \& O'Dowd (1989). Elements such as active listening, eliciting illness expectations, linking physical and emotional causes, eliminating blame, providing information and suggestions about treatment options, and negotiating treatment goals have been shown to facilitate positive interactions between patient and physician and engender patient satisfaction (Smith, et al., 2006; Moriss, et al., 2007). However, it suggests more of a "gold standard" and it is neither fully nor typically practiced in primary care (Hartz, Noyes, Bentler, Damiano, Willard, \& Momany, 2000). After consulting with the expert panel, the control condition was modified to include elicitation of subjective complaints and illness expectations; linking physical and emotional causes, and providing empathy (Appendix M).

\section{Enhanced consultation interview.}

While the enhanced interview condition incorporates the tenets of the reattribution model which has been suggested for consultation between primary care providers and patient, it goes beyond to integrate the elements associated with 
motivating patients towards successful referral to mental health treatment. These include the following: 1) Anticipating the need for therapy (e.g., the introduction to mental health therapy during the consultation; 2) Linking of emotional and physical components of health. This integration was accomplished by explaining the interrelatedness of emotional stress and physical symptoms while also acknowledging that either element may come first or be more important than the other; 3) Emphasizing optimal treatment which includes both medical care and mental health therapy. This entailed discussing the benefit of treating both the emotional and physical impact simultaneously rather than on the basis of the exclusion process; 4) Dispelling myths or erroneous assumptions that patients sometimes have about counseling. For example, counseling was described to address the stress of patients with unexplained physical symptoms; 5) Establishing how the provider will remain involved in the patient's care (e.g., it was underscored how the patient's physical symptoms would be continued to be monitored by the medical provider; and 6) Providing ease of referral process (e.g., endorsing and introducing a therapist) (Appendix N).

\section{Procedures}

\section{Flyer}

The flyer and the advertisements described the purpose of the study: how providers could help patients deal with the stress of having medically unexplained physical symptoms in order to assist both medical and mental health providers to 
better understand what is needed to help improve care. Also described were the criteria for participation, compensation and contact information for the investigator. Patients who wanted to enroll in the study were asked to contact the number on the flyer and leave their contact information either in voice mail or by email.

\section{Informed Consent, Screening, and Pretest}

For those individuals who contacted the researcher via the telephone number provided on the flyer, the researcher responded with a telephone script (Appendix O). The researcher first explained the purpose of the study including the eligibility. Participants who continued to show interest and believed they were eligible were next read the consent form (Appendix P). For those participants who agreed to give verbal consent, the researcher documented consent by signing and dating the consent form. The researcher next verified eligibility. Once eligibility was established, the participant was asked to complete the MET, which was read and the participant's responses documented by the researcher. The researcher next explained that the participant had two ways to complete and return the materials for the second portion of the study. 1) The questionnaires could be mailed by the researcher and completed and returned by the participant (with a pre addressed stamped envelope), or 2) The questionnaires could be sent by email and the participant could save the questionnaires, complete the questionnaires, and email them back to the researcher. After participants indicated a preference for completing the study, they were 
randomly assigned to one of two conditions: 1) care as usual consultation interview vignette or 2) enhanced consultation interview vignette.

\section{Vignette Administration and Posttest}

To facilitate the vignette administration and posttest portions of the study, the researcher provided the participants with the following materials: Instruction Form (Appendix Q), Community Resource Sheet (Appendix R), SOMS-7, one of two vignettes depending on the randomization of the conditions), MET-posttest), FMP, Credibility/Expectancy, and demographic questionnaires.

The entire process (including the initial contact) took approximately one hour. The participant was informed that upon receipt of the completed study materials, the researcher would send or give directly to the participant a check for \$50. This was accompanied by a thank you note (Appendix S).

\section{Analysis}

\section{Dependent Variable}

Motivation to engage in mental health treatment was evaluated with 3 outcome variables: a newly developed Motivation to Engage in Therapy questionnaire (MET-pretest), Credibility and Expectancy subscales, and FMP subscales, Psychotherapeutic Treatment Expectations (PTE) and Openness to Psychotherapy (OP).

Independent Variable 
Type of condition (care as usual consultation interview or enhanced consultation interview)

Co-variate

Motivation to engage in therapy (MET) pretest questionnaire

Group differences were tested with chi-square analysis for frequencies and ttests for means. In the correlation analyses, Pearson's coefficient was computed. Separate analyses of covariance were performed for each motivation measure (METposttest, Credibility, Expectancy, and PTE subscale revised for outliers; and OP subscale revised for missing data). There was a very small percentage of missing values for all outcome measures (less than 2\%) with the exception of two questions on the OP subscale, \#8 and \#42. The number of participants not responding to these two questions was $24 \%$ and $16 \%$, respectively. Completion of the latter question was optional. The total number of unanswered questions for the two questions on the OP subscale was problematic and these questions were removed from the summed scale. Therefore, the number of subjects varied slightly for different measures. The variable: SOMS-7, which was highly skewed; in both number and intensity, was transformed using a square root transformation. The skewness of this measure was also noted in another study (Timmer, et al., 2006). Outliers were removed for the following univariate variables: education (two PhDs participants had beyond 26 years of education) and age (one respondent was 70) for univariate analyses, 
however they were retained for multivariate analyses as they had negligible effects on the results. For the FMP (PTE) subscale, one outlier was removed.

\section{Assumptions}

ANCOVA assumptions were first evaluated. The reliability of the covariate (MET-pretest) yielded a Cronbach's alpha of .770, which suggests that the pretest measure had strong internal consistency reliability. An evaluation of the correlation between the covariate (MET-pretest) and dependent measure (MET-posttest) yielded a coefficient of .690 , which was well above the recommended .40 . The correlation between the MET-pretest and Credibility scale also was above .40 (.43). The correlation between the MET-posttest and the Expectancy scale, the FMP subscales PTE and OP were slightly below .4 (.375, .393, and .373).

For multivariate analyses, outliers were examined by first computing a Mahalanobis Distance for each case, and then tested using a chi-square distribution, with a conservative value of alpha ( $\mathrm{p}<.001)$. One case was identified and the analyses were rerun with the deleted case. Distributions for each group were examined for skewness and kurtosis and shown to be within normal limits after deletion of the outlier. Deletion of this case resulted in negligible effects for all outcome measures; therefore, the data were retained in the ANCOVA analyses. 


\section{CHAPTER FIVE: RESULTS}

The sociodemographic characteristics of the two groups are shown in Table 1. Group comparisons were evaluated with t-test and chi-square $\left(\chi^{2}\right)$. Due to multiple categories for race, marital status and diagnosis, these sociodemograpic variables were first dichotomized (highest percentage category with all other categories) in order to compute $\chi^{2}$. The care as usual consultation interview group and enhanced consultation interview groups differed with regard to two sociodemographic factors. The analogue enhanced consultation interview group scored significantly higher than the care as usual consultation interview group on working part-time $\chi^{2}[1]=6.17, p=.027$ and perceiving counseling as positive $\left(\chi^{2}, 1\right)=5.096$, $p<.05$ ). Upon further examination of these two variables, between group differences remained significant for only those who found counseling positive and the FMP (OP) subscale. In general, findings were not better explained by these unexpected differences in groups. Validity of Measures

The validity of the MET scale was evaluated with a principle components analysis to identify and compute composite motivation scores for factors thought to underlie the scale. Results of the factor analysis suggest plausible one and two factor solutions. A stronger first factor with higher loading on seven items tapping doctororiented dimension and a weaker second factor with three items tapping patientoriented dimension were found. Based on statistical considerations (low factor 
saturation of the second factor) and the single factor tapping both doctor and patientoriented dimensions, the single factor solution was retained. Reliability analyses showed strong reliability coefficients for the single factor solution and a moderate reliability coefficient for the second factor (alphas of .86 and .71 respectively). Table 2 shows the correlation matrix for the MTF-posttest and Table 3 shows loadings for each item in the MTF scale for a one factor solution. The loadings show the correlation between each item with the one factor and suggest those items that cluster together. All of the items have fairly strong loadings on one overall factor except item 12 . The total variance explained by the single factor is $38.5 \%$.

Table 4 shows zero-order correlations between all the motivation scales. The MET-posttest was highly correlated with Credibility and moderately correlated with Expectancy subscales (.652 and .497) which provided support for convergent validity. Those respondents that scored high on motivation for the MET-posttest measure were associated with higher scores on how credible they anticipated therapy would be. And, to a slightly lesser extent those respondents that scored high on motivation for the MET scored higher on how much improvement in symptoms they expected. Also noteworthy were moderate to strong correlations between the METposttest and PTE subscale revised and OP subscale revised. Those respondents that scored high on the MET-posttest had more favorable expectations for psychological therapy over physical care and openness to therapy. 
Convergent validity was also demonstrated for the FMP (PTE) and (OP) subscales. There were significant and strong correlations between the PTE and the Credibility and Expectancy subscales ( $\mathrm{r}=.388$ and .443). The OP subscale also was strongly correlated with the Credibility and Expectancy subscales ( $\mathrm{r}=.556$ and .430$)$. Higher scores for openness to psychotherapy were correlated with higher scores on the perceptions of credibility for therapy and greater expectancy of what therapy could accomplish.

While the FMP (NIC) subscale and FMP (PLE) subscales were not the focus

of this study, it is interesting that the (PLE) subscale was moderately associated with most of the motivation scales and highly correlated with Expectancy scale. Higher scores on the (PLE) subscale reflect higher scores for psychological attribution of symptoms. In general, participants who had stronger psychological attribution for their symptoms were more motivated to participate in therapy. These findings are consistent with others: Speckens et al., 1995; Schneider and Klauer (2001).

\section{Research Hypothesis and Questions}

The study hypothesized that patients receiving the analogue enhanced consultation interview would show increased motivation to engage in mental health treatment as compared to patients receiving the analogue care as usual consultation interview. This research hypothesis was supported for 4 of the 5 dependent measures (MET-posttest; and the Credibility, Expectancy, and FMP (OP) subscales). After adjusting for the covariate, there were significant differences between the two 
analogue consultation conditions for these outcome measures: The largest effects were found for MET-posttest $[F(1.126)=19.18, \mathrm{p}=.000$, Cohen's $d=1.6]$, and the FMP $(\mathrm{OP})$ revised subscale $[F(1,123)=8.64, \mathrm{p}=.004$, Cohen's $\mathrm{d}=1.6]$. Also demonstrating strong effect sizes were the Credibility scale, $[F(1,125)=18.75, \mathrm{p}=$. 000, Cohen's d=.9] and Expectancy scale, $[F(1,123)=6.98, \mathrm{p}=.009$, Cohen's d=.8]. Table 5 shows the results of all ANCOVA's.

There was a significant mean difference between the two interview conditions on the MET-posttest, $\mathrm{p}<.001$ with a large effect size of 1.6. This finding demonstrates that those in the care as usual interview group scored 4.5 points lower on the MET-posttest than those in the enhanced consultation interview group. This can also be interpreted as indicating the average participant in the enhanced interview consultation condition was more motivated to engage in therapy than $94.5 \%$ of the participants in the care as usual condition.

The mean difference between the two analogue interview conditions on the Credibility subscale also was significant, $\mathrm{p}<.001$ with a large effect size of .9. There was a 1.8 point difference between care as usual interview group on the Credibility subscale compared to those in the enhanced interview consultation interview. In other words, the average participant in the enhanced interview consultation found therapy to be a more credible option than $82 \%$ of those in the care as usual condition.

Likewise, the Expectancy subscale demonstrated a significant mean difference between the two interview conditions, $\mathrm{p}<.01$ with a large effect size of .8 . 
Those in the care as usual interview group scored 1.3 points lower on the Expectancy subscale than those in the enhanced interview consultation interview group. Thus, the average participant in the enhanced interview condition was more motivated to engage in therapy than $79 \%$ of the participants in the care as usual condition.

Finally, there was a significant mean difference between the two interview conditions on the FMP (OP) subscale, $\mathrm{p}<.01$ with a large effect size of 1.6. Those in the care as usual interview group scored 5.3 points lower on the $\mathrm{FMP}(\mathrm{OP})$ subscale than those in the enhanced interview consultation interview group. For the FMP (OP) subscale, the average participant in the enhanced condition was more open to participating in therapy than $94.5 \%$ of the participants in the care as usual condition to engage in therapy.

Research Question 2: To what extent are demographic variables and severity of symptoms associated with increased motivation to engage in mental health treatment?

The relationships between the socio-demographic variables and the motivation scales were examined using Pearson product-moment correlation coefficient. The socio-demographic variables associated with motivation for therapy included education, prior counseling, current counseling and positive counseling experiences. There were small but positive correlations found between education and the Credibility subscale $(\mathrm{r}=.18, \mathrm{~N}=126, \mathrm{p}<.05)$ and between prior counseling and the Credibility scale $(r=.22, \mathrm{~N}=127, \mathrm{p}<.05)$. Those participants with higher levels of 
education and prior counseling had higher scores on the perceived credibility. A significant moderate positive relationship between was found between those in current counseling and the FMP (OP) subscale $(r=.315, \mathrm{~N}=123, \mathrm{p}<.01)$. Those participants currently participating in counseling had higher scores on the FMP (OP) subscale. A small, negative correlation was found between negative counseling experience and MET-posttest ( $\mathrm{r}=-.22, \mathrm{~N}=98, \mathrm{p}<.05)$, credibility $(\mathrm{r}=-.29, \mathrm{~N}=97$, $\mathrm{p}<.05)$, and expectancy $(\mathrm{r}=-.28, \mathrm{~N}=95, \mathrm{p}<.05)$; and a moderate correlation was found between negative counseling experience and the FMP (OP) subscale ( $r=-.38, N=97$, $\mathrm{p}<.05)$. Those who had negative counseling experiences exhibited lower levels of motivation on these scales. Interestingly, there were no associations found between the number or intensity of physical symptoms with any of the motivation scales.

Additional correlation analyses further examined whether the relationship between demographic variables and motivation (for each outcome measure) differed between the care as usual and enhanced conditions. There was a significant positive relationship for education and motivation on the Credibility subscale for the enhanced condition ( $\mathrm{r}=.30, \mathrm{~N}=60, \mathrm{p}<.05)$ and a significant positive correlation between prior counseling and motivation on the Credibility subscale for the enhanced condition $\mathrm{r}=.34, \mathrm{~N}=64, \mathrm{p}<.01$. These significant correlations were further investigated in a regression analysis. While controlling for the covariate, METpretest, the relationships between the demographic variables and motivation on the Credibility scale did not reach significance across the two conditions. 


\section{Post hoc Analysis to Control for Positive Counseling Experiences}

Because the groups differed with regard to scores on perceiving counseling as a positive experience and part time employment, the main outcome measures were reanalyzed, controlling for these variables along with the covariate (MET-pretest) and type of intervention. The regression analysis for positive counseling experiences supported the same pattern of results for ANCOVA's with the exception of the FMP(OP) subscale which demonstrated a non-significant trend relationship between the enhanced consultation and positive counseling experiences, $F(3,91)=12.02$, p= .08. The regression analysis for part time employment supported the same pattern of results for all ANCOVA's. In general, the results held, and were not better accounted for by the sample heterogeneity.

A supplemental regression analysis was conducted to further examine whether participants who scored high or low on the MET-pretest or scored high or low on negative counseling experiences responded differently to the type of intervention for each outcome measure. All the motivation measures were regressed on the MET-pretest, the enhanced interview condition, the interaction between the interaction between MET-pretest and the enhanced condition, and finally the interaction between negative counseling experience and the enhanced condition. All variables were centered to control for multicolleniarity which was introduced by the interaction terms. Findings demonstrated that participants scored differently to the type of intervention on both the MET and Credibility subscale when the covariates of 
the MET-pretest and previous counseling experiences were further examined. Table 6 shows the results from investigating these covariates and their interactions considered to have an effect on these two motivation scales.

There was a statistically significant interaction between negative counseling experience and the enhanced consultation interview for the MET-posttest, $t(92)=$ 2.574, $\mathrm{p}<.05 . R^{2}=.57$. Additionally, there was a trend-level relationship for negative counseling experience and the enhanced consultation interview for the Credibility subscale, $t(91)=-1.943, \mathrm{p}=.055) \cdot R^{2}=.61$. This result suggests that the relationship between enhanced consultation condition and the MET-posttest was moderated by those with previously negative counseling experiences. In other words, while controlling for the stronger positive effect of the enhanced consultation interview, those with previously negative counseling experiences were less favorable (scored lower) towards therapy on the MET-posttest measure and to a lesser extent the Credibility scale. 
Table 1

Descriptives for sociodemographic characteristics. $\mathrm{N}=129$

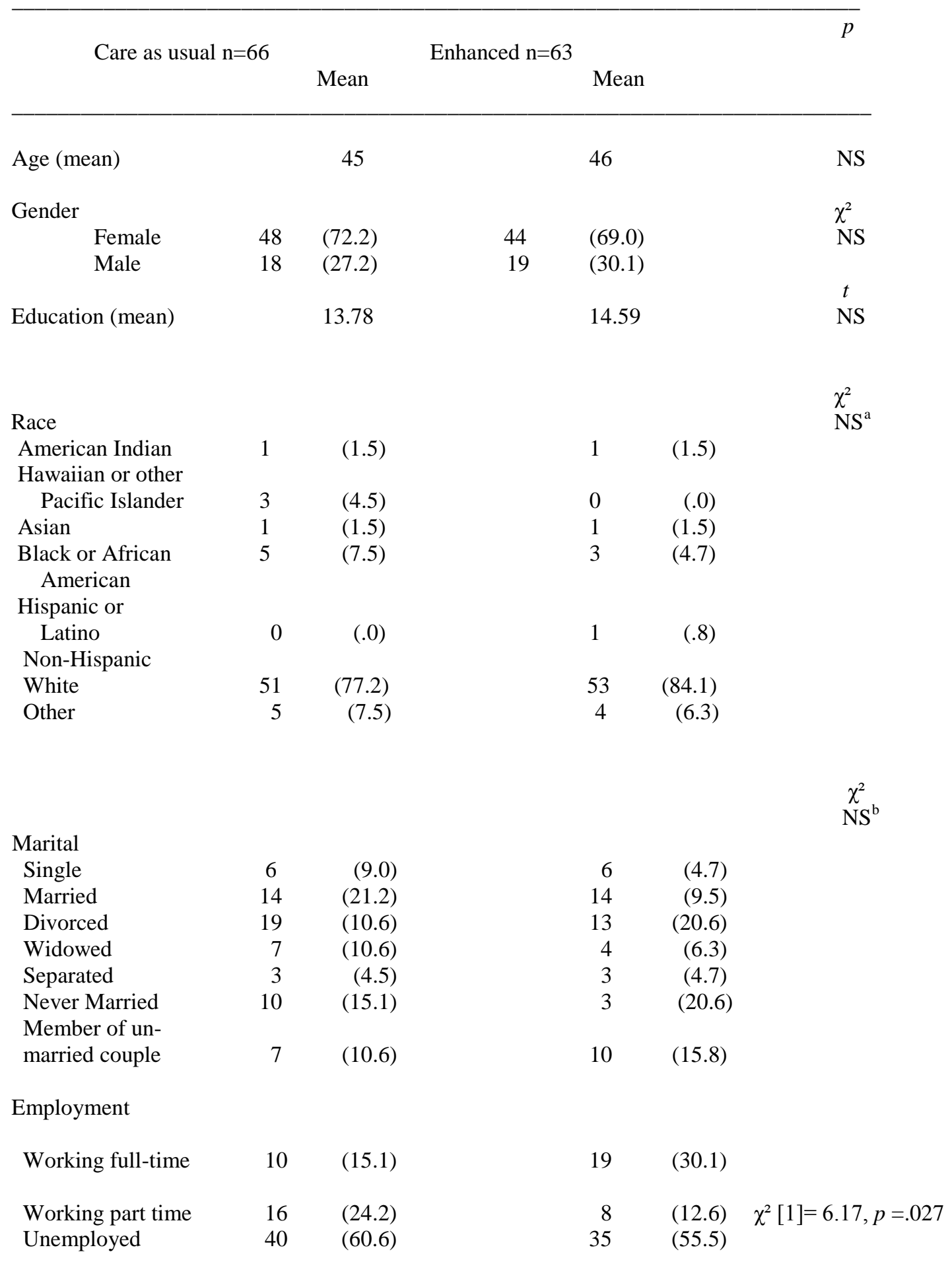


Disabled

$\begin{array}{lll}\text { Yes } & 36 \\ \text { No } & 30\end{array}$

$\begin{array}{lll} & & \chi^{2} \\ 23 & (36.5) & \text { NS } \\ 40 & (63.4) & \end{array}$

Income

$\chi^{2}$

No

30
)

$40 \quad$ (63.4)

Income

$<\$ 25,000$

$\$ 25,000$ to $<\$ 70,000$

49

(74.2)

$\$ 70,000$ or more

14

Prior Counseling

$\begin{array}{lll}\text { Yes } & 49 & (74.2) \\ \text { No } & 16 & (25.3)\end{array}$

Diagnosis

$\begin{array}{lll}\text { Anxiety } & 3 & (4.5) \\ \text { Depression } & 6 & (9.0) \\ \text { Bipolar } & 2 & (3.0) \\ \text { PTSD } & 4 & (6.0) \\ \text { Other } & 1 & (1.5) \\ \text { More than one diag. } & 4 & (6.0) \\ \text { Personality Disorder } & 1 & (1.5) \\ & & \\ \text { Counseling Helpful } & & \\ \text { Yes } & 32 & (48.4) \\ \text { No } & 26 & (39.3)\end{array}$

Current Counseling

Yes

17

(25.7)

$45 \quad$ (68.1)

$43 \quad(68.2)$

7 (11.1)

(.0)

(6.3)

(3.1)

(6.3)

(1.5)

(12.6)

(.0)

$\chi^{2}$

NS

No

$11 \quad$ (17.4)

$\chi^{2}[1]=5.096, \mathrm{p}<.05$

$\chi^{2}$

NS

${ }^{a}$ Race was dichotomized into two groups to examine group differences for the category with highest percentage (White) and all other categories

${ }^{b}$ Marital status was dichotomized into two groups to examine group differences for the category with highest percentage (Divorced) and all other categories

${ }^{c}$ Diagnosis was dichotomized into two groups to examine group differences for the category with highest percentage (More than one diagnoses) and all other categories

Values are number of participants with percentages in parentheses. 
Table 2. Correlation Matrix for MET Posttest Scale

\begin{tabular}{|c|c|c|c|c|c|c|c|c|c|c|c|c|}
\hline & 1 & 2 & 3 & 4 & 5 & 6 & 7 & 8 & 9 & 10 & 11 & 12 \\
\hline Item 1 & 1.000 & & & & & & & & & & & \\
\hline Item 2 & $.258 * *$ & 1.000 & & & & & & & & & & \\
\hline Item 3 & $.223^{*}$ & $.324^{* *}$ & 1.000 & & & & & & & & & \\
\hline Item 4 & $.178 *$ & $.175^{*}$ & $.299 * *$ & 1.000 & & & & & & & & \\
\hline Item 5 & .066 & $.323^{* *}$ & $.239 * *$ & $.273 * *$ & 1.000 & & & & & & & \\
\hline Item 6 & $.232 * *$ & $.590 * *$ & $.389 * *$ & $.243^{* *}$ & $.414 * *$ & 1.000 & & & & & & \\
\hline Item 7 & $.304^{* *}$ & $.411^{* *}$ & .130 & $.187^{*}$ & $.314^{* *}$ & $.508^{* *}$ & 1.000 & & & & & \\
\hline Item 8 & $.183^{*}$ & $.252^{* *}$ & $.494 * *$ & $.595 * *$ & $.193 *$ & $.338 * *$ & $.178 *$ & 1.000 & & & & \\
\hline Item 9 & $.215 *$ & $.600 * *$ & $.310 * *$ & $.304^{* *}$ & $.360 * *$ & $.617^{* *}$ & $.435^{* *}$ & $.329 * *$ & 1.000 & & & \\
\hline Item 10 & $.214^{*}$ & $.557^{* *} *$ & $.362^{* *}$ & $.275^{* *}$ & $.347^{* *}$ & $.604^{* *}$ & $.405^{* *}$ & $.383^{* *}$ & $.831^{* *}$ & 1.000 & & \\
\hline Item 11 & .125 & $339 * *$ & $320 * *$ & $344^{* *}$ & .166 & $.467 * *$ & $391 * *$ & $.338 * *$ & $.503^{* *}$ & $.496 * *$ & 1.000 & \\
\hline Item 12 & -.069 & -.030 & $.201 *$ & .112 & -.041 & .059 & .081 & .120 & -.102 & -.048 & .109 & 1.000 \\
\hline
\end{tabular}

** Pearson $r$ correlation coefficient is significant at the 0.01 level (2-tailed).

* Pearson $r$ correlation coefficient is significant is significant at the 0.05 level (2-tailed). 
Table 3

Factor loadings based on a principle components analysis with one factor solution for MET

Component Factor

1. The only way my physical symptoms will get better is obtaining medical care.

2. If my doctor recommends that I go to counseling for my physical symptoms, it probably means that the doctor thinks my symptoms are all my head.

3. I have a good understanding of how counseling can help with my physical symptoms.

4. I believe that whether my symptoms are caused by physical or emotional reasons, I need to get help for both.

5. I wouldn't go to counseling because the process of finding a counselor is difficult.

6. If my doctor recommended adding counseling to my treatment plan, I would feel that the doctor is looking for a way to get rid of me.

7. If my doctor suggested adding counseling to the treatment plan, I would not feel that the doctor believes I have a physical problem.

8. Counseling is just as important as medical care for helping me cope with my physical symptoms.

9. I worry that if I go to counseling, my doctor will think that I don't need medical care.

10. If I went to counseling, it might suggest to my medical providers that my physical problems don't really exist.

11. If my doctor suggested that counseling be added to the treatment plan, I would feel that my needs are being respected.

12. I would be more likely to go to counseling if it was available in the same building as my doctor. 
Table 4

Correlations among MET-posttest, FMP subscales, Credibility and Expectancy subscales

\begin{tabular}{|c|c|c|c|c|c|c|c|}
\hline & 1 & 2 & 3 & 4 & 5 & 6 & 7 \\
\hline 1. MET12-posttest & - & & & & & & \\
\hline 2. NIC subscale & $-.025-$ & - & & & & & \\
\hline 3. PLE subscale & $.302 * *$ & $.225 *$ & - & & & & \\
\hline 4. PTE3revised & $.434^{* *}$ & .074 & $.456 * *$ & - & & & \\
\hline 5. OP revised & $.525 * *$ & $.189 *$ & $.360 * *$ & $.397 * *$ & - & & \\
\hline 6. Credibility & $.652 * *$ & .127 & $.451 * *$ & $.388 * *$ & $.556 * *$ & - & \\
\hline 7. Expectancy & $.497 * *$ & .137 & $.507 * *$ & $.443^{* *}$ & $.430 * *$ & $.735 * *$ & - \\
\hline
\end{tabular}

$\mathrm{N}=129$. MET-posttest=post motivation to engage questionnaire; FMP1 subscale= Negative illness consequences (NIC); FMP2 subscale =Psychological Lay etiology (PLE); FMP3 subscale $=$ Psychotherapeutic Treatment Expectations (PTE); and FMP4 subscale=Openness to Psychotherapy (OP); Credibility =the subscale of Credibility/Expectancy Scale; Expectancy = subscale of Credibility/Expectancy Scale.

** Pearson r correlation coefficient is significant at the 0.01 level (2-tailed).

* Pearson $r$ correlation coefficient is significant is significant at the 0.05 level (2-tailed

$\vec{\Phi}$ 
Table 5

Analysis of Covariance for Outcome Measures

Comparison of Analogue Care as Usual Consultation Interview and Analogue Enhanced Consultation Interview

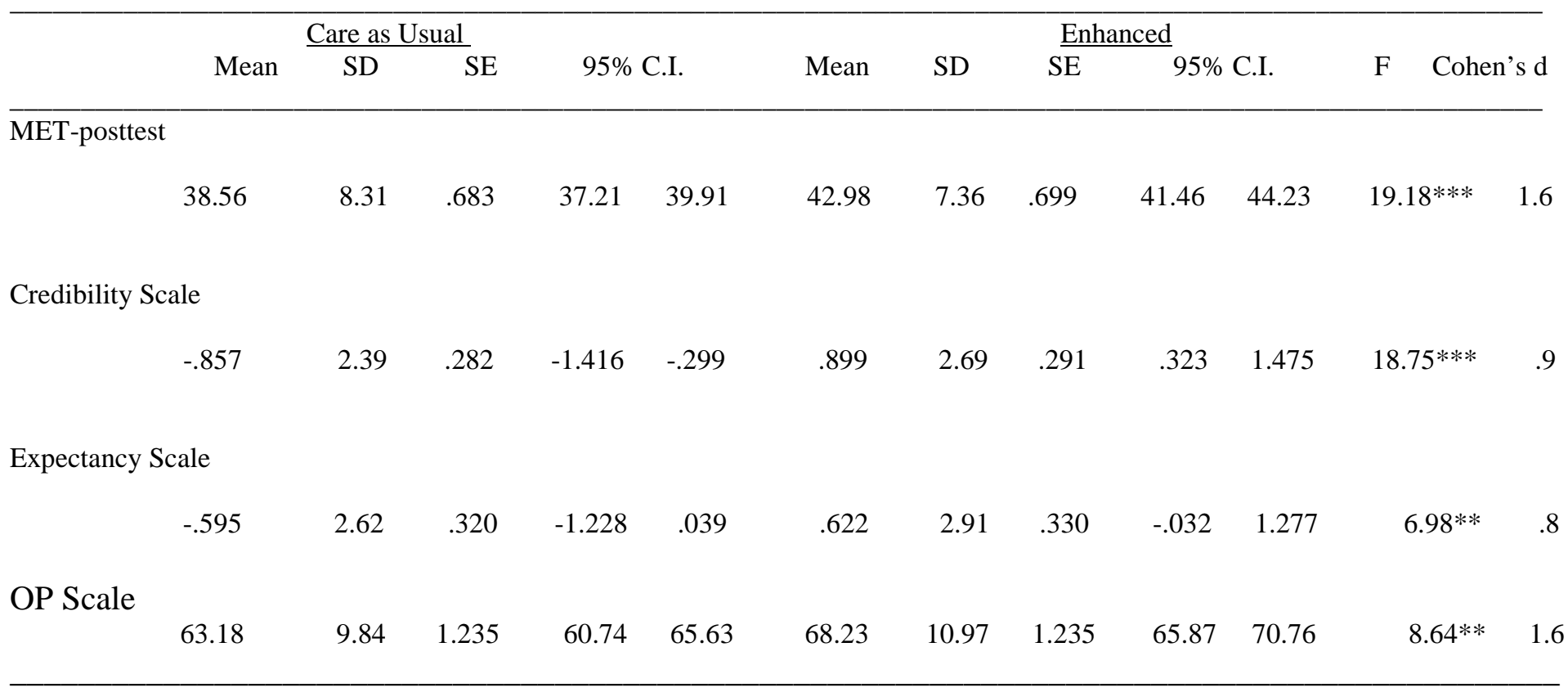

MET-posttest=post motivation to engage questionnaire; Credibility = subscale of Credibility/Expectancy Scale;

Expectancy = subscale of Credibility/Expectancy Scale; FMP (OP) = Openness to Psychotherapy (OP).

Care as Usual =analogue control condition; Enhanced =analogue experimental condition.

${ }^{*} p<.05$. ${ }^{* *} p<.01 .{ }^{* * *} p<0.001$.

宫 
Table 6

Regression analysis for interaction terms controlling for positive effect of the enhanced consultation condition on the MET and Credibility measures.

\begin{tabular}{llrr}
\hline Dependent Variable & B & SE & P \\
\hline MET posttest & & & .000 \\
MET pretest & $.705^{* * *}$ & .104 & .000 \\
Enhanced & $.316^{* * *}$ & 1.260 & .931 \\
Negative counseling experiences & -.008 & 1.694 & .321 \\
MET pretest x enhanced & -.093 & .555 & .012 \\
Negative counseling experiences x enhanced & $-.230^{*}$ & 2.770 & .002 \\
Credibility & & & .000 \\
MET pretest & $.358^{* *}$ & .042 & .523 \\
Enhanced & $.370^{* * *}$ & .514 & .544 \\
Negative counseling experiences & -.068 & .668 & .055 \\
MET pretest x enhanced & .068 & .064 & 1.126 \\
Negative counseling experiences x enhanced & $-.212^{+}$ &
\end{tabular}

MET posttest (MET posttest motivation to engage in therapy questionnaire)

MET pretest (MET-pretest motivation to engage in therapy questionnaire)

Condition- type of intervention (analogue care as usual consultation interview vs. analogue enhanced consultation interview)

${ }^{+} \mathrm{p}<.10$ trend. ${ }^{*} \mathrm{p}<.05 .{ }^{* *} \mathrm{p}<0.01 .{ }^{* * *} \mathrm{p}<.001$

ஓ 


\section{CHAPTER SIX: DISCUSSION}

The focus of this study was to examine whether an enhanced medical consultation interview would be superior to a care as usual consultation interview in increasing the motivation of individuals with somatization to engage in psychological therapy along with their medical care. Overall, there were significant differences between the two analogue interventions - the care as usual and enhanced consultation interviews - on 4 of the 5 motivation scales. Main effects for MET-posttest, Credibility, Expectancy and the FMP4 (OP) subscales demonstrated large effect sizes: Cohen’s $\mathrm{d}=1.6, .9, .8$, and 1.6 respectively.

These findings may be due, in part, to the inclusion of content in the enhanced analogue intervention vignette that had been advanced by different investigators as having potential to motivate individuals to engage in mental health therapy. However, none of these elements had been specifically tested. For example, Looper and Kirmayer (2002) suggested that the provision of psychotherapy in the context of a medical setting is more consistent with a patient's view of care and therefore is an acceptable option. Bakal, et al. (2006) and Speckens et al. (1995) argued that motivation for somatizing patients to engage in therapy may be improved by reducing the patients' fear of abandonment by their doctor. In a study by Martin, Rauh, Fichter, and Rief (2007), the rationale for participation in mental health therapy was described as the benefit which augments coping skills for physical symptoms (instead of searching for psychological causes of symptoms), resulting in high levels of patient 
acceptance for counseling. Integrating the components informed by previous studies into an analogue consultation demonstrated that the discourse of the enhanced vignette was, indeed, more successful for motivating individuals for counseling than the care as usual vignette.

That the FMP (PTE) measure was not significant as a main effect could be due to statements in this scale which reflect comparisons between physical and psychological treatment. Statements such as "True relaxation would help me more than psychological treatment" or "I am better off with a physician than a psychotherapist with regard to my condition" show that the scale measures attitudes and expectations about the value of physical treatment over psychological treatment. This is in contrast to the MET-posttest measure which didn't include comparisons and thus require participants to choose one treatment over the other. Rather, the statements were characterized by a unilateral statement (e.g., "The only way my symptoms will improve is with medical care.”) or they reflected the idea of "adding” both physical and psychological treatment together (e.g., "I believe that whether my symptoms are caused by physical or emotional reasons, I need to get help for both" or "If my doctor suggested that counseling be added to the treatment plan, I would feel that my needs are being respected"). Likewise, the credibility and expectancy subscales did not require participants to have to choose between alternative physical and psychological treatments. Statements in the credibility subscale were phrased in a way that precluded 
participants from having to choose one type of therapy over another (e.g., "How useful do you think counseling would be in reducing your symptoms?”).

The strong effects held for the following motivation measures: MET-posttest, Credibility, Expectancy - even after all possible covariates thought to influence motivation (MET-pretest, type of consultation, counseling helpful, and part-time employment) were examined. One exception was the effects for the FMP (OP) subscale, which trended toward significance. This finding is not particularly surprising since this scale addresses past and vicarious as well as future anticipation of therapy (e.g., “One or more of my friends had good overall experience with psychological treatment" or "In the past I have toyed with the idea of seeking out psychological treatment”). In contrast, the MET-posttest; Credibility and Expectancy subscales addressed current readiness (e.g., "I believe that whether my symptoms are caused by physical or emotional reasons, I need to get help for both" or "If you were to go to counseling or are in counseling now, how much improvement in your symptoms do you think will occur by the end of counseling?”). Moreover, a substantial number of participants declined to answer questions 8 and 42 on this scale, and the items were subsequently deleted from the scale. The missing responses (although question 42 was optional) could have contributed to the non significant result.

There may be other reasons why the FMP scales were unable to detect differential effects between the two conditions in the final analysis. Subtle nuances or differences inherent in European vs. United States language and culture could have 
influenced how participants in the current study interpreted and responded to the wording of questions. The FMP has more routinely been used for comparing effects of treatment over time. The instrument also has been used more often within a therapeutic context rather than within medical consultation.

Additional regression analyses examining the relationships of the METpretest, counseling helpful, and type of condition with the motivation measures (METposttest, Credibility, and Expectancy), while controlling for the overall positive effect towards counseling in the enhanced condition, found a significant interaction for the enhanced consultation interview group and negative view of counseling. This finding was significant for the MET-posttest motivation measure and trended towards significance for the credibility subscale. Essentially, those with less favorable attitudes about counseling who were assigned to the enhanced consultation interview were less motivated to engage in therapy than those with more favorable attitudes towards counseling. This suggests that negative feelings about counseling influenced motivation to engage in therapy (on the MET-posttest motivation measure).

Although it may not be all that surprising and somewhat intuitive that those who have had negative experiences with counseling would not likely be receptive to counseling for what they perceive as a physical problem, a number of reasons for this finding are considered. First, participants who had previous negative experiences might develop negative expectations for future mental health treatment. Those who had a bad experience may have consequently developed a negative bias towards 
counseling and are unlikely to envision a positive one for any condition. Second, if participants had a negative experience of counseling for what might have been a more customary "psychological” issue, the suggestion that counseling would be offered in connection with a "physical” condition may seem farfetched. Finally, those with negative feelings about counseling might be reacting to stigma they perceived when previously seeking help from a mental health provider. The risk may not feel worth it to them.

It is also noteworthy that this finding was significant for the MET and not the other measures. Perhaps the items composed in this newly developed measure were sensitive enough to discern this difference between the two groups. Those with unfavorable attitudes towards counseling, therefore, might benefit from additional education about the nature, purpose and advantages of counseling. Having patients complete a questionnaire to elicit information about past experiences with counseling before the medical consultation might help to identify individuals who might not have had an optimal counseling experience. Those with negative experiences could be invited to share and process their perceptions about counseling with a therapist. This initial step may facilitate an alternative view of counseling that would promote patient's reconsideration of counseling as an adjunct to medical care for physical symptoms. Part of this discussion would also include reassurance that medical care would be provided regardless of the decision to enter therapy. 
Sociodemographic characteristics associated with motivation for psychotherapy included participants who had higher education and prior counseling (credibility) and current counseling (FMP (OP) subscales). This finding may suggest that those with higher education and prior and current experience with counseling perceive therapy as more reasonable and appropriate for reducing somatization symptoms. Those with higher education may also have had more exposure to information and resources regarding counseling, and those with prior counseling experiences may have sufficient opportunities to assess its utility. While higher education has been shown to be associated with higher motivation for therapy using the FMP scales (Timmer, Bleichhardt, \& Rief, 2006), the association between previous therapy and motivation remains equivocal.

The MET-posttest measure demonstrated high internal consistency and convergent validity with the other motivation scales. It was anticipated that this measure would tap into underlying dimensions that other scales lacked. However, the high correlation between the MET-posttest and the Credibility subscale suggest potential overlap in the dimensions being measured. Further research on the METposttest and Credibility subscale measures may help to identify more precisely whether unique dimensions are being examined.

\section{Theory Integration}

The theoretical constructs thought to be most important in forming the bases of the enhanced consultation interview appear to have influenced the findings for this 
intervention. More specifically, these constructs help to explain how and why this intervention may have worked. Although it is difficult to isolate which of the three theories was more or less influential, an argument can be made that elements from all three theories appeared integral to the process of motivating individuals to engage in therapy along with their medical consultation. Dualism appears to be the one common factor addressed by these three theories and its reduced impact may have helped to enhance motivation for mental health therapy.

\section{Cognitive dissonance.}

Reconciliation of two opposing beliefs about oneself lies at the heart of cognitive dissonance theory (Festinger \& Carlsmith, 1959). There is a strong need to reduce the stress caused by the imbalance. It is possible that the discourse of the enhanced vignette preempted the internal conflict that would likely ensue if beliefs about physical versus psychological nature of symptoms are challenged. The enhanced vignette highlighted how symptoms could be either physical, psychological or both, with one or the other type more prevalent at a given time. This vignette communicated the message that patient's symptoms are acknowledged and accepted at face value regardless of their underlying cause. This in effect removes the dispute over whether symptoms are physical or psychological (dualism). Consequently, patients don’t have to work to balance opposing beliefs about their symptoms. Without having to direct their energy towards gaining acceptance of their perspective, patients may be freed up to entertain and explore the potential benefits of therapy. 


\section{Attributions.}

Attribution theory posits that people think and behave depending on their interpretation and assignment of causes for experiences (Roesch \& Weiner, 2001). These attributions are described as polarities (e.g., positive versus negative, physical versus psychological, controllable versus uncontrollable, stable versus unstable). Extending this premise to physical complaints, attributions are made about diagnosis and treatment. These attributions then guide decisions about coping and motivating behaviors (Michela \& Wood, 1986). Attention to these possible attributional styles may have helped to obscure the dualistic position of assessment and treatment of symptoms and thus enhanced motivation of patients to engage in therapeutic treatment. For example, if patients are not locked into one or the other (physical vs. psychological) interpretation of their symptoms, they may be more willing to explore the benefits of counseling. The discourse of the enhanced consultation may help patients to shift their understanding of psychological treatment from exploring deepseated emotional problems to the management of stress associated with their physical symptoms. This form of consultation emphasized that symptoms can optimally be treated but care must include the amelioration of stress that comes with physical symptoms regardless of whether these symptoms are categorized as physical or psychological. This is an optimistic position which subtly suggests to patients that symptoms are manageable (e.g., polarity of controllable versus uncontrollable). 
Finally, the enhanced consultation interview addresses the polarity of stable versus unstable by suggesting that symptoms can alternate between physical, emotional, or both. The medical provider's continued involvement and assessment implies that physical symptoms are indeed fluid and can fluctuate. The medical provider will be available to modify treatment as new information comes forward.

\section{Expectancy.}

Expectancy is another theory thought to have been impacted by the enhanced consultation intervention. The interrelated propositions that form the basis of this approach include strength of belief that action will lead to improved outcomes (e.g., “If I work at this, I will get better”) or “If I work at this, can I really reach my goal?”); and how satisfied, valuable, convincing or attractive an outcome will be (e.g., "Is it worth it?” or “Do I prefer this outcome over others?”). The medical provider discusses with confidence that, in his or her experience, individuals with somatization and who engage in mental health therapy can realize improvements in both physical and emotional symptoms. The offering of combined physical and psychological support in the enhanced interview addresses each of these expectancy propositions and also averts the dualistic debate. This strategy may help to reduce stigma that often accompanies the recommendation of (only) "psychological” treatment, thereby making therapy a more attractive option (Valence). Patients can expect that the act of going to counseling will not cause them to forfeit their relationship with their medical practitioner. In fact, they benefit from having both types of professionals available to 
help address their symptoms. This can help minimize anxiety and, instead, invoke a sense of confidence and security. Furthermore, the clarification of the intent of therapy (to address stress caused by symptoms) may be more in line with patients' expectations and more consistent with their ideas for realizing improvement.

In summary, the enhanced consultation interview emboldens the patient to consider a more holistic approach to the symptoms they bring to the medical practitioner. The particular discourse offered in this vignette allows patients to feel respected, heard, and believed, without having to fight or defend the nature of, and treatment options for, their symptoms. Finally, patients have a clear understanding of the rationale and motive for the therapeutic process.

\section{Strengths and Limitations}

A strength of this study was its ability to addresses a serious a gap in the literature regarding how providers can facilitate patient's motivation for mental health treatment. Much speculation has been offered about barriers and conditions that might influence patient's motivation for counseling during the medical consultation. Yet, there has not heretofore been a study designed to test these elements against the more typical consultation interview. An additional strength of this study was the optimization of internal validity by using randomized assignment and adding a covariate (MET-pretest) to statistically adjust for differences in the motivation measures that might be a result from differences in the pre-existing groups. Also contributing to the strength of this study was the development of the MET. Although it 
was informed by the other two measures of motivation for therapy, the MET added elements thought to be unique to the study population. The MTF demonstrated high internal consistency and was the most sensitive of the outcomes measures for detecting differences between the conditions. Moreover, this instrument was able to detect the interaction between negative counseling experiences and the enhanced interview condition.

The rather robust findings in this study suggest that an analogue intervention in written discourse has sufficient discriminative value to help detect aspects of consultation that would motivate those with somatization to participate in therapy. The current investigation provides support and direction for development of a more reallife portrayal of the consultation interview (face to face, actual intervention) to be empirically tested in the future. It is conceivable that a more real life representation might show even stronger differences. Requiring little time, training, and effort makes this intervention adaptable and feasible to implement in private practice settings as well as larger organizations.

Some of the limitations of this research involve practical issues such as the costs required to conduct a study with a true probability sample. A convenience sample (volunteers with medically unexplained physical symptoms) rather than a randomly selected sample was used, which limits generalizability of the findings to other populations. Convenience samples run the risks of self-selected participation for reasons which could inadvertently bias results. The sample may have underrepresented 
those individuals with medically unexplained symptoms who did not speak English or access the advertisements used to recruit participants. Additionally, the current recession might have motivated some individuals to participate for reimbursement, offering exaggerated, feigned or confabulated symptoms. Finally, the study included a self-rating of medically unexplained physical symptoms without corroboration from a medical provider. While recruiting a convenience sample was a strategic decision based on the difficulty of obtaining a population-based sample of individuals with somatization, the sampling approach makes it difficult to confirm unequivocally the representativeness of the sample.

The cross-cultural application of the FMP may have posed a limitation by inadvertently introducing a cultural bias into the instrument when it was translated from German to English. This bias may have resulted in unintended alteration of content that consequently distorted responses of the participants. Examination of the FMP's internal consistency reliability and convergent validity provides some reassurance that this problem did not occur.

The interrelatedness of three theories thought to influence motivation to engage in mental health treatment makes it difficult to examine the extent to which each contributes to variation in the scores for increased motivation. Future studies might utilize comparative designs which could help prioritize the most essential elements of the enhanced consultation interview that motivated patients to engage in mental health. Along similar lines, a longitudinal design would be important to 
examine how motivation was sustained during therapy and how symptoms were affected over several time points.

Finally, the participants were exposed to simulated rather than actual interventions. Participants were asked to read a vignette, place themselves in the shoes of the patient, and rate how motivated they would be to engage in mental health treatment. This experience lacks the contextual information that might have resulted in a different pattern of participation. Participants involved in an actual consultation would have additional sensory input available during the discussion with their medical provider. This sensory information, such as tone of voice, expression, posture, and mannerisms, might impact patients’ motivation to participate in therapy. For example, during the consultation, a patient notices that his or her provider gives very little eye contact and speaks without much inflection in his or her voice. The patient might perceive this provider to be disinterested, irritated, or blaming, which could affect how the patient interprets the provider's recommendation for therapy. The patient might infer from such an interaction that the provider doesn't believe the patient and is offering therapy as a way to quickly end the consultation. The scenario just described might deter a patient from engaging in therapy, especially if that patient was initially opposed to mental health treatment. 


\section{Implications}

\section{Practice Implications}

While the findings from this study will need to be interpreted with caution, they provide encouraging information to suggest that the enhanced consultation approach can increase motivation for mental health therapy. These results have practice implications for medical and mental health providers as well as patients.

\section{Policy Implications.}

The reattribution and collaborative care models have been put forth as ideal approaches to treat patients with medically unexplained physical symptoms. Patientcentered communication forms the foundation of the reattribution model (Goldberg, Gask, \& O'Dowd, (1989). The primary elements include acknowledgment of patients’ physical symptoms, beliefs, and psychosocial stressors; extension of problem beyond just the physical to consider the psychological; and facilitating the understanding of how physical and psychological are connected and finally negotiating treatment. The collaborative care model includes a five-step patient-centered process to cultivate a positive relationship between medical provider and patient and three-stepped method to educate and facilitate patient involvement in treatment (Smith, et al., 2003).

Referrals are made to other mental health therapists, if patients are considered likely to benefit. Additionally, the medical provider incorporates some elements of CBT within the medical consultation. 
While both of these medically-oriented models have demonstrated positive outcomes with those who have medically unexplained physical symptoms, there are several problems with these models, described in Chapter 2 that might be overcome with the approach detailed in the current study. These include lack of comprehensive treatment and improvement in both physical and emotional outcomes (Morris, et al., 2007); onus on the medical provider to deliver the care and physician's reluctance to be trained in these models (Dowrick et al., 2008; Salmon et al., 2007); lack of cost benefit (Luo et al., 2007); and lack of information related to the outcomes and feasibility of these models in U.S. private practice clinics.

Medically-oriented models typically demand significant resources to both teach and implement. Yet, these costs have not shown to be offset by benefits of these treatment practices.

Perhaps most important, CBT has been well substantiated in several systematic reviews as the only evidenced-based treatment for those with medically unexplained physical symptoms (Sumathipala, 2007). CBT itself has the best track record for success with these types of patients when offered by trained therapists. Yet, CBT needs to be provided in concert with medical care to make it more acceptable to patients as well as comprehensive. Instead of teaching physicians to do therapy, perhaps it makes more sense to teach them to collaborate with mental health workers and to learn fairly straightforward approaches, such as the method validated in this study, for discussing the benefits of integrated treatment with patients. Education, 
specifically medical curricula, often helps to define what is important and valued in professional roles (Salmon, 2007). It may be through this venue that acceptance is achieved for medical consultation visits to endorse the use and benefit of mental health therapy.

The findings from this study also help substantiate the need for dismantling of current reimbursement practices for medical treatment. Funds that would more typically be consumed by many health referrals, tests and intrusive procedures could be diverted to enable medical providers to spend a little more time in the consultation process addressing integrative health needs. In the long run, costs in health and mental health care could be reduced. The passage of the Paul Wellstone Mental Health and Addiction Equity Act, HR 1424, 2008) can be seen as a step in the right direction. By creating more parity between mental health and physical health care coverage, it sends the message that both are integral to care.

\section{Implications for Medical Providers}

The chief advantage of the approach validated in this study for medical providers is having clear discussion points to integrate into consultation with patients that would help motivate them for psychotherapy. This approach would require a modest effort to learn and little time to incorporate in the consultation interview with the patient. Feeling more confident about what elements to cover that would lead patients toward therapy may make medical providers less likely to dismiss or eschew patients with somatization. Medical providers also may feel a sense of relief to know 
that they don't have to convince the patient of the inadequate evidence for the physical origin of symptoms. Additionally, medical providers could be less constrained by their own cognitive dissonance about having to fix something that may not be fixable with physical medicine. They would also not be required to act as both the therapist and the medical provider, a role that would undoubtedly require learning an additional set of skills. Medical providers, in general, and physicians more specifically, have been shown to be unwilling to be trained in models of care in which they must provide psychological care over and above their medical training (Salmon et al., 2007). Utilizing the method validated by the current study, medical providers could fully employ their medical expertise to assess, monitor and care for the patient while partnering with a mental health therapist who could provide the counseling. In this way, the medical provider is not the sole treatment provider, but is supported by the mental health provider who can help shoulder the responsibility for psychological care and offer a more comprehensive treatment plan.

\section{Implications for Mental Health Providers.}

Mental health professionals and social workers specifically, are keenly adept at recognizing, assessing and treating the biopsychosocial nuances that might come to bear on a patient's health and well being. Treatment improves when signs of stress, coping and loss can be situated and understood in the context of the patient's cultural, social, economic, and religious experience. Furthermore, the expertise of mental health counselors can help medical providers raise their awareness of these factors and 
the important role they play in the presentation of symptoms. Without social worker involvement, these issues would likely go unnoticed or be dismissed, which could result in suboptimal care. The medical provider can instead use this knowledge to formulate a more customized and effective treatment plan for the patient.

An integrative treatment approach, if fostered at the onset of the medical consultation, could help social workers commence work on more substantive issues with the patient in a timelier fashion without having to first work through patient's reluctance to accept the merits of counseling. This joint approach also fosters the importance and credibility of the mental health provider's role in the treatment of patients with unexplained symptoms. As medical providers come to appreciate the therapeutic benefits of mental health counseling with these patients, it is conceivable that more parity between the professions and perhaps more equitable insurance reimbursement can ensue.

\section{Implications for Patients.}

Findings from this study advance the approach to care in which there is a juxtaposition of medical and mental health professionals. This seems to result in the most holistic, effective and acceptable treatment. Patients benefit from receiving the expertise of each type of provider as well as the synergistic effects resulting from the combination of providers. They receive quality medical care and quality mental health care as well as the best evidenced based therapy (CBT) for medically unexplained physical symptoms. Moreover, the provision of this combined approach from the 
onset helps to normalize the recommendation for mental health care since it is not given as a last resort when providers don't know what else to do. This normalization of care further reduces the stigma of patients receiving "psychological" care for physical symptoms. It becomes the standard for treatment rather than the exception. This concept of "team" treatment approach has been in place for other medical settings such as hospice where patients (and families) come to expect that disciplines will be working together in order to best manage their symptoms. It is anticipated that the perceptions of patients with somatization regarding joint care will be transformed from a contrived exception to a natural step.

\section{Future Directions.}

This study provides a springboard for future research of patients with medically unexplained symptoms. First, replication of this research with a real life portrayal of the medical consultation (face-to-face intervention) could be conducted to further substantiate the effects found in the analogue study. Second, a longitudinal study might investigate the level of symptom improvement for those patients who engaged in both physical and psychological treatment. Effects would be measured for physical and emotional symptoms. Third, a study may explore the effects of this consultation with other populations (e.g., depression, PTSD, anxiety). This research would require slight modifications of the medical consultation method (e.g., replacing the condition of physical symptoms with depression or PTSD). Forth, future studies might explore the extent to which each of the three theories contribute to the variations 
of scores for increased motivation in order to prioritize the most critical elements that should be integrated in medical consultation.

\section{Conclusion}

With such an intervention in hand, the medical provider can anticipate a more comprehensive assessment and treatment with the additional view and support of the counselor. The mental health provider can become a valuable and credible member of the treatment team offering assessment and treatment from a wide lens perspective which complements the physician's efforts and acknowledges the patient's uniqueness. The patient will reap the benefits from a the combined medical and psychological armamentarium which tackles the problem of medically unexplained symptoms from many angles, including pain, physical functioning, relationships, employment, finances, depression, anxiety, etc. An intervention of this nature has potential to remove the proverbial debate of physical vs. emotional and the concomitant stigma often associated with dualistic care. This holistic approach affords the patient with expertise and support that can address the often interwoven complexities of managing unexplained physical symptoms (See Appendix A. for Somatization Model of Care). 


\section{References}

Abramson, L. Y., Seligman, M. E. P., \& Teasdale, J. D. (1978). Learned helplessness in humans: Critique and reformulation. Journal of Abnormal Psychology, 87, 49-74.

Aiarzaguena, J. M., Grandes, G., Gaminde, I., Salazar, A., Sanchez, A., \& Arino, J. (2007). A randomized controlled clinical trial of a psychosocial and communication intervention carried out by GPs for patients with medically unexplained symptoms. Psychological Medicine, 37(2), 283-294.

Aiarzaguena, J. M., Grandes, G., Salazar, A., Gaminde, I., \& Sanchez, Ã. I. (2008). The diagnostic challenges presented by patients with medically unexplained symptoms in general practice. Scandinavian Journal of Primary Health Care, 26(2), 99 - 105.

Allen, L. A., Escobar, J. I., Lehrer, P. M., Gara, M. A., \& Woolfolk, R. L. (2002). Psychosocial treatments for multiple unexplained physical symptoms: A Review of the Literature. Psychosomatic Medicine, 64(6), 939-950.

Allen, L. A., Woolfolk, R. L., Escobar, J. I., Gara, M. A., \& Hamer, R. M. (2006). Cognitive-Behavioral therapy for somatization Disorder: A randomized controlled trial. Archives of Internal Medicine, 166(14), 1512-1518.

American Psychiatric Association. (2000) Diagnostic and statistical manual of mental disorders (4th ed.) Text Revision. Washington, DC:

Andreski, P., Chilcoat, H., \& Breslau, N. (1998). Post-traumatic stress disorder and somatization symptoms: a prospective study. Psychiatry Research, 79(2), 131138.

Arnold, I. A., Speckens, A. E. M., \& van Hemert, A. M. (2004). Medically unexplained physical symptoms: The feasibility of group cognitivebehavioural therapy in primary care. Journal of Psychosomatic Research, 57(6), 517-520.

Bakal, D., Steiert, M., Coll, P., \& Schaefer, J. (2006). An experiential mind and body approach to the management of medically unexplained symptoms. Medical hypotheses, 67(6), 1443-1447. 
Barsky, A. J., \& Ahern, D. K. (2004). Cognitive behavior therapy for hypochondriasis: A randomized controlled trial. Journal of American Medical Association, 291(12), 1464-1470.

Barsky, A., Ahern, D. K., Bailey, E. D., \& Delamater, B. A. (1996). Predictors of persistent palpitations and continued medical utilization. Journal of Family Practice, 42, 465-472.

Barsky, A. J., \& Borus, J. F. (1999). Functional somatic syndromes. Annals of Internal Medicine, 130(11), 910.

Barsky, A., Orav, J., \& Bates, D. (2005). Somatization increases medical utilization and costs independent of psychiatric and medical comorbidity. Archives of General Psychiatry, 62, 903-910.

Bausell, R. B \& Li, Yu-Fang. (2002). Power analysis for experimental research: A practical guide for the biological, medical and social sciences. United Kingdom, Cambridge University Press.

Bensing, J. M., \& Verhaak, P. F. M. (2006). Somatisation: a joint responsibility of doctor and patient. Lancet, 452-454.

Berardi, D., Menchetti, M., Dragani, A., Fava, C., Leggieri, G., \& Ferrari, G. (2002). The Bologna Primary Care Liaison Service: first year evaluation. Community Mental Health Journal, 38, 439-445.

Bergh, H., Baigi, A., Fridlund, B., \& Marklund, B. (2006). Life events, social support and sense of coherence among frequent attenders in primary health care. Public Health, 120(3), 229-236.

Bleichhardt, G., Timmer, B., \& Rief, W. (2004). Cognitive-behavioural therapy for patients with multiple somatoform symptoms--a randomised controlled trial in tertiary care. Journal of Psychosomatic Research, 56(4), 449-454.

Bleyen, K., Vertommen, H., Vander Sttene, G., \& Van Audenhove, C. (2001). Psychometric properties of the psychotherapy expectancy inventory-revised (PEI-R). Psychotherapy Research, 11(1), 69-83.

Brosschot, J., Pieper, S., \& Thayer, J. (2005). Expanding stress theory: prolonged activation and preservative cognition. Psychoneuroendocrinology, 30(10), 1043-1049. 
Brown, R. J. (2007). Introduction to the special issue on medically unexplained symptoms: Background and future directions. Clinical Psychology Review, 27(7), 769-780.

Burton, C. (2003). Beyond somatization: A review of the understanding and treatment of medically unexplained physical symptoms (MUPS). British Journal of General Practice, 53, 233-241.

Butler, C. C., \& Evans, M. (1999). The 'heartsink' patient revisited. The Welsh philosophy and general practice discussion group. British Journal of General Practice, 49(440), 230-233

Chew-Graham, C. (2005). "Why do doctors feel pressurized?" Journal of Psychosomatic Research, 59(4), 261-262.

Chiles, J. A., Lambert, M. J., \& Hatch, A. L. (1999). The impact of psychological intervention on medical cost offset: A meta-analytic review. Clinical Psychology: Science and Practice, 6, 204-220.

Cockburn, J., \& Pit, S. (1997). Prescribing behaviour in clinical practice: patients' expectations and doctors' perceptions of patients' expectations-a questionnaire study. British Medical Journal, 315(7107), 520-523.

Cowles L. A. \& Lefcowitz, L. M. (1995 ). Interdisciplinary expectations of the medical social worker in the hospital setting: Part 2. Health Soc Work, 20(4), 279-286.

Craig, T. K. J., Cox, A. D., \& Klein, K. (2002). Intergenerational transmission of somatization behaviour: a study of chronic somatizers and their children. Psychological Medicine, 32(05), 805-816.

Craske, M. G., Edlund, M. J., Sullivan, G., Roy-Byrne, P., Sherbourne, C., Bystritsky, A., Shein, M. (2005). Perceived unmet need for mental health treatment and barriers to care among patients with panic disorder. Psychiatric Services, 56(8), 988-994.

Deary, V., Chalder, T., \& Sharpe, M. (2007). The cognitive behavioural model of medically unexplained symptoms: A theoretical and empirical review. Clinical Psychology Review, 27(7), 781-797.

Deale, A., Chalder, T., \& Wessely, S. (1998). Illness beliefs and treatment outcome in chronic fatigue syndrome. Journal of Psychosomatic Research, 45(1), 77-83. 
Deci, E. I., \& Ryan, R. M. (1985). Intrinsic motivation and self-determination in human behavior. New York: Plenum.

de Cruppe, W., Hennch, C., Buchholz, C., Muller, A., Eich, W., \& Herzog, W. (2005). Communication between psychosomatic C-L consultants and general practitioners in a German health care system. General Hospital Psychiatry, 27(1), 63-72.

De Gucht, V., \& B., F. (2002). Somatization: A critical review of conceptual and methodological issues. Psychosomatics, 43(1), 1-9.

De Gucht, V., \& Maes, S. (2006). Explaining medically unexplained symptoms: Toward a multidimensional, theory-based approach to somatization. Journal of Psychosomatic Research, 60(4), 349-352.

Delsignore, A., \& Schnyder, U. (2007). Control expectancies as predictors of psychotherapy outcome: A systematic review. British Journal of Clinical Psychology, 46(4), 467-483.

Devilly, G. J., \& Borkovec, T. D. (2000). Psychometric properties of the credibility/expectancy questionnaire. Journal of Behavior Therapy and Experimental Psychiatry, 31, 73-86.

de Waal, M. W., Eekhof, A., \& van Hemert, A. M. (2004). Somatoform disorders in general practice: prevalence, functional impairment and comorbidity with anxiety and depressive disorders. British Journal of Psychiatry, 184, 470-476.

Di Blasi, Z., Harkness, E., Ernst, E., Georgiou, A., \& Kleijnen, J. (2001). Influence of context effects on health outcomes: a systematic review. Lancet, 357(9258), 757.

Dickinson, W, P., Dickinson, L. M., deGruy, F. V., Main, Deborah S., Candib, Lucy M., Rost, K. (2003). A randomized clinical trial of a care recommendation letter intervention for somatization in primary care. Annals of Family Medicine, 1, 228-235.

Dimsdale, J. E., \& Dantzer, R. (2007). A Biological Substrate for Somatoform Disorders: Importance of Pathophysiology. Psychosomatic Medicine, 69(9), 850-854.

Dowrick, C., Gask, L., Hughes, J., Charles-Jones, H., Hogg, J., Peters, S., 
.....Morriss, R. (2008). General practitioners' views on reattribution for patients with medically unexplained symptoms: a questionnaire and qualitative study. BMC Family Practice, 9(1), 46.

Dowrick, C. F., Ring, A., Humphris, G. M., \& Salmon, P. (2004). Normalisation of unexplained symptoms by general practitioners: a functional typology. British Journal of General Practice, 54, 165 - 170.

Eriksen, H. R., \& Ursin, H. (2002). Sensitization and subjective health complaints. Scandinavian Journal of Psychology, 43(2), 189.

Escalona, R., Achilles, G., Waitzkin, H., \& Yager, J. (2004). PTSD and somatization in women treated at a VA primary care clinic. Psychosomatics, 45(4), 291-296.

Escobar, J. I., Gara, M. A., Diaz-Martinez, A. M., Interian, A., Warman, M., Allen, L. A., .........Rodgers, D. (2007). Effectiveness of a time-limited cognitive behavior therapy type intervention among primary care patients with medically unexplained symptoms. Annals of Family Medicine, 5(4), 328-335.

Escobar, J. I., Burman, M. A., Karno, M., Forsythe A., Golding, J.M. Somatization in the community: relationship to disability and use of services. American Journal of Public Health, 77, 837-840.

Escobar, J. I., Rubio-Stipec, M., Canino, G., \& Karno, M. (1989). Somatic Symptom Index (SSI): A new and abridged somatization construct. Journal of Nervous and Mental disease, 177, 140-146.

Escobar, J. I., Waitzkin, H., Silver, R. C., Gara, M., \& Holman, A. (1998). Abridged somatization: a study in primary care. Psychosomatic Med, 60(4), 466-472.

Farber, Barry A., Brink, Deboral C. Raskin, Patricia, M. (1998). The psychotherapy of Carl Rogers: Cases and Commentary. The Gilford Press: NY, NY.

Feder, A., Olfson, M., Gameroff, M., Fuentes, M., Shea, S., Lantigua, R. A., \& Weissman, M. (2001). Medically unexplained symptoms in an urban general medicine practice. Psychosomatics, 42(3), 261-268.

Festinger, L \& Carlsmith, J.M. (1959). Cognitive consequences of forces compliance, Journal of Abnormal and Social Psychology 58 (2):203-210. 
Fink, P., Sorensen, L., Engberg, M., Holm, M., \& Munk-Jorgensen, P. (1999).

Somatization in primary care: Prevalence, health care utilization, and general practitioner recognition. Psychosomatics, 40(4), 330-338.

Freud, S. (1990). Beyond the pleasure principle. New York: W. W. Norton \& Co.

Frostholm, L., Oernboel, E., Christensen, K. S., Toft, T., Olesen, F., Weinman, J., \& Fink, P. (2007). Do illness perceptions predict health outcomes in primary care patients? A 2-year follow-up study. Journal of Psychosomatic Research, 62(2), 129-138.

Gill, J. M., Szanton, S. L., \& Page, G. G. (2005). Biological underpinnings of health alterations in women with PTSD: A sex disparity. Biological Research for Nursing, 7(1), 44-55.

Gillock, K. L., Zayfert, C., Hegel, M. T., \& Ferguson, R. J. (2005). Posttraumatic stress disorder in primary care: prevalence and relationships with physical symptoms and medical utilization. General Hospital Psychiatry, 27(6), 392399.

Gilman, Sander L., Helen King, Roy Porter, G. S. Rousseau, \& Showalter, E. Hysteria Beyond Freud. Berkeley: University of California Press, c1993 1993. http://ark.cdlib.org/ark:/13030/ft0p3003d3/

Goldberg, D., Gask, L., \& O'Dowd, T. (1989). The treatment of somatization: Teaching techniques of reattribution. Journal of Psychosomatic Research, 33(6), 689-695.

Gureje, O., \& Simon, G. (1999). The natural history of somatization in primary care. Psychological Medicine, 29, 669-676.

Gureje, O., Simon, G. E., Ustun, T. B., \& Goldberg, D. P. (1997). Somatization in cross-cultural perspective: A World Health Organization study in primary care. American Journal of Psychiatry, 154, 989-995.

Guze, S. B., \& Perley, M. J. (1963). Observations on the natural history of hysteria. American Journal of Psychiatry, 119, 960-965.

Hadjistavropoulos, H. D., Craig, K. D., \& Hadjistavropoulos, T. (1998). Cognitive and behavioral responses to illness information: the role of health anxiety. Behaviour Research and Therapy, 36(2), 149-164. 
Hartz, A. J., Noyes, R. J., Bentler, S. E., Damiano, P. C., Willard, J. D., \& Momany, E. T. (2000). Unexplained symptoms in primary care: perspectives of doctors and patients. General Hospital Psychiatry, 22, 144-152.

Henningsen, P., Zipfel, S., \& Wolfgang, H. (2007). Management of functional somatic syndromes. The Lancet, 369, 946-955.

Hiller, W., Fichter, M. M., \& Rief, W. (2003). A controlled treatment study of somatoform disorders including analysis of healthcare utilization and costeffectiveness. Journal of Psychosomatic Research, 54(4), 369-380.

Hiller, W., Rief, W., \& Brahler, E. (2006 ). Somatization in the population: from mild bodily misperceptions to disabling symptoms. Social Psychiatry Psychiatric Epidemiology, 41, 704-712.

Hiller, W., Rief .W, Fichter, M. (1997). How disabled are patients with somatoform disorders? General Hospital Psychiatry 19, 432- 8.

Hotopf, M., Mayou, R., Wadsworth, M., \& Wessely, S. (1999). Childhood Risk Factors for Adults With Medically Unexplained Symptoms: Results From a National Birth Cohort Study. Am J Psychiatry, 156(11), 1796-1800.

Hotopf, M., Wilson-Jones, C., Mayou, R., Wadsworth, M., \& Wessely, S. (2000). Childhood predictors of adult medically unexplained hospitalisations: Results from a national birth cohort study. The British Journal of Psychiatry, 176(3), 273-280.

Huntington, J. (1981). Social work and general medical practice: Collaboration or conflict. London: George Allen University.

Huitt, W. (2006). The cognitive system. Educational Psychology Interactive. Valdosta, GA: Valdosta State University.

Jones, E. E., Kanouse, D., Kelley, H. H., Nisbett, R. E., Valins, S., \& Weiner, B. (1972). Attribution: Perceiving the causes of behavior. Morristown, NJ: General Learning Press.

Joyce, A. S., Ogrodniczuk, J. S., Piper, W. E., \& McCallum, M. (2003). Expectancy, the therapeutic alliance, and treatment outcome in short-term individual therapy. Journal of Psychotherapy Practice and Research, 7, 236-248. 
Kashner, T. M., Rost, K., Cohen, B., Anderson, M., \& Smith, G. R., Jr. (1995).

Enhancing the health of somatization disorder patients. Effectiveness of shortterm group therapy. Psychosomatics, 36(5), 462-470.

Katon, W., Lin, E., Von Korff, M., Russo, J., Lipscomb, P., \& Bush, T. (1991). Somatization: A spectrum of severity. American Journal of Psychiatry, 148, 34-40.

Katon, W., \& Walker, E. A. (1998). Medically unexplained symptoms in primary care. Journal of Clinical Psychiatry, 59(20), 15-21.

Katon, W., Sullivan, M., Walker, E. (2001). Medical Symptoms without identified pathology: Relationship to psychiatric disorders, childhood and adult trauma, and personality traits. Annals of Internal Medicine, 134, 917-925.

Kazdin, A. E. (1979). Therapy outcome question requiring control of credibility and treatment generated expectancies Behavior Therapy, 10, 81-93.

Keyes, C. L. M., \& Ryff, C. D. (2003). Somatization and mental health: A comparative study of the idiom of distress hypothesis. Social Science \& Medicine, 57(10), 1833-1845.

Kilhlstrom, J. F., \& Kilhlstrom, C. L. (1999). Self, sickness, somatization, and systems of care. In R. J. Contrada \& R.D. Ashmore (Eds.). Self, identity, and physical health: interdisciplinary exploration (pp. 23-42). New York: Oxford University Press.

Kirmayer, L. J., Groleau, D., Looper, K. J., \& Dominice Dao, M. (2004). Explaining medically unexplained symptoms. Canada Journal of Psychiatry, 49(10), 663672.

Kirmayer, L. J., \& Looper, K. J. (2006). Abnormal illness behaviour; physiological, psychological and social dimensions of coping with distress. Current opinion in psychiatry, 19, 54-60.

Kirmayer, L. J. \& Robbins, J. M. (1991). Three forms of somatization in primary care: prevalence, co-occurrence, and sociodemographic characteristics. Journal of Nervous Mental Disorders, 179(11), 647-655.

Kirmayer, L. J., \& Young, A. (1998). Culture and somatization: clinical, epidemiological, and ethnographic perspectives. Psychosomatic Medicine, 60(4), 420-430. 
Kisely, S., \& Simon, G. (2006). An international study comparing the effect of medically explained and unexplained somatic symptoms on psychosocial outcome. Journal of Psychosomatic Research, 60(2), 125-130.

Kolk, A. M. M., Schagen, S., \& Hanewald, G. J. F. P. (2004). Multiple medically unexplained physical symptoms and health care utilization: Outcome of psychological intervention and patient-related predictors of change. Journal of Psychosomatic Research, 57(4), 379-389.

Komiti, A., Judd, F., \& Jackson, H. (2006). Social Psychiatry and Psychiatric Epidemiology, 41(9), 738-745.

Kravitz, R. L. (2001). Measuring patients' expectations and requests. Annals of Internal Medicine, 134(9 Part 2), 881-888.

Kroenke, K. (2003). Patients presenting with somatic complaints: epidemiology, psychiatric comorbidity and management. International Journal Methods of Psychiatric Research, 12, 34-43.

Kroenke, K. (2007). Efficacy of treatment for somatoform disorders: A review of randomized controlled trials. Psychosomatic Medicine, 69(9), 881-888.

Kroenke, K., \& Price, R. (1993). Symptoms in the community. Prevalence, classification, and psychiatric comorbidity. Archives of Internal Medicine, 153, 2474-2480.

Kroenke, K., \& Swindle, R. (2000). Cognitive behavioral therapy for somatization and symptom syndromes: A critical review of controlled clinical trials.

Psychotherapy and Psychosomatics, 69, 205-215.

Larisch, A., Schweickhardt, A., Wirsching, M., \& Fritzsche, K. (2004). Psychosocial interventions for somatizing patients by the general practitioner: A randomized controlled trial. Journal of Psychosomatic Research, 57(6), 507-514.

Lawrie, S. M. (2000). Newspaper coverage of psychiatric and physical illness. Psychiatric Bulletin, 24, 104-106.

Leary, M. R., MacDonald, G., \& Price Tangney, J. (2005). Handbook of Self and Identity. New York: New York: Guilford Publications. 
Leiknes, K. A., Finset, A., Moum, T., \& Sandanger, I. (2007). Course and predictors of medically unexplained pain symptoms in the general population. Journal of Psychosomatic Research, 62(2), 119-128.

Lesser, J. G. (2000). Clinical social work and family medicine: A partnership in community service. Health \& Social Work, 25(2), 119.

Leserman, J. (2005). Sexual Abuse History: Prevalence, Health Effects, Mediators, and Psychological Treatment. Psychosomatic Medicine, 67(6), 906-915.

Leventhal, H., \& Cameron, L. (1987). Behavioral theories and the problems of compliance. Patient Education and Counselling, 10, 117-138.

Little, P., Dorward, M., Warner, G., Stephens, K., \& Moore, M. (2004). Importance of patient pressure and perceived pressure and perceived medical need for investigations, referral and prescribing in primary care: nested observational study. British Medical Journal, 328, 444.

Looper, K. J., \& Kirmayer, L. J. (2002). Behavioral medicine approaches to somatoform disorders. Journal of Consultation Clinical Psychology, 70, 810827.

Looper, K. J., \& Kirmayer, L. J. (2004). Perceived stigma in functional somatic syndromes and comparable medical conditions. Journal of Psychosomatic Research, 57(4), 373-378.

Lorenz, J., Hauck, M., Paur, R. C., Nakamura, Y., Zimmermann, R., Bromm, B., \& Engel, A. (2005). Cortical correlates of false expectations during pain intensity judgments--a possible manifestation of placebo/nocebo cognitions. Brain, Behavior and Immunity, 19, 235-295.

Luo, Z., Goddeeris, J., Gardiner, J. C., \& Smith, R. C. (2007). Costs of an intervention for primary care patients with medically unexplained symptoms: A randomized controlled trial: Psychiatric Services, 58(8) 1079-1086.

Macedoa, J. A., Hessec, J., Turnera, J. D., Meyerd, J., Hellhammerc, D. H., \& Mullera, C. P. (2008). Glucocorticoid sensitivity in fibromyalgia patients: Decreased expression of corticosteroid receptors and glucocorticoid-induced leucine zipper Psychoneuroendocrinology, 33(6), 799-809.

Maier, S. F., Watkins, L. R., \& Fleshner, M. (1994). Psychoneuroimmunology: The Interface Between Behavior, Brain, and Immunity. American Psychologist, 49(12), 1004-1017. 
Marin, C., \& Carron, R. (2002). The origin of the concept of somatization. Psychosomatics, 43(3), 249-250.

Martin, A., Buech, A., Schwenk, C., \& Rief, W. (2007). Memory bias for healthrelated information in somatoform disorders. Journal of Psychosomatic Research, 63(6), 663-671.

Martin, A., Rauh, E., Fichter, M., \& Rief, W. (2007). A one-session treatment for patients suffering from medically unexplained symptoms in primary care: A randomized clinical trial. Psychosomatics, 48(4), 294-303.

Maslow, A. (1943). A theory of human motivation. Psychological Review, 50, 370396. Retrieved June 2001, from http://psychclassics.yorku.ca/Maslow/motivation.htm

May, C. R., Rose, M. J., \& Johnstone, F. C. W. (2000). Dealing with doubt: How patients account for non-specific chronic low back pain. Journal of Psychosomatic Research, 49(4), 223-225.

McLeod, C.C., Budd, M. A., \& McClelland, D. C. (1997). Treatment of somatization in primary care. General Hospital Psychiatry, 19, 251-258.

McFarlane, A. C., Ellis, N., Barton, C., Browne, D., \& Van Hooff, M. (2008). The conundrum of medically unexplained symptoms: Questions to consider. Psychosomatics, 49(5), 369-377.

McGuire, J., Bikson, K., \& Blue-Howells, J. (2005). How many social workers are needed in primary care? A patient-based needs assessment example. Health \& Social Work, 30(4), 305-313.

Meissner, W. W. (2006). Psychoanalysis and the mind--body relation: Psychosomatic perspectives. Bulletin of the Menninger Clinic, 70(4), 295-315.

Michela, J. L. \& Wood, J. V. (1986). Causal attributions in health and illness. In: Kendal P.C., (ed.). Advances in cognitive-behavioral research and therapy (pp. 179-235). New York, New York: Academic Press,

Mitchell, A., \& O'Keane, V. (1998). Steroids and depression. British Medical Journal, 316(7127), 244-245. 
Moran, P. W. (1999). Psychological interventions and medical off-set: Implications for integrative care. Clinical Psychology Science and Practice, 6, 242-244.

Morriss, R., Dowrick, C., Salmon, P., Peters, S., Rogers, A., Dunn, G., ......Gask, L. (2006). Turning theory into practice: rationale, feasibility and external validity of an exploratory randomized controlled trial of training family practitioners in reattribution to manage patients with medically unexplained symptoms (the MUST). General Hospital Psychiatry, 28(4), 343-351.

Morriss, R., Dowrick, C., Salmon, P., Peters, S., Dunn, G., Rogers, A., ...Gask, L. (2007). Cluster randomised controlled trial of training practices in reattribution for medically unexplained symptoms. British Journal of Psychiatry, 191(6), 536-542.

Morriss, R. K., Gask, L., Ronalds, C., Downes-Grainger, E., Thompson, H., \& Goldberg, D. (1999).Clinical and patient satisfaction outcomes of a new treatment for somatized mental disorder taught to general practitioners. British Journal of General Practice, 49, 263-267.

Muchinsky, Paul. (2008). Psychology Applied to Work: An introduction to industrial and organizational psychology. Hypergraphic Press, Inc. $9^{\text {th }}$ Ed.

NASW Behavioral Health Practice Update, October, 2003

Nettleton, S. (2006). 'I just want permission to be ill': Towards a sociology of medically unexplained symptoms. Social Science \& Medicine, 62(5), 11671178.

Noyes, R., Jr., Langbehn, D. R., Happel, R. L., Stout, L. R., Muller, B. A., \& Longley, S. L. (2001). Personality dysfunction among somatizing patients. Psychosomatics, 42(4), 320-329.

Oyama, O., Paltoo, C., \& Greengold, J. (2007). Somatoform disorders. American Family Physician, 76(9), 1333-1338.

Panconesi, E., \& Argentieri, S. (2000). Epistemological aspects of psychosomatic dermatology. Dermatoolgy Psychosomatics, 1, 53-55.

Pang, K. Y. C. (1990). The construction of a Korean popular illness among Korean elderly immigrant women in the United States. Culture, Medicine and Psychiatry. 14, 495-512. 
Pear, Robert. (2008, March 6). House approves bill on mental health parity, New York Times.

Peterson, E. (2007). Fibromyalgia managment of a misunderstood disorder. Journal of the American Academy of Nurse Practitioners 19, 341-348.

Peters, S., Stanley, I., Rose, M., \& Salmon, P. (1998). Patients with medically unexplained symptoms: Sources of patients' authority and implications for demands on medical care. Social Science \& Medicine, 46(4-5), 559-565.

Raine, R., Haines, A., Sensky, T., Hutchings, A., Larkin, K., \& Black, N. (2002). Systematic review of mental health interventions for patients with common somatic symptoms: can research evidence from secondary care be extrapolated to primary care? British Medical Journal, 325(7372), 1082doi:10.1136/bmj.325.7372.1082.

Rhodes, L. A., McPhillips-Tangum, C. A., Markham, C., \& Klenk, R. (1999). The power of the visible: the meaning of diagnostic tests in chronic back pain. Social Science \& Medicine, 48(9), 1189-1203.

Rief, W., \& Broadbent, E. (2007). Explaining medically unexplained symptomsmodels and mechanisms. Clinical Psychology Review, 27(7), 821-841

Rief, W., \& Hiller, W. (2003). A new approach to the assessment of the treatment effects of somatoform disorders. Psychosomatics, 44(6), 492-498.

Rief, W., Hiller, W., \& Margraf, J. (1998). Cognitive aspects of hypochondriasis and the somatization syndrome. Journal of Abnormal Psychology, 107(4), 587-595.

Rief, W., Nanke, A., Emmerich, J., Bender, A., \& Zech, T. (2004). Causal illness attributions in somatoform disorders: Associations with comorbidity and illness behavior. Journal of Psychosomatic Research, 57(4), 367-371.

Rief, W., Schaefer, S., Heiller, W., \& Fichter, M. M. (1992). Lifetime diagnoses in patients with somatoform disorders: which came first? Euopean Archives of Psychiatry and Clinical Neuroscience, 241, 236-240.

Ring, A., Dowrick, C. F., Humphris, G. M., Davies, J., \& Salmon, P. (2005). The somatising effect of clinical consultation: What patients and doctors say and do not say when patients present medically unexplained physical symptoms. Social Science \& Medicine, 61(7), 1505-1515. 
Roelofs, K., \& Spinhoven, P. (2007). Trauma and medically unexplained symptoms: Towards an integration of cognitive and neuro-biological accounts. Clinical Psychology Review, 27(7), 798-820.

Roesch, S. C., \& Weiner, B. (2001). A meta-analytic review of coping with illness: Do causal attributions matter? Journal of Psychosomatic Research, 50(4), 205219.

Rosendal, M., Olesen, F., \& Fink, P. (2005). Management of medically unexplained symptoms. British Medical Journal, 330(7481), 4-5.

Rost, K., Kashner, T. M., \& Smith, G. R., Jr. (1994). Effectiveness of psychiatric intervention with somatization disorder patients: Improved outcomes at reduced costs. General Hospital Psychiatry, 16, 381-387.

Rumpold, G., Doering, S., Smrekar, U., Schubert, C., Koza, R., Schatz, D. S., .......Schuessler, G. (2005). Changes in motivation and the therapeutic alliance during a pretherapy diagnostic and motivation-enhancing phase among psychotherapy outpatients. Psychotherapy Research, 15(1), 117-127.

Rygh, L., Svendesen, F., Fiska, A., Haugan, R., Hole, k., \& Tjolsen A. (2005). Longterm potentiation in spinal nociceptive systems-how acute pay may become chronic. Psychoneuroendocrinology, 30(10), 959-964.

Salmon, P. (2007). Conflict, collusion or collaboration in consultations about medically unexplained symptoms: The need for a curriculum of medical explanation. Patient Education and Counseling, 67(3), 246-254.

Salmon, P., Peters, S., Clifford, R., Iredale, W., Gask, L., Rogers, A., Dowrick, C., \& Hughes (2007). Why do general practitioners decline training to improve management of medically unexplained symptoms? Journal of General Internal Medicine, 22, 565-571.

Salmon, P., Peters, S., \& Stanley, I. (1999). Patients' perceptions of medical explanations for somatisation disorders: qualitative analysis. British Medical Journal, 318(7180), 372-376.

Salmon, P., Ring, A., Dowrick, C. F., \& Humphris, G. M. (2005). What do general practice patients want when they present medically unexplained symptoms, and why do their doctors feel pressurized? Journal of Psychosomatic Research, 59(4), 255-260. 
Salmon, P., Wissow, L., Carroll, J., Ring, A., Humphris, G. M., Davies, J. C., \& Dowrick, C.(2007). Doctors' responses to patients with medically unexplained symptoms who seek emotional support: criticism or confrontation? General Hospital Psychiatry, 29(5), 454-460.

Schneider, W., Basler, H. D., \& Beisenherz, B. (1989). Fragebogen zur Messung der Psychotherapiemotivation, FMP [Questionnaire for Measurement of Psychotherapy Motivation] . Weinheim, Germany: Beltz.

Schneider, W., \& Klauer, T. (2001). Symptom level, treatment motivation, and the effects of inpatient psychotherapy. Psychotherapy Research, 11, 153-167.

Schweickhardt, A., Larisch, A., Wirsching, M., Fritzsche, K., \& (2007). Short-term psychotherapeutic interventions for somatizing patients in the general hospital: A randomized controlled study. Psychotherapy and Psychosomatics, 76, 339346.

Sensky, T., MacLeod, A. K., \& Rigby, M. F. (1996). Causal attributions about common somatic sensations among frequent general practice attenders. Psychological Medicine, 26, 641-646.

Shaw, J., \& Creed, F. (1991). The cost of somatization. Journal of Psychosomatic Research, 35(2-3), 307-312.

Sherman, J. J., LeResche, L., Huggins, K. H., Mancl, L. A., Sage, J. C., \& Dworkin, S. F. (2004). The relationship of somatization and depression to experimental pain response in women with temporomandibular disorders. Psychosomatic Medicine, 66(6), 852-860.

Simon, G. E., \& Von Korff, M. (1991). Somatization and psychiatric disorder in the NIMH Epidemiologic Catchment Area Study. American Journal of Psychiatry, 148, 1494-1500.

Smith, G. R., Jr., Monson, R. A., \& Ray, D. C. (1986). Patients with multiple unexplained symptoms. Their characteristics, functional health, and health care utilization. Archives of Internal Medicine, 146(1), 69-72.

Smith, R. C., Lein, C., Collins, C., Lyles, J. S., Given, B., Dwamena, F. C.,..... Given, C. (2003). Treating Patients with Medically Unexplained Symptoms in Primary Care. JGIM: Journal of General Internal Medicine, 18(6), 478-489. 
Smith, R. C., Lyles, J. S., Gardiner, J. C., Sirbu, C., Hodges, A., Dwamena, F. C.,..... Goddeeris, J. (2006). Primary care clinicians treat patients with medically unexplained Symptoms: A randomized controlled trial. JGIM: Journal of General Internal Medicine, 21(7), 671-677.

Speckens, A. E. M., van Hemert, A. M., Bolk, J. H., Hawton, K. E., \& Rooijmans, H. G. M. (1995). The acceptability of psychological treatment in patients with medically unexplained physical symptoms. Journal of Psychosomatic Research, 39(7), 855-863.

Spertus, I., Yehuda, R., Wong, C., Halligan, S., \& Seremetis, S. (2003). Childhood emotional abuse and neglect as predictors of psychological and physical symptoms in women presenting to a primary care practice. Child Abuse and Neglect, 27, 1247-1258.

Stone, J., Colyer, M., Feltbower, S., Carson, A., \& Sharpe, M. (2004). Psychosomatic: A systematic review of its meaning in newspaper articles. Psychosomatics, 45(4), 287-290.

Ströhle A, H. F. (2003). Stress responsive neurohormones in depression and anxiety. Pharmacopsychiatry, 36 (supplement 3), S207-214.

Stuart, S., \& Noyes, R. J. (1999). Attachment and interpersonal communication in somatization. Psychosomatic Journal of Consultation Liaison Psychiatry, 40, 34-43.

Sumathipala, A. (2007). What is the evidence for the efficacy of treatments for somatoform disorders? A critical review of previous intervention studies: Psychosomatic Medicine, 69(9), 889-900.

Sumathipala, A., Hewege, R., Hanwella, R., \& Mann, A. H. (2000). Randomized controlled trial of cognitve behavioral therapy for repeated consultations for medically unexplained complaints: A feasibility study in Sri Lanka. Psychological Medicine, 30, 747-757.

Systems Challenge: Integrating behavioral health care into primary care practices. 1998. The Permanente Journal. Volume 2 (3), 39-44.

Tabachnick, B. G., \& Fidell, L. S. (2007). Using multivariate statistics ( $5^{\text {th }}$ ed.). New York: HarperCollins. 
Taillefer, S. S., Kirmayer, L. J., Robbins, J. M., \& Lasry, J.-C. (2002). Psychological correlates of functional status in chronic fatigue syndrome. Journal of Psychosomatic Research, 53(6), 1097-1106.

Taylor, G. J. (2002). Mind - body - environment: George Engel’s psychoanalytic approach to psychosomatic medicine. Australian and New Zealand Journal of Psychiatry, 36, 449-457.

The Paul Wellstone Mental Health and Addiction Equity Act, HR 1424, 2008. Retrieved Jan 15, 2008 from, http://www.govtrack.us/congress/bill.xpd?bill=h110-1424.

Timmer, B., Bleichhardt, G., \& Rief, W. (2006). Importance of psychotherapy motivation in patients with somatization syndrome. Psychotherapy Research, 16(3), 348-356.

Torgerson, D. (2001). Contamination in trials: is cluster randomisation the answer? British Medical Jouranl, 322, 355-357.

van Beek, N., \& Verheul, R. (2008). Motivation for treatment in people with personality disorders. Journal of Personality Disorders, 22(1), 89-100.

Vandenbergen, J., Vanheule, Stijn, Rosseel, Yves, Desmet, Mattias, Verhaeghe, Paul. (2009). Unexplained chronic fatigue and core conflictual relationship themes: A study in a chronically fatigued population. Psychology and Psychotherapy: Theory, Research and Practice, 82, 31-40.

van der Feltz-Cornelis, C. M., van Oppen, P., Adèr, H. J., \& van Dyck, R. (2006). Randomised controlled trial of a collaborative care model with psychiatric consultation for persistent medically unexplained symptoms in general practice. Psychotherapy and Psychosomatics, 75(5), 282-289.

Van der Hart, O., \& Friedman, B. (1989). Reader's guide to Pierre Janet: A neglected intellectual heritage. Dissociation 2(1), 3-16.

Verkuil, B., Brosschot, J. F., \& Thayer, J. F. (2007). A sensitive body or a sensitive mind Associations among somatic sensitization, cognitive sensitization, health worry, and subjective health complaints. Journal of Psychosomatic Research, 63(6), 673-681.

Vroom, V. (1964). Work and motivation. New York: Wiley. 
Watson, D., \& Pennebaker, J. W. (1989). Health complaints, stress, and distress: Exploring the central role of negative affectivity. Psychological Review, 96(2), 234-254.

Weiner, B. (1974). Achievement motivation and attribution theory. Morristown, N.J.: General Learning Press.

Weiner, B. (1986). An attributional theory of motivation and emotion. New York: Springer-Verlag.

Weiner, B. (1995). Judgments of responsibility: A foundation for a theory of social conduct. New York: Guilford.

Weinman, J., Petrie, K. J., Moss-Morris, R., \& Horne, R. (1996). The illness perception questionnaire: a new method for assessing the cognitive representation of illness. Psychology and Health, 11, 43-53.

Werner, A., Isaksen, L. W., \& Malterud, K. (2004). 'I am not the kind of woman who complains of everything': Illness stories on self and shame in women with chronic pain. Social Science \& Medicine, 59(5), 1035-1045.

Wileman, L., May, C., \& Chew-Graham, C. A. (2002). Medically unexplained symptoms and the problem of power in the primary care consultation: a qualitative study. Family Practice, 19(2), 178-182.

Woolfolk, R. L., \& Allen, L. A. (2007). Treating somatization. A cognitive behavioral approach. New York, New York: The Guilford Press.

World Health Organization. (1993). The ICD-9 classification of mental and behavioral disorders: Diagnostic criteria for research. Geneva, Switzerland: Author.

Yeung, A., Kung, W., Chung, H., Rubenstein, G., Rofi, P., Mischoulon, D., \& Fava, M. (2004). Integrating psychiatry and primary care improves acceptability to mental health services among Chinese Americans. General Hospital Psychiatry, 4, 256-260. 
APPENDIX A. Somatization Model of Care

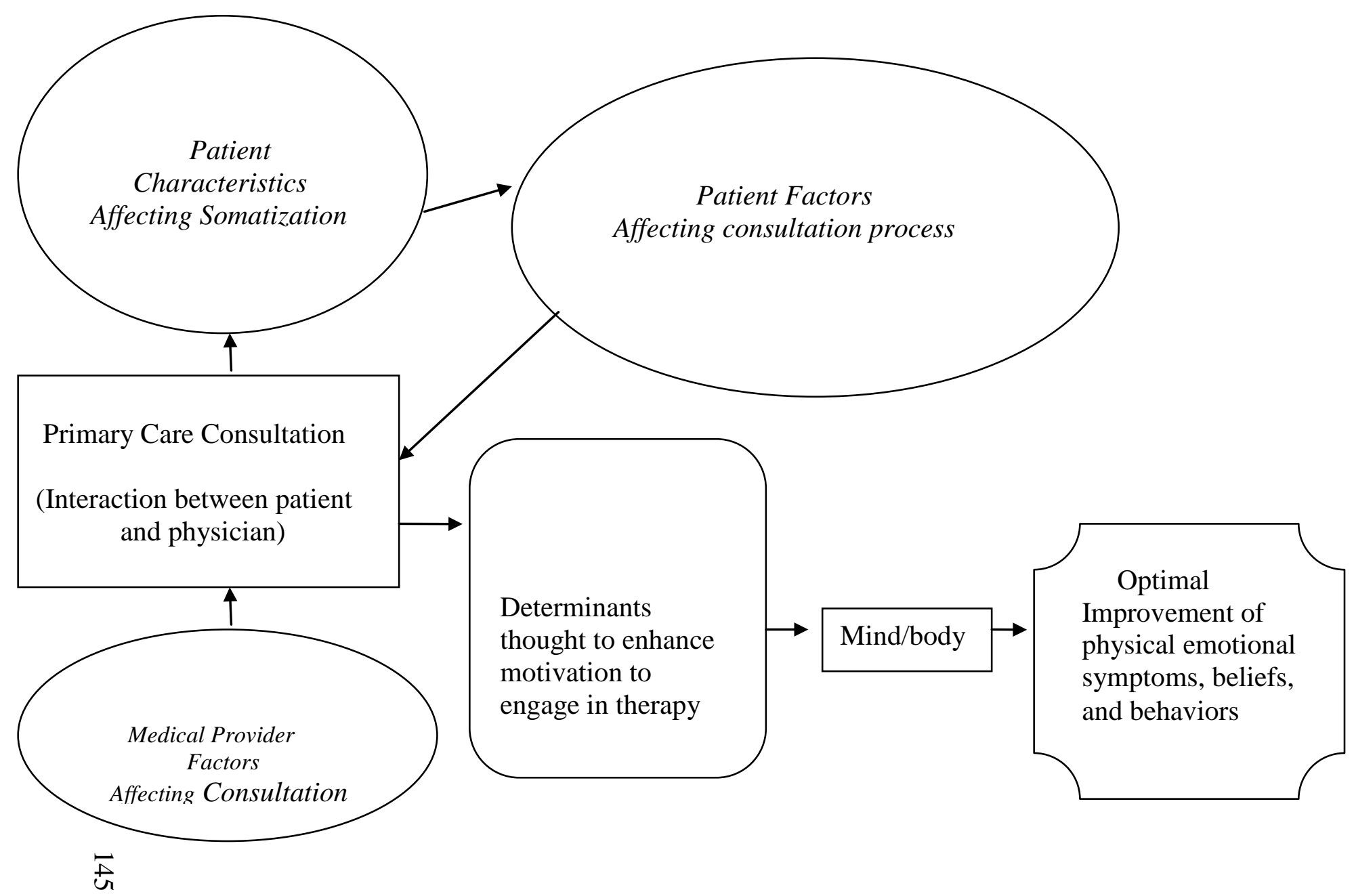




\section{Appendix B Recruitment Flyer}

\section{DO YOU HAVE PHYSICAL SYMPTOMS THAT YOUR MEDICAL PROVIDER CAN'T EXPLAIN?}

\section{If you do, you are invited to participate in a study}

A study examining how providers can help patients deal with the stress of having medically unexplained physical symptoms is being conducted in areas throughout Oregon as part of a PhD dissertation at Portland State University.

You are invited to take part in this study if:

- $\quad$ You have at least 2 medically unexplained physical symptoms for the last 6 months that your health provider hasn't been able to explain;

- $\quad$ You are between the ages of 18 and 65.

The study consists of completing questionnaires that will take approximately one hour and will be conducted by email or regular mail.

You will receive $\$ 50$ upon your return of the completed questionnaires.

If you think that you might be interested in the study, please contact Terry Chianello at 541-410-2274 or email me at tchianello@msn.com. 


\section{Appendix C. Provider Letter}

A study that will examine the relationship of patients with medically unexplained physical symptoms and engagement in mental health treatment is being conducted throughout areas of Oregon as part of my PhD dissertation in Social Research at Portland State University.

The treatment of those with medically unexplained physical symptoms can be difficult for provider and patient. Systematic reviews of randomized controlled trials have demonstrated that combined physical and mental health treatment can be optimal in reducing both physical and psychological symptoms for many patients with medically unexplained physical symptoms. Typically, it is the medical consultation where the discussion of optimal care takes place. In spite of the solid efforts of respectful and caring medical practitioners to motivate patients to consider psychological care along with medical care, many patients are resistant to mental health treatment. Moreover, patients often feel offended, shamed and blamed when the option of mental care treatment is raised. A series of untoward events can ensue which include doctor shopping; extensive tests or procedures, and increased health care costs. The result can leave both provider and patient with an unacceptable outcome.

The central aim of the study is to identify what essential elements need to be discussed during the medical consultation that will encourage patients with medically unexplained symptoms to engage in mental health therapy while under the care of their primary medical provider. To date, there has not been a study that has systematically identified and investigated these elements in the course of the medical consultation process. This will be an analogue (simulated) study with participants randomized into one of two conditions: enhanced medical consultation and care as usual condition.

Participation in this research may help patients begin to explore other approaches to address their symptoms. Medical providers also may benefit from the findings of the study--a discussion strategy to motivate patients to engage in mental health while preserving the medical relationship.

I would very much appreciate the opportunity to discuss the possibility of posting the enclosed flyers in your organization or practice. Your input regarding how best this would work in your particular organization or practice is welcomed.

If you have any questions regarding the study, please contact me at (541) 410-2274. Sincerely,

Terry Chianello, MSW, LCSW 


\section{Appendix D Craigslist Advertisement}

Reply to: event-Number @craigslist.org

Posting Title: Do you have physical symptoms that your health provider can't explain?

Posting Description: If you have unexplained symptoms, you are invited to participate in a study

This study examines how health providers can help patients deal with the stress of having managing medically unexplained physical symptoms. The study will take place throughout Oregon. This research is being conducted as part of a PhD dissertation at Portland State University.

You are invited to take part in this study if:

- You have at least 2 medically unexplained physical symptoms for the last 6 months that your health provider hasn't been able to explain;

- You are between the ages of 18 and 64 .

The study consists of completing questionnaires that will take approximately one hour and will be conducted by mail, email, or in person at a convenient location and time.

Study participants receive $\$ 50$. 


\section{Appendix E. Advertisement for Newsletters and Magazines}

A study examining how health providers can discuss integrative care with patients having medically unexplained physical symptoms is being conducted in areas throughout the Northwest as part of a $\mathrm{PhD}$ dissertation at Portland State University.

You are invited to take part in this study if:

- $\quad$ You have at least 2 medically unexplained physical symptoms for the last 6 months that your health provider hasn't been able to explain;

- $\quad$ You are between the ages of 18 and 65.

Study participants receive $\$ 50$.

If you think that you might be interested in the study, please contact Terry Chianello at 541-410-2274 or email me at tchianello@msn.com. 


\section{Appendix F. SOMS-7}

Instruction:

A number of different bodily complaints are listed below.

Please indicate (by placing an " $\mathbf{X}$ " next to number) whether you have suffered from these symptoms within the past 7 days.

Consider only symptoms, for which no clear causes have been found by physicians, and which have affected your wellbeing.

I have read the instructions: Yes No

In the past 7 days, I suffered from the following complaints:

(1) Headaches

(2) Pain in the stomach

(3) Back pain

(4) Joint pain

(5) Pain in the legs and/ or arms

(6) Chest pain

(7) Pain in the anus

(8) Pain during sexual intercourse

(9) Pain during urination

(10) Nausea

(11) Bloating

(12) Stomach discomfort or churning feeling in the stomach

\begin{tabular}{crrrr}
\multicolumn{3}{c}{ Degree of Impairment } & & \multicolumn{2}{c}{ very severe } \\
not at all & mild & medium & severe & 3 \\
0 & 1 & 2 & 3 & 4 \\
0 & 1 & 2 & 3 & 4 \\
0 & 1 & 2 & 3 & 4 \\
0 & 1 & 2 & 3 & 4 \\
0 & 1 & 2 & 3 & 4 \\
0 & 1 & 2 & 3 & 4 \\
0 & 1 & 2 & 3 & 4 \\
0 & 1 & 2 & 3 & 4 \\
0 & 1 & 2 & 3 & 4 \\
0 & 1 & 2 & 3 & 4 \\
0 & 1 & 2 & 3 & 4 \\
0 & 1 & 2 &
\end{tabular}


Instruction:

A number of different bodily complaints are listed below.

Please indicate (by placing an " $X$ " next to number) whether you have suffered from these symptoms within the past 7 days.

Consider only symptoms, for which no clear causes have been found by physicians, and which have affected your wellbeing.

In the past 7 days, I suffered from the following complaints:

\section{Degree of Impairment}

(13) Vomiting (pregnancy excluded)

(14) Bringing swallowed food up again

(15) Hiccough, or burning sensations in chest or stomach

(16) Food intolerance

(17) Loss of appetite

(18) Bad taste in mouth, or excessively coated tongue

(19) Dry mouth

(20) Frequent diarrhea

(21) Discharge of fluids from anus

(22) Frequent urination

(23) Frequent bowel movements

(24) Strong heart pounding

not at all mild medium severe very severe




\section{Instruction:}

A number of different bodily complaints are listed below.

Please indicate (by placing an " $\mathbf{X}$ ” next to number) whether you have suffered from these symptoms within the past 7 days.

Consider only symptoms, for which no clear causes have been found by physicians, and which have affected your wellbeing.

In the past 7 days, I suffered from the following complaints:

\section{Degree of Impairment}

(25) Discomfort in the area around the heart

(26) Sweating (hot or cold)

(27) Flushing or blushing

(28) Breathlessness (without exertion)

(29) Painful breathing or hyperventilation

(30) Excessive tiredness or mild exertion

(31) Blotchiness or discoloration of the skin

(32) Sexual indifference (loss of libido)

(33) Unpleasant sensations in or around the genitals

$\otimes$

(34) Impaired coordination or balance

(35) Paralysis or localized weakness

(36) Difficulty swallowing or lump in the throat

(37) Aphonia (loss of voice)

$\begin{array}{llccc}\text { not at all } & \text { mild } & \text { medium } & \text { severe } & \text { very severe } \\ 0 & 1 & 2 & 3 & 4 \\ 0 & 1 & 2 & 3 & 4 \\ 0 & 1 & 2 & 3 & 4 \\ 0 & 1 & 2 & 3 & 4 \\ 0 & 1 & 2 & 3 & 4 \\ 0 & 1 & 2 & 3 & 4 \\ 0 & 1 & 2 & 3 & 4 \\ 0 & 1 & 2 & 3 & 4 \\ 0 & 1 & 2 & 3 & 4 \\ & & & & \\ 0 & 1 & 2 & 3 & 4 \\ 0 & 1 & 2 & 3 & 4 \\ 0 & 1 & 2 & 3 & 4 \\ 0 & 1 & 2 & 3 & 4\end{array}$


Please indicate whether you have suffered from these symptoms within the past 7 days. Consider only symptoms for which no clear causes have been found by physicians, and which have affected your well-being.

In the past 7 days, I suffered from the following complaints:

\section{Degree of Impairment}

$\begin{array}{lr} & \text { not } \\ \text { (38) Urinary retention } & 0 \\ \text { (39) Hallucinations } & 0 \\ \text { (40) Loss of touch or pain sensation } & 0 \\ \text { (41) Unpleasant numbness or tingling sensations } & 0 \\ \text { (42) Double vision } & 0 \\ \text { (43) Blindness } & 0 \\ \text { (44) Deafness } & 0 \\ \text { (45) Seizures } & 0 \\ \text { (46) Amnesia (loss of memory) } & 0 \\ \text { (47) Loss of consciousness } & 0\end{array}$

$\begin{array}{ll}\text { ot all } & \text { mild } \\ 0 & 1 \\ 0 & 1 \\ 0 & 1 \\ 0 & 1 \\ 0 & 1 \\ 0 & 1 \\ 0 & 1 \\ 0 & 1 \\ 0 & 1 \\ 0 & 1\end{array}$

medium

severe very severe

$\otimes$

For women:

(48) Painful menstruation

(49) Irregular menstruation

(50) Excessive menstrual bleeding

(51) Continuous/ frequent vomiting during pregnancy

(52) Unusual or copious vaginal discharge

$\begin{array}{ll}0 & 1 \\ 0 & 1 \\ 0 & 1 \\ 0 & 1 \\ 0 & 1\end{array}$

For men:

(53) Erectile or ejaculatory dysfunction

SOMS-7 (C) W. Rief, W. Hiller, M. M. Fichter, 2001

University of Marburg, Germany 
Appendix G. $\quad$ DEMOGRAPHIC INFORMATION

1. What is your age?

2. Gender

Male

Female Other

3. How many years of education have you have completed? (Count high school or GED as 12)

4. How do you describe yourself? (Please circle or place an " $\mathrm{x}$ " near the one option that best describes you)

- American Indian or Alaska Native

- Hawaiian or Other Pacific Islander

- Asian or Asian American

- Black or African American

- Hispanic or Latino

- Non-Hispanic White

- Other

5. Marital status (put an $\mathrm{x}$ near the option that best describes you)

- Married

- Divorced

- Widowed

- Separated

- Never been married

- A member of an unmarried couple

- Single

5. What is your employment status? (put an $\mathrm{x}$ near the option that best describes you)

- Working full-time

- Working part-time

- Unemployed

6. Are you disabled?

Yes

No 
7. What is your household income? (put an $\mathrm{x}$ near the option that best describes you)

- Less than $\$ 15,000$ per year

- $\$ 15,000$ to $<\$ 25,000$ per year

- $\$ 25,000$ to $<\$ 40,000$ per year

- $\$ 40,000$ to $<\$ 70,000$ per year

- $\$ 70,000$ to $<\$ 100,000$ per year

- $\$ 100,000$ or more per year

8. Have you ever been in counseling before?

Yes__ No_

If yes, did your counselor suggest a diagnosis?

Yes__ No_

If yes, what was the diagnosis you received?

Did you find counseling helpful?

Yes__ No_ _

Are you currently in counseling?

Yes__ No_

9. Is there anything that you would like to hear from your doctor that might help you feel better about getting help for

both physical and emotional care?

10. If you wanted to add counseling to your medical treatment plan, would there be anything getting in your way?

Thank you for completing this questionnaire! 


\section{Appendix H. FMP}

(C) 1989 Beitz Test GmbH, Göttingen

Beltz Test GmbH

Rohnsweg 25, D-37085 Gottingen, Germany

Tel: +49 (0)551 49609-0 Fax: -88 


\section{Appendix I. Credibility/Expectancy Questionnaire}

Based on the DISCUSSION YOU JUST READ (if your doctor talked to you this way), place an " $\mathrm{X}$ " under the number that corresponds to the number which best describes your response.

1. How logical would counseling offered to you seem?

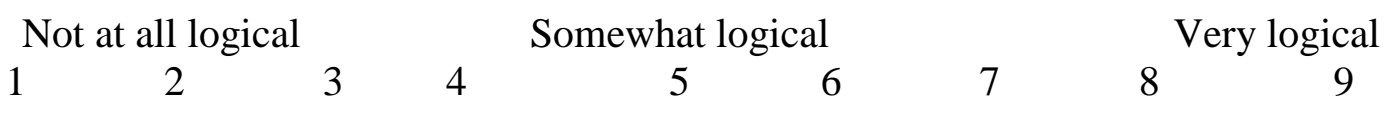

2. How useful do you think counseling would be in reducing your symptoms?
Not at all useful
$\begin{array}{lllll}2 & 3 & 4 & 5 & 6\end{array}$
Very useful

3. How confident would you be in recommending counseling to a friend who experiences similar problems?

Not at all

12

$\begin{array}{lll}2 & 3 & 4\end{array}$

Somewhat

$\begin{array}{llllll}5 & 6 & 7 & 8 & 9\end{array}$

4. If you were to go to counseling or are in counseling now, how much improvement in your symptoms do you think will occur by the end of counseling?

None at all

1

2

34

5

6

Total Improvement

(1)

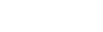

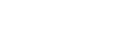

Please identify what you really feel about counseling and its likely success.

5. If you were to go to counseling, how much do you really feel that counseling will help you to reduce your symptoms?

Not at all useful

1

$\begin{array}{lcllll}\text { Somewhat useful } & & & & \text { Very useful } \\ \text { So } & 4 & 6 & 7 & 8 & 9\end{array}$


6. If you were to go to counseling, how much improvement in your symptoms do you really feel will occur by the end of counseling?

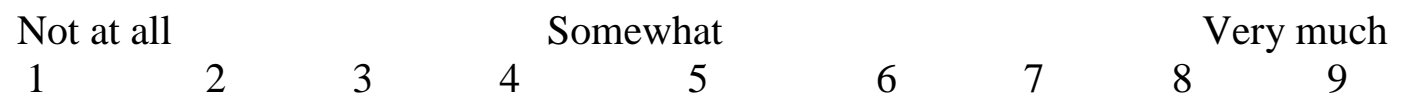

Copyright. Grant J. Devilly \& Thomas D. Borkovec

(2000 Elsevier Science Ltd. All rights reserved) 
Appendix J. MET PRETEST Please rate how strongly you agree with each of these statements.

\begin{tabular}{|c|c|c|c|c|c|}
\hline & $\begin{array}{l}\text { Strongly } \\
\text { Disagree }\end{array}$ & Disagree & $\begin{array}{l}\text { Neither } \\
\text { Agree nor } \\
\text { Disagree }\end{array}$ & Agree & $\begin{array}{l}\text { Strongly } \\
\text { Agree }\end{array}$ \\
\hline $\begin{array}{l}\text { 1. The only way my physical symptoms } \\
\text { will get better is if I get help from a } \\
\text { medical provider. }\end{array}$ & $\square 5$ & $\square 4$ & $\square 3$ & $\square 2$ & $\square 1$ \\
\hline $\begin{array}{l}\text { 2. If my doctor recommends that I go to } \\
\text { counseling for my physical symptoms, } \\
\text { it probably means that the doctor thinks } \\
\text { my symptoms are all my head. }\end{array}$ & $\square 5$ & $\square 4$ & $\square 3$ & $\square 2$ & $\square 1$ \\
\hline $\begin{array}{l}\text { 3. I have a good understanding of how } \\
\text { counseling can help me. }\end{array}$ & $\square 1$ & $\square 2$ & $\square 3$ & $\square 4$ & $\square 5$ \\
\hline $\begin{array}{l}\text { 4. I believe that whether my symptoms are } \\
\text { caused by physical or emotional } \\
\text { reasons, getting help for both makes } \\
\text { sense. }\end{array}$ & $\square 1$ & $\square 2$ & $\square 3$ & $\square 4$ & $\square 5$ \\
\hline $\begin{array}{l}\text { 5. I wouldn't go to counseling because the } \\
\text { process of finding a counselor is } \\
\text { difficult. }\end{array}$ & $\square 5$ & $\square 4$ & $\square 3$ & $\square 2$ & $\square 1$ \\
\hline $\begin{array}{l}\text { If my doctor recommended adding } \\
\text { counseling to my treatment plan, I } \\
\text { would feel that the doctor is looking for } \\
\text { a way to get rid of me. } \\
\end{array}$ & $\square 5$ & $\square 4$ & $\square 3$ & $\square 2$ & $\square 1$ \\
\hline $\begin{array}{l}\text { 7. If my doctor suggested adding } \\
\text { counseling to the treatment plan, I } \\
\text { would not feel that the doctor believes I } \\
\text { have a physical problem. }\end{array}$ & $\square 5$ & $\square 4$ & $\square 3$ & $\square 2$ & $\square 1$ \\
\hline $\begin{array}{l}\text { 8. Counseling is just as important as } \\
\text { medical care for helping me cope with } \\
\text { my physical symptoms. }\end{array}$ & $\square 1$ & $\square 2$ & $\square 3$ & $\square 4$ & $\square 5$ \\
\hline $\begin{array}{l}\text { 9. I worry that if I go to counseling, my } \\
\text { doctor will think that I don't need } \\
\text { medical care. }\end{array}$ & $\square 5$ & $\square 4$ & $\square 3$ & $\square 2$ & $\square 1$ \\
\hline $\begin{array}{l}\text { 10. If I went to counseling, it would mean } \\
\text { that my physical problems don't really } \\
\text { exist. }\end{array}$ & $\square 5$ & $\square 4$ & $\square 3$ & $\square 2$ & $\square 1$ \\
\hline $\begin{array}{l}\text { 11. If my doctor suggested that I go to } \\
\text { counseling, I would feel that my needs } \\
\text { are being respected. }\end{array}$ & $\square 1$ & $\square 2$ & $\square 3$ & $\square 4$ & $\square 5$ \\
\hline $\begin{array}{l}\text { 12. I would be more likely to go to } \\
\text { counseling if it was available in the } \\
\text { same building as my doctor. }\end{array}$ & $\square 1$ & $\square 2$ & $\square 3$ & $\square 4$ & $\square 5$ \\
\hline
\end{tabular}


Appendix K. MET POSTTEST. Based on the DISSCUSION YOU JUST READ, please rate how Strongly you agree with each of these statements. (Place an $\mathrm{x}$ in the box)

\begin{tabular}{|c|c|c|c|c|c|}
\hline & $\begin{array}{l}\text { Strongly } \\
\text { Disagree }\end{array}$ & Disagree & $\begin{array}{l}\text { Neither } \\
\text { Agree nor } \\
\text { Disagree }\end{array}$ & Agree & $\begin{array}{l}\text { Strongly } \\
\text { Agree }\end{array}$ \\
\hline $\begin{array}{l}\text { 1. The only way my physical symptoms } \\
\text { will get better is if I get help from a } \\
\text { medical provider. }\end{array}$ & $\square 5$ & $\square 4$ & $\square 3$ & $\square 2$ & $\square 1$ \\
\hline $\begin{array}{l}\text { 2. If my doctor recommends that I go to } \\
\text { counseling for my physical symptoms, } \\
\text { it probably means that the doctor thinks } \\
\text { my symptoms are all my head. }\end{array}$ & $\square 5$ & $\square 4$ & $\square 3$ & $\square 2$ & $\square 1$ \\
\hline $\begin{array}{l}\text { 3. I have a good understanding of how } \\
\text { counseling can help me. }\end{array}$ & $\square 1$ & $\square 2$ & $\square 3$ & $\square 4$ & $\square 5$ \\
\hline $\begin{array}{l}\text { 4. I believe that whether my symptoms are } \\
\text { caused by physical or emotional } \\
\text { reasons, getting help for both makes } \\
\text { sense. }\end{array}$ & $\square 1$ & $\square 2$ & $\square 3$ & $\square 4$ & $\square 5$ \\
\hline $\begin{array}{l}\text { 5. I wouldn't go to counseling because the } \\
\text { process of finding a counselor is } \\
\text { difficult. }\end{array}$ & $\square 5$ & $\square 4$ & $\square 3$ & $\square 2$ & $\square 1$ \\
\hline $\begin{array}{l}\text { 6. If my doctor recommended adding } \\
\text { counseling to my treatment plan, I } \\
\text { would feel that the doctor is looking for } \\
\text { a way to get rid of me. }\end{array}$ & $\square 5$ & $\square 4$ & $\square 3$ & $\square 2$ & $\square 1$ \\
\hline $\begin{array}{l}\text { 7. If my doctor suggested adding } \\
\text { counseling to the treatment plan, I } \\
\text { would not feel that the doctor believes I } \\
\text { have a physical problem. }\end{array}$ & $\square 5$ & $\square 4$ & $\square 3$ & $\square 2$ & $\square 1$ \\
\hline $\begin{array}{l}\text { 8. Counseling is just as important as } \\
\text { medical care for helping me cope with } \\
\text { my physical symptoms. }\end{array}$ & $\square 1$ & $\square 2$ & $\square 3$ & $\square 4$ & $\square 5$ \\
\hline $\begin{array}{l}\text { 9. I worry that if I go to counseling, my } \\
\text { doctor will think that I don't need } \\
\text { medical care. }\end{array}$ & $\square 5$ & $\square 4$ & $\square 3$ & $\square 2$ & $\square 1$ \\
\hline $\begin{array}{l}\text { 10. If I went to counseling, it would mean } \\
\text { that my physical problems don't really } \\
\text { exist. }\end{array}$ & $\square 5$ & $\square 4$ & $\square 3$ & $\square 2$ & $\square 1$ \\
\hline $\begin{array}{l}\text { 11. If my doctor suggested that I go to } \\
\text { counseling, I would feel that my needs } \\
\text { are being respected. }\end{array}$ & $\square 1$ & $\square 2$ & $\square 3$ & $\square 4$ & $\square 5$ \\
\hline $\begin{array}{l}\text { 12. I would be more likely to go to } \\
\text { counseling if it was available in the } \\
\text { same building as my doctor. }\end{array}$ & $\square 1$ & $\square 2$ & $\square 3$ & $\square 4$ & $\square 5$ \\
\hline
\end{tabular}




\section{Appendix L. Expert Panel Ratings of the Enhanced and Care as Usual Vignettes}

Please rate the following statements using the 5-point Likert Scale

1. Does this vignette reflect typical responses of a medical provider to a patient with medically unexplained physical symptoms?

$\begin{array}{lrrrr}\text { Strong } & \text { Disagree } & \text { Neither } & \text { Agree } & \text { Strongly Agree } \\ \text { Disagree } & & \text { Agree nor Disagree } & & \\ 1 & 2 & 3 & 4 & 5\end{array}$

2. Is the possibility of mixed etiology (physical and emotional) communicated?

$\begin{array}{lrrrr}\text { Strong } & \text { Disagree } & \text { Neither } & \text { Agree } & \text { Strongly Agree } \\ \text { Disagree } & & \text { Agree nor Disagree } & & \\ 1 & 2 & 3 & 4 & 5\end{array}$

3. Does the provider communicate the message that he/she will still be involved if the patient goes to counseling?

\begin{tabular}{|c|c|c|c|c|}
\hline Strong & Disagree & Neither & Agree & Strongly Agree \\
\hline Disagree & & Agree nor Disagree & & \\
\hline 1 & 2 & 3 & & 4 \\
\hline
\end{tabular}

5

4. Did the provider convey belief in the patient's symptoms?

\begin{tabular}{|c|c|c|c|c|}
\hline Strong & Disagree & Neither & Agree & Strongly Agree \\
\hline Disagree & & Agree nor Disagree & & \\
\hline 1 & 2 & 3 & & 4 \\
\hline
\end{tabular}

5

5. Does the provider imply that the symptoms may be in the patient's head?

$\begin{array}{lcccc}\text { Strong } & \text { Disagree } & \text { Neither } & \text { Agree } & \text { Strongly Agree } \\ \text { Disagree } & & \text { Agree nor Disagree } & \\ 1 & 2 & 3 & 4\end{array}$


Appendix M. DISCUSSION

(a)

PLEASE READ THE FOLLOWING CONVERSATION BETWEEN A
MEDICAL PROVIDER AND A PATIENT

(Refer to this discussion to respond to the next 3 questionnaires)

Provider Good morning. How are you feeling today?

Patient Not good. My pain has been really acting up again. I am getting so tired of it.

Patient I was hoping that the tests and workup we did last time would tell me how to get rid of this pain. It has me worried that something is really wrong and no one is able to find out what it is.

Provider We have completed the medical history and physical. We also ran tests we thought might help to pinpoint what is causing your pain. However, the tests we ran didn't help us figure out what is wrong.

Provider Why don't you give me an update about your pain?

Patient Well my pain is still in my legs and arms and back. I notice it practically all the time.

Provider What do you think is causing your pain?

Patient I am not sure, it might be my joints, or a disease they haven’t found yet.

Provider Do you think stress or emotional problems might be causing your pain?

Patient I am not any more stressed than usual. And, I don't have any psychological problems that I know of.

Provider Are you depressed or anxious?

Patient Well, my pain doesn't let me do the things I want, like gardening and other chores—even fun things like going out with friends, walks, etc. I feel upset when I can't do these things. It really gets in the way of my sleep too. 
Provider It sounds like your pain is still causing you a lot of problems. How are you dealing with it?

Patient I just grin and bear it. Not much else I can do. I put up with it, I have no choice. It would sure help to know what is causing my pain.

Patient There must be something that can be done.

Provider The tests don’t point to any disease or cause of your physical pain.

Provider Many patients worry about having an illness that no one has figured out and feel they need to have more tests or more visits with their doctor.

Patient Well, I am not ready to give up and am not sure that you have done all the necessary tests. Perhaps we haven’t looked hard enough.

Provider At this point, we have run all the tests necessary to get to the bottom of your pain, and we haven't found anything that can help us identify what is wrong.

Patient So, what are you saying?

Provider I am not sure how to help you.

Provider I wish I could help you but there isn’t anything else I can do.

Patient Are you trying to tell me that you no longer to need to see me?

Provider Well, there isn't much left for me to do. I can suggest that you go to counseling. My office staff has some information on counselors in the area. 


\section{Appendix N. DISCUSSION (b)}

\section{PLEASE READ THE FOLLOWING CONVERSATION BETWEEN A MEDICAL PROVIDER AND A PATIENT}

\section{(Refer to this discussion to respond to the next 3 questionnaires)}

Provider Good morning. How are you feeling today?

Patient Not good. My pain has been really acting up again. I am getting so tired of it.

Patient I was hoping that the tests and work up we did last time would tell me how to get rid of this pain. It has me worried that something is really wrong and no one is able to find out what it is.

Provider The tests we ran didn't help us figure out what is wrong. Why don't you give me an update about your pain?

Patient Well my pain is still in my legs and arms and back. I notice it practically all the time.

Provider What are your thoughts on what might be causing your pain?

Patient I am not sure, it might be my joints, or a disease they haven't found yet.

Provider It must be frustrating -especially since the tests we have done have not told us what is wrong.

Provider I am wondering how your pain is affecting your life?

Provider Pain can sometimes lead to other problems for people such as stress. Stress can add to pain and really get in the way of managing the problem. Sometimes people feel depressed or anxious. Has that happened for you?

Patient Well if you mean that my pain doesn't let me do the things I want, like gardening and other chores-even fun things like going out with friends, walks, etc. then yeah, it is causing me stress. I feel upset when I can't do these things. It really gets in the way of my sleep too. 
Provider It sounds like your pain has caused a lot of problems. That makes a lot of sense. I can see how this would bother anyone. How do you manage the stress that your pain has caused?

Patient I just grin and bear it. Not much else I can do. I put up with it, I have no choice.

Patient So what do we do next?

Provider I would hope that we can identify what is causing your pain and then be able to treat it. We could run a few more tests, but I am worried that the tests won't reveal anything that can help us figure out what is wrong.

Provider Sometimes physical symptoms remain unexplained.

Patient You mean that there might not be a diagnosis for symptoms like mine?

Provider Symptoms such as yours-- generalized pain, tension, fatigue, poor sleep can remain unexplained. I want you to know that I believe that you have physical symptoms. However, sometimes, we really don’t know what is causing the pain. The cause of pain can fluctuate. At times it can be all physical, sometimes times it can emotional or sometimes a little of both. But, regardless of "cause" of the symptoms, most patients who have pain that can't be explained can become stressed.

But a good treatment plan really needs to tackle the physical pain and any accompanying emotional stress. Counseling is something that I have found very helpful in situations where we might not know or find out exactly what is causing your pain. I want to be clear that counseling is not a substitute for medical care; it is an addition to the medical support that I will provide. The counselor's job is to help you deal with any stress that is associated with your physical symptoms, not to look for a psychological cause of your pain. A counselor can be your sounding board, offer ideas, strategies and discuss anything else that may be bothering you. You and I will continue to work closely with each other to monitor and address your physical symptoms. I mention the idea of adding a counselor to our treatment plan now-just in case the few tests we have left doesn't tell us anything. How does the idea of adding a counselor to our treatment plan sound to you? I could have you meet the counselor whose office is right down the hall from me. 


\section{Appendix O. Telephone Script}

Participant has called / emailed and communicated interest.

Researcher "Hello, this is Terry Chianello, I am the PhD student who is conducting the study on medically unexplained physical symptoms.” Is this an OK time to talk about a study?

\section{If no, Is there a better time to call?}

\section{If person gives a better time of day to call again, researcher will note person's}

preference and call back.

\section{If yes, continue with the following.}

Researcher: "I am calling to see if you are still interested in hearing more about the study?

If no,

Researcher: "Thank you for your time.”

If yes,

Researcher "Great. I appreciate your interest. This is a study that examines how health providers can help patients deal with the stress of having medically unexplained physical symptoms. Those who are eligible for the study need to have at least 2 medically unexplained physical symptoms for the last 6 months. If you would like to learn more, I can read you the consent form.

If yes,

Researcher: Reads the consent and answers any questions. "Now that you have heard the consent and had any questions answered, do you still want to participate?”

If no,

Researcher: "Thank you for your time." 
If yes,

Researcher records individual's name and date on consent record. Finally, researcher asks the participant if they would like a copy of the results once the study is completed. If yes, the researcher records the participant's contact information to send the findings on a separate sheet, which does not include study ID number.

Researcher: “Thank you. Let’s begin. Can you tell me your medically unexplained physical symptoms are and how long you have had them?”

Participant:

Researcher: “Are you actively being treated for other diagnoses such as Cancer, Diabetes, or any other health problems that would cause your physical symptoms?

If yes,

Researcher: "I am sorry that I cannot include you in the study since your symptoms may be due to an illness for which you are actively being treated or "participants must have at least 2 symptoms to be included in the study. Thank you for your time.”

Participant : If No,

Researcher: $\quad$ OK, now that we've determined you are eligible for the study,"I have 12 questions to ask you. Each question is rated on a 5 point scale -from strongly disagree to strongly agree. I will read the statement and I would like you to tell me how much you agree with it.”

Once completed.....

Researcher: "Thank you for completing the first part of the study. How would you prefer to complete the second portion of the study?”

In person: Which location, date and time

By mail: Address:

Email:

Researcher: "Thank you so much. You will be receiving the second part of the study this week" (depending on the preference of the participant, mail or email). 


\section{Appendix P. PARTICIPANT CONSENT \\ in STUDY of \\ Medically Unexplained Physical Symptoms and \\ Engagement in Mental Health Therapy}

\section{Principal Investigator}

Terry Chianello, PhD student in the School of Social Work at Portland State University. Telephone: 541-410-2274.

\section{Why have I been asked to take part in this research study?}

You have been invited to take part in this study because you have had at least two medically unexplained physical symptoms for the last 6 months.

\section{Who is conducting the study?}

I am conducting this study as a PhD student at Portland State University, where my supervisor is Dr. Laurie Powers. To graduate with a doctoral degree, I have to complete a research project approved by Portland State University.

\section{Why is this research study being done?}

You are being asked to take part in this study to help medical providers learn how to help patients deal with the stress of having unexplained physical symptoms.

\section{How many people will take part in the study?}

About 150 people will be in the study.

\section{What will happen if I take part in this research study?}

You will be asked a few questions to be sure that you can be in the study. If you can take part, you will first ask you to answer 12 short questions. Then you will be sent some other questionnaires that will take you about 1 hour to finish. You can get these questionnaires by email, regular mail, or arrange to do them in person at a convenient location and time. After you're done completing these questionnaires, you can return them to me in a pre-stamped envelope or in person.

\section{How long will $I$ be in the study?}

You will be done with the study when you return the questionnaires to me. 


\section{Can I stop being in the study?}

You do not have to take part in this study, and if you start and later change your mind, you may quit at any time. If you stop this study, it will not affect your relationship with your doctors or with other medical providers.

Can anyone else stop me from being in the study? (The local hospital IRB is requesting that $I$ include this statement)

Since your participation is confidential, no one else except my supervisor and me will know that you took part in the study. Therefore, only you and us can stop you from being in the study.

\section{What side effects or risks can I expect from being in the study?}

You may find that some of the questions seem personal or completing the questionnaires might make you tired.

\section{How will I be protected from any risks?}

If you do become upset by taking part in this study, you will be given a resource information sheet that includes mental health hotlines. If you want additional help, I will contact a mental health worker or call a crisis hotline on your behalf.

\section{Are there benefits to taking part in this study?}

Your participation in the study may improve what we know of how people understand and cope with the emotions of medically unexplained physical symptoms.

\section{What other choices do I have if I do not take part in this study?}

If you to not take part in this study, you can continue on your own to seek care for the symptoms you have been having. I am not aware of similar studies for you.

\section{Will my answers be kept private?}

To protect your confidentiality, any information you provide for this study will be kept private. The questionnaires given for you to complete will have code numbers instead of your name. The information you provide will be kept in a locked file and will only be available to my and my supervisor. These materials will be destroyed in about one year after the study is over. 


\section{What are the costs of taking part in this study?}

To thank you for being in this study, I will give you $\$ 50$ for completing the questionnaires and returning them to me.

\section{How will I learn the results of the study?}

The study will be done in about 8 months. I will send you the results of the study unless you tell me that you are not interested.

Consent obtained for participant to receive results of study by Terry Chianello via telephone

Date: $\quad$ Name of Participant

\section{Do any of doctors who will be taking care of me have a personal financial (monetary) interest in this study that may affect how they treat me?}

Neither my supervisor nor I have personal financial interests or reasons to do this study.

\section{Where can I get more information?}

If you have concerns or problems about being in this study or your rights as a research participant, please contact the Human Subjects Research Review Committee, Office of Research and Sponsored Projects, Portland State University, (503) 725-4288 / 1-877-480-4400. You may also contact Dr. Laurie Powers at 503-725-9605. If you have questions about the study, contact Terry Chianello at 541-410-2274.

Thank you for your interest in this study.

Printed Name of Subject 


\section{Appendix Q. $\quad$ INSTRUCTION SHEET}

Thank you for your interest in participating in the study on how medical providers can help patients deal with the stress of medically unexplained physical symptoms. Your participation will help to improve our understanding of individuals with medically unexplained physical symptoms.

Below is a step-by-step guide to complete the rest of the study. Please follow the steps in the order listed. If you have any questions, please contact me at 541-410-2274 or by email at tchianello@msn.com.

Step 1. $\quad$ Please complete DOCUMENT \#1, the pink titled sheet (SOMS7)

Step 2. $\quad$ Please read DOCUMENT \# 2 the blue titled sheet (Discussion) and base your responses to the next 3 questionnaires on this discussion.

Step 3. $\quad$ Please complete DOCUMENT \#3, the green titled questionnaire (12-item posttest)

Step $4 . \quad$ Please complete DOCUMENT \#4, the purple titled questionnaire (Credibility/Expectancy)

Step 5. Please complete DOCUMENT \#5, the red titled questionnaire (FMP)

Step 6. Please complete DOCUMENT \# 6, the gray titled questionnaire (Demographic)

Step 7. For those receiving and completing these materials by mail, please enclose all the documents above in the self-stamped envelope and mail to me.

For those receiving materials by email, first save the documents to a file. Mark your responses. Save the documents, then attach them in an email and send them back to me.

As soon as I receive these materials, I will send you a check for $\$ 50$ by mail. If you are completing these materials in person, you will be given the check at that time. 


\title{
Appendix R. Resource Information Sheet
}

\author{
RESOURCE INFORMATION SHEET
}

\author{
Deschutes County \\ Scott Johnson, Director \\ Deschutes County Mental Health Dept. \\ 2577 NE Courtney Drive \\ Bend, OR 97701 \\ Information: 541-322-7500 \\ Crisis Line: 1-888-232-7192 \\ FAX: 541-322-7565 \\ TTY: 541-322-7610 \\ Crook County \\ Crook County Mental Health Program \\ Lutheran Community Services \\ 203 NE Court \\ Prineville, OR 97754 \\ Information: 541-447-7441 \\ Crisis Line: 1-888-232-7192 \\ FAX: 541-447-6694 (Courthouse, City Hall) \\ TTY: 1-800-735-2900 (O.R.S.) \\ Jefferson County \\ Best Care Treatment Services \\ Crisis Line: 1-888-232-7192 \\ FAX: 541-475-6196 \\ TTY: 1-800-735-2900 (O.R.S.) \\ St. Charles Medical Center \\ 2500 NE Neff Road \\ Bend, Oregon \\ 541 389-7160
}

IF YOU NEED IMMEDIATE HELP, CALL 911 


\section{Appendix S. Thank you note}

Dear Participant,

I would like to thank you for your participation in the study investigating the emotional aspects of managing medically unexplained medical symptoms.

Enclosed you will find a check for $\$ 50$.

Your participation is highly valued and will help us improve our understanding of individuals with medically unexplained physical symptoms.

Sincerely,

Terry Chianello 